\title{
'It just comes with the territory': Discursive normalisation of sexual harassment in bars
}

\author{
by
}

Lisa D. Armstrong

A thesis submitted to the Faculty of Graduate and Postdoctoral Affairs in partial fulfillment of the requirements for the degree of

Master of Arts

in

Applied Linguistics and Discourse Studies

Carleton University

Ottawa, Ontario

C 2016, Lisa D. Armstrong 


\begin{abstract}
This thesis is concerned with bartenders' construction of their experiences with customer sexual harassment. Increasingly recognized as problematic and unwanted in other workplaces, sexual harassment in bars is somewhat understudied, and little to no research has been undertaken in this context from a discourse analytic perspective. This study, motivated by own bartending experience, attempts to contribute to knowledge by investigating the role of discourse in the normalisation of sexual harassment. Using data collected from the social media website reddit.com, as well as three semi-structured interviews with female bartenders, I utilize analytical tools from Critical Discourse Analysis and Systemic Functional Linguistics to determine if and how bartenders themselves are complicit in this normalisation. Furthermore, I situate my findings in Fairclough's (1992; 1995) 3-dimensional analytical framework, which allows me to connect the text analysis with the wider socio-cultural context. Bartenders often do not classify their experiences as harassment; rather, they consider it unremarkable and 'just part of the job'. The results of this study suggest that bartenders use discourse that reinforces the normalisation of sexual harassment. These findings highlight the need for a discursive analytic approach to studying and addressing customer sexual harassment of bartenders.
\end{abstract}




\section{Acknowledgements}

My utmost thanks go first to my supervisors. My mentor and supervisor, Dr. Jaffer Sheyholislami, has believed in me and my research from the first time we talked, motivating and helping me beyond the scope of what a lowly master's student would expect. Furthermore, he brings me back down when I threaten to fly off the face of the earth. Thank you for being a role model, Jaffer. Dr. Graham Smart has pushed me to write better and try harder; I have valued his writing expertise as well as his criticism.

To the ALDS administrative staff who have made my life so much easier; thank you all from the bottom of my heart, especially Joan who always answers my panicky emails with endless patience.

Without a great cohort, these past two years may have been torture; my classmates have been absolutely helpful and sympathetic. Thanks Lindsay and Codie, for writing and crying with me. Alli, thank you for the unending support and for being my biggest cheerleader through this ordeal. To Britt a special thanks for being my academic soulmate and for teaching me many more things than I could ever learn in school.

My amazing parents have never doubted me-or if they have, they never told me. Bless them, and thank you Mom, for reading parts of this thesis along the way.

Finally, I would like to thank my husband and favourite person, Darrell. It sounds trite, but without his support, patience, and encouragement, I wouldn't be here; he's made it possible for me to pursue my education and done so without complaint. 


\section{Table of Contents}

Abstract.................................................................................................................................. ii

Acknowledgements ..........................................................................................................................ii

Table of Contents ................................................................................................................. iv

List of Tables ............................................................................................................................... viii

List of Illustrations....................................................................................................................... ix

1 Chapter: Introduction .............................................................................................................. 1

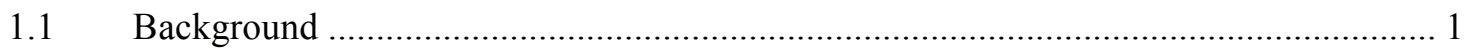

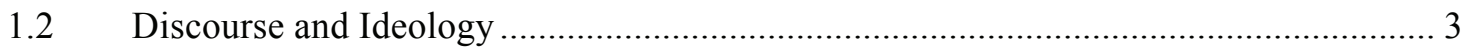

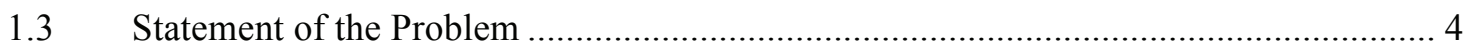

1.3.1 Discourse and Sexual Harassment ...................................................................... 4

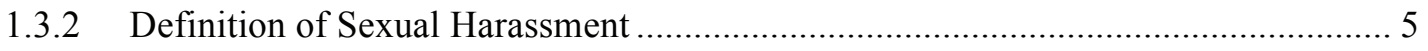

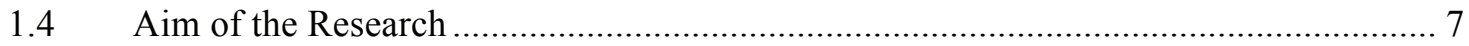

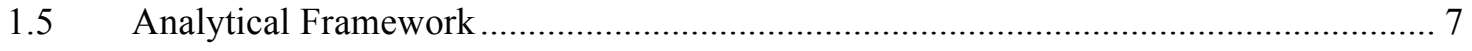

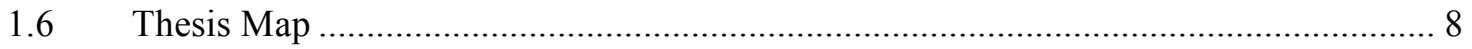

2 Chapter: Literature Review............................................................................................. 10

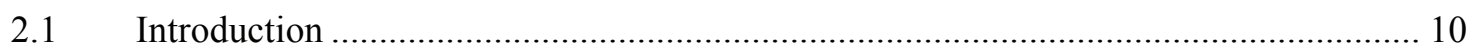

2.2 Causes of the Prevalence of Sexual Harassment in Bars ......................................... 10

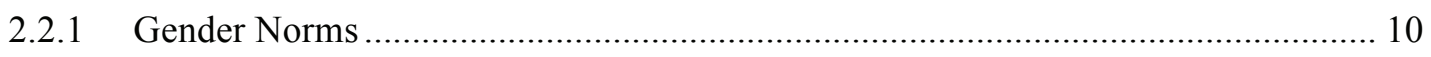

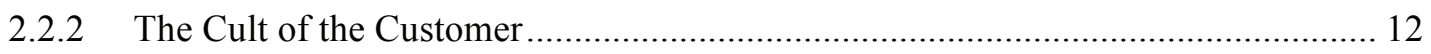

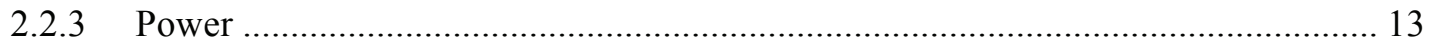

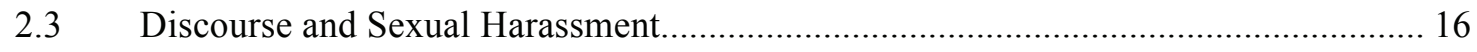

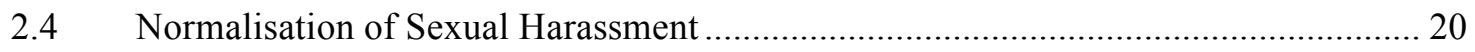

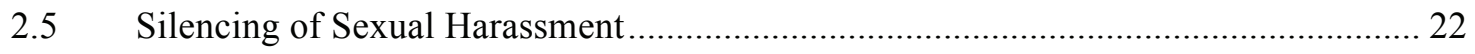

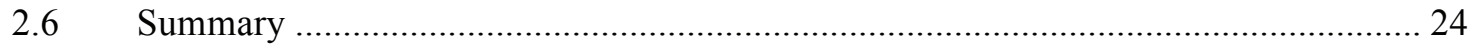


3 Chapter: Research Approach ....................................................................................... 26

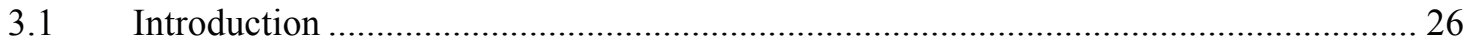

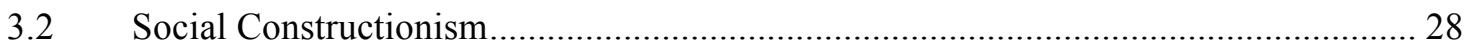

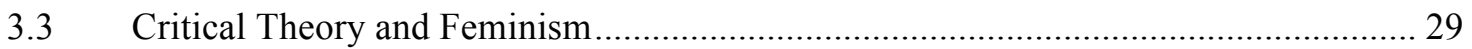

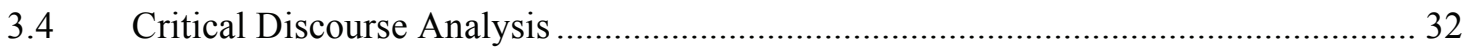

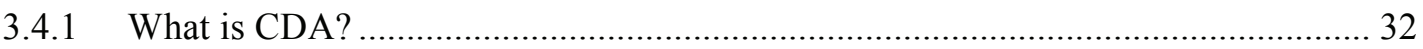

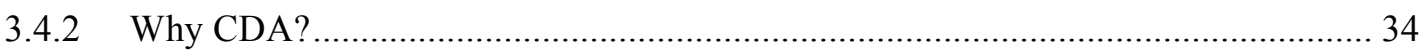

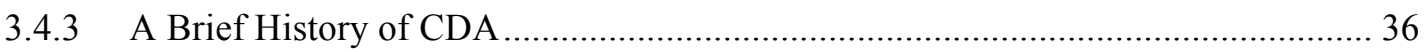

3.4.4 Fairclough and his 3-Dimensional Framework......................................................... 37

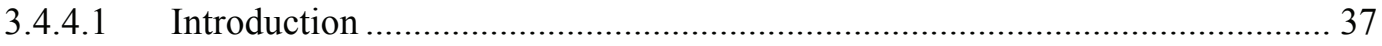

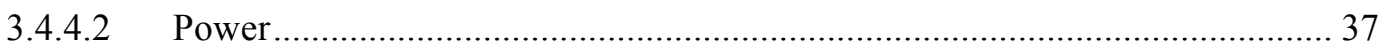

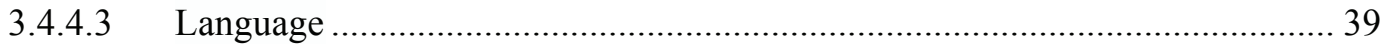

3.4.4.4 The Framework ………………………………………………………..... 40

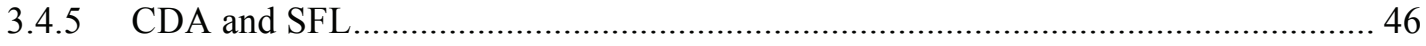

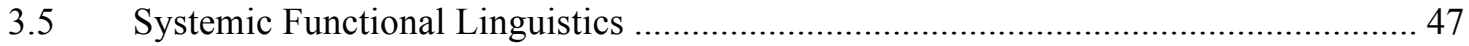

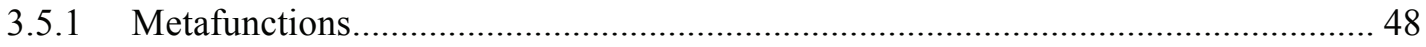

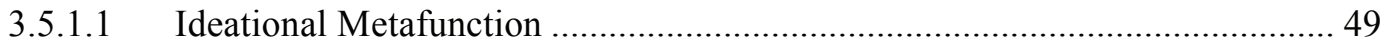

3.5.1.2 Interpersonal Metafunction. ....................................................................... 51

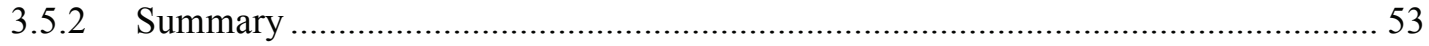

4 Chapter: Methods ........................................................................................................ 54

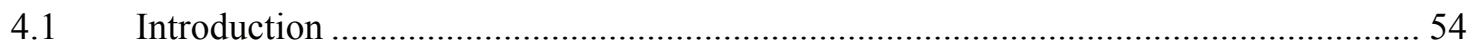

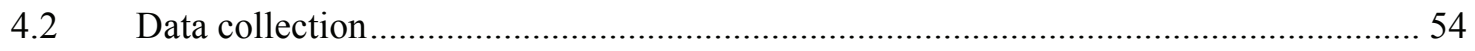

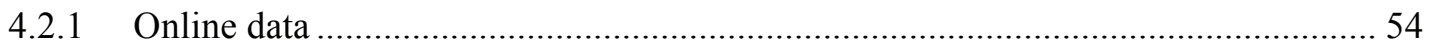

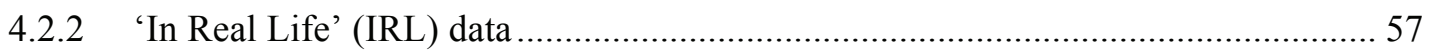

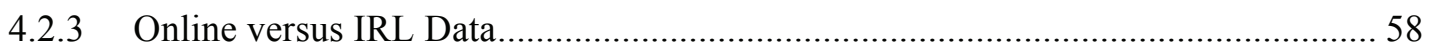

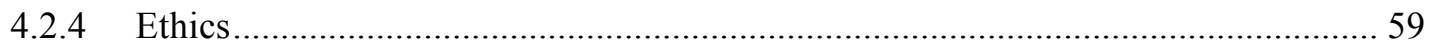




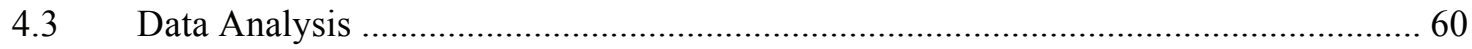

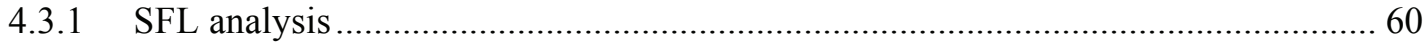

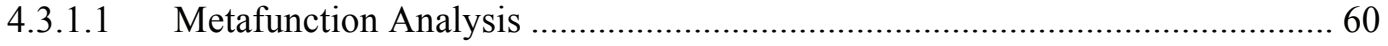

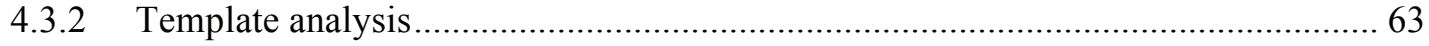

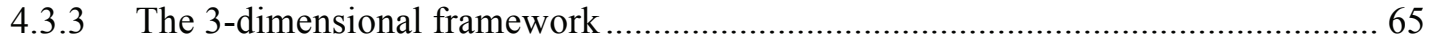

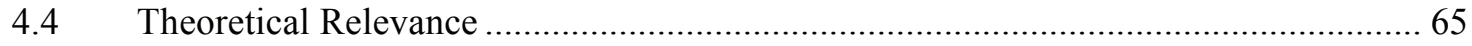

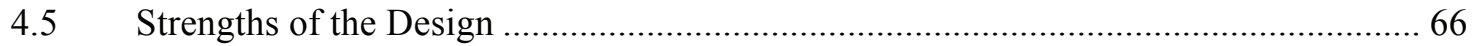

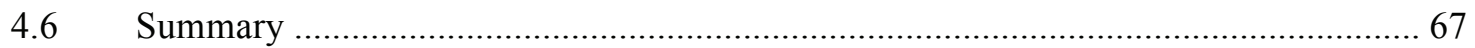

5 Chapter: Findings .............................................................................................6 69

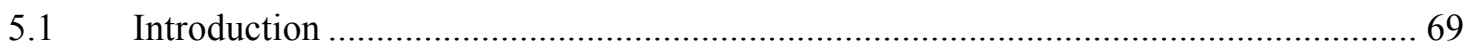

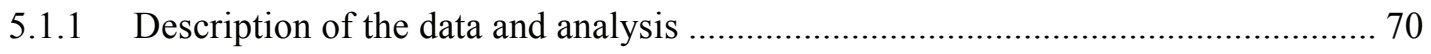

5.2 Transitivity and the Construction of the Ideal Bartender ........................................ 72

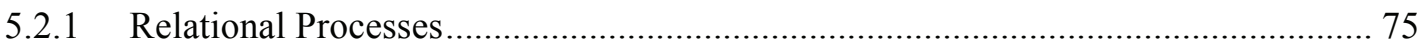

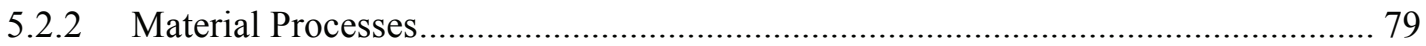

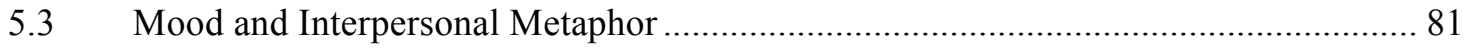

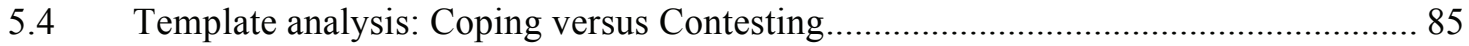

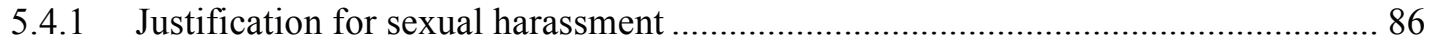

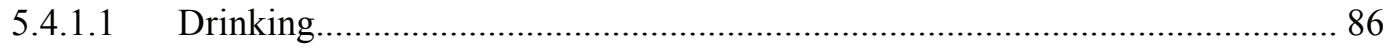

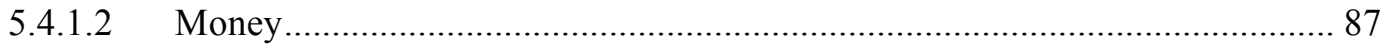

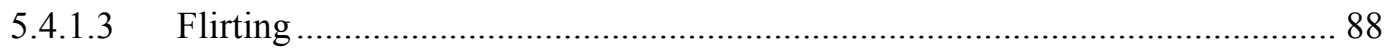

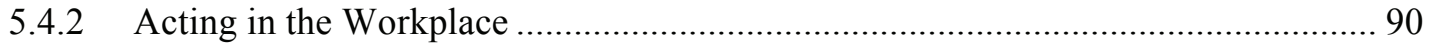

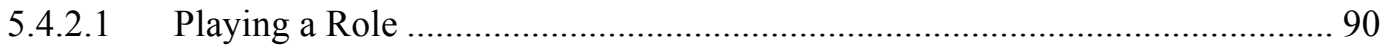

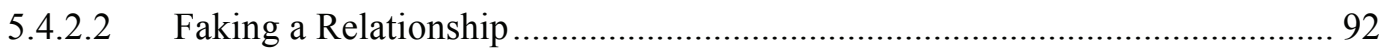

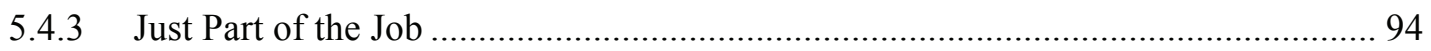

5.4.4 Resistance

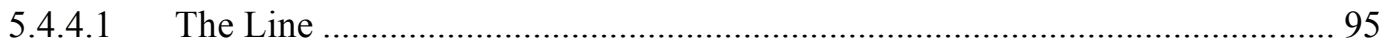




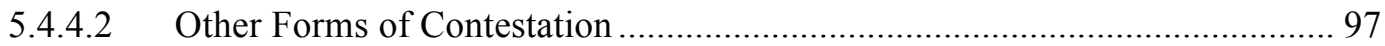

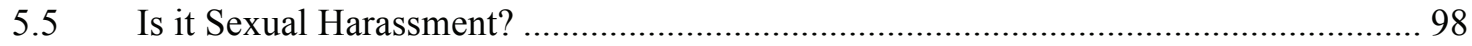

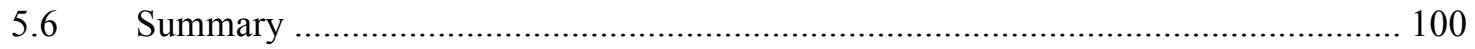

6 Chapter: Discussion and Conclusion ............................................................................ 102

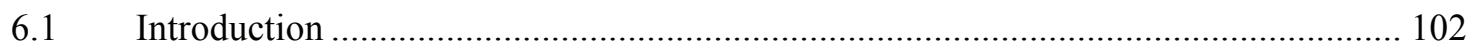

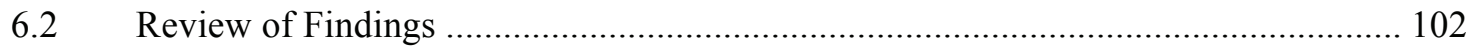

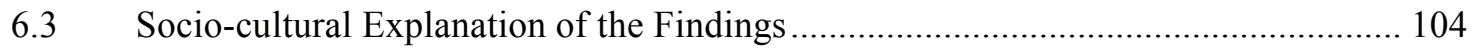

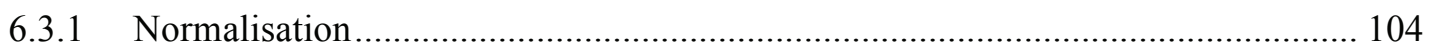

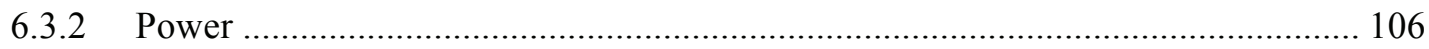

6.4 Limitations and Future Research Directions ........................................................... 109

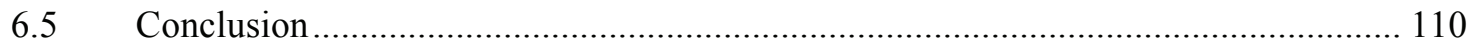

Appendices.................................................................................................................................... 114

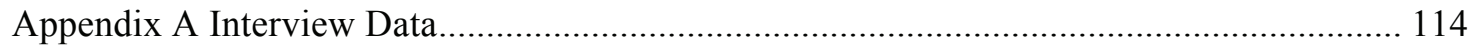

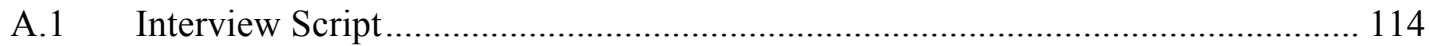

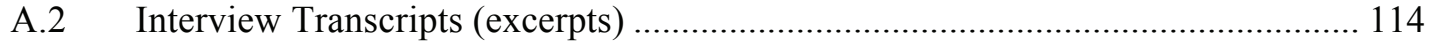

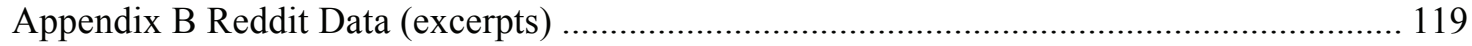

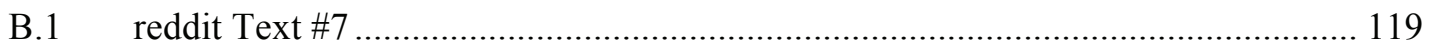

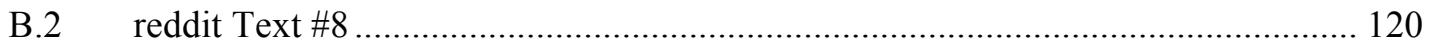

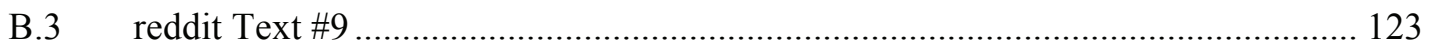

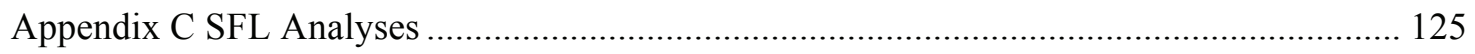

C.1 Transitivity and Mood analyses (excerpts) ….................................................. 125

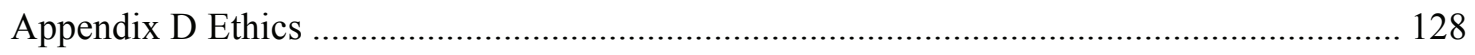

Appendix E Ontario Human Rights Code excerpt—Section 2.1 ....................................... 129

References................................................................................................................................... 133 


\section{List of Tables}

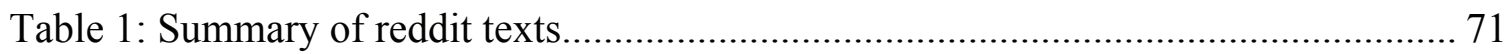

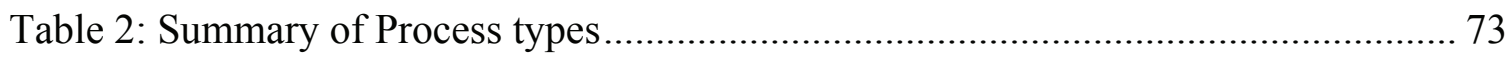

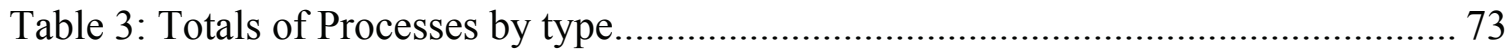

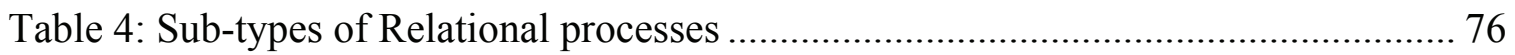




\section{List of Illustrations}

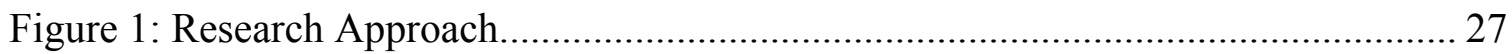

Figure 2: Fairclough's 3-D framework (Janks, 1997, p. 330) ………………………...... 41

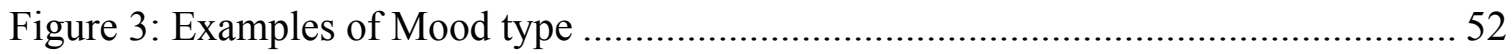

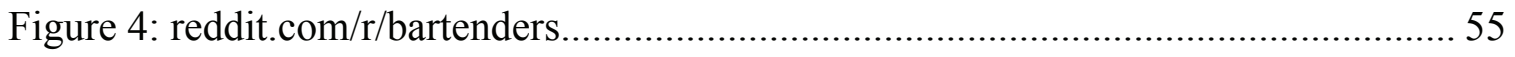

Figure 5: Bartending sub-reddit (comment thread) …………........................................ 56

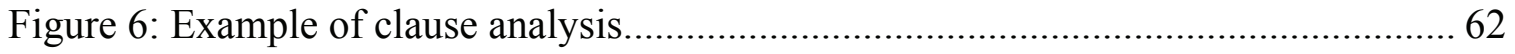

Figure 7: Fairclough's 3-D framework (Fairclough, 1995, p. 98)................................... 70

Figure 8: Relational sub-types (adapted from Eggins, 2004, p. 239) ………………...... 75

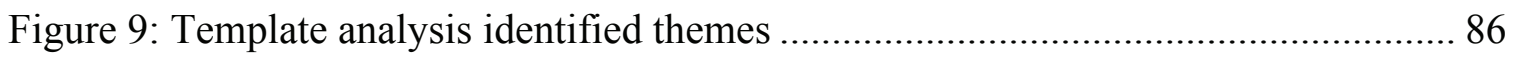




\section{Chapter: Introduction}

This thesis is concerned with how bartenders construct their experiences with sexual harassment in their workplace. Increasingly recognized as problematic and unwanted in other workplace contexts, sexual harassment is often unaddressed in the hospitality industry (Gilbert, Guerrier, \& Guy, 1998). Where sexual harassment in bars has been studied, it has been found that bartenders not only see it as 'just part of the job', but also often fail to even use the term "sexual harassment" to define their experiences (Folgerø \& Fjeldstad, 1995; Brunner and Dever, 2014; Matulewicz, 2015). Using primarily analytic tools from the research methods of Critical Discourse Analysis (hereafter CDA) and Systemic Functional Linguistics (SFL), I will analyse data from a social media website which serves as a sort of ad hoc advice column for bartenders, as well as data from three semi-structured interviews with female bartenders. Conducted within a CDA framework, these analyses attempt to reveal how bartenders are complicit in or resistant to the construction of sexual harassment as 'just part of the job'.

\subsection{Background}

For almost twenty years, I worked as a bartender/food server in a variety of bars, pubs, and restaurants. In that time, customers 'hit on"1 me and my co-workers with regularity, and although it sometimes discomfited me, it did not occur to me to call it sexual harassment. It was an annoyance, not a legal nor a moral matter, I would have said. It was in an undergraduate Sociology course that it first occurred to me that bartending was

\footnotetext{
1 "Hit on" as I use it here means "to make sexual advances toward", or "to proposition"; in my experience, it usually refers to verbal advances rather than physical, but that need not necessarily be the case.
} 
sexualized labour; it was not until the beginning of my graduate studies that I realized that the behaviour I had tolerated from customers for years actually constituted sexual harassment. Why had this never occurred to me? Moreover, during my years of bartending, I would have not only tolerated such behaviour (and did), but expected my co-workers to tolerate it as well. In general, my belief was that those bartenders who complained about the customers 'hitting on' them were trouble-makers and clearly not suited to the industry. Despite my intelligence, even despite my education, it took me years to realize that what I took to be normal was not acceptable behaviour.

In the course of my graduate studies in SFL and CDA, it became clear to me that language played a pivotal role in both the behaviour of the customer (hitting on someone, as noted, is often a verbal behaviour) and in the response to that behaviour, whether a response to the customer directly, or a response in the form of conversations bartenders have with each other about the behaviour. This knowledge, added to my previous realization that bartending is a site for problematic behaviours, provided the impetus for this research. My life and work experience have influenced my work here, and I would be remiss not to acknowledge that. It is my hope that, at the very least, this thesis will answer some of the questions I have about these phenomena.

To this point, I have introduced the topic of this thesis - the investigation of the discourse of bartenders as it relates to their experiences with sexual harassment - and explained that my experiences as a bartender have shaped my research choices. The remainder of this chapter will be structured as follows: first, I explain the concepts of 'discourse' and 'ideology' as they are used in this thesis. While sexual harassment is the social problem I investigate, Discourse Studies is the area of scholarship in which the 
thesis is situated, and hence the use of these terms necessitates a clear definition. Next, I explain the legal definition of the term 'sexual harassment', and the objectives of this research. Finally, I outline the analytical approaches I employ, and conclude the chapter with a roadmap of the remainder of the thesis.

\subsection{Discourse and Ideology}

The term 'discourse' is somewhat contentious (Fairclough, 1992, p. 3), and warrants elaboration. In a linguistic sense, 'discourse' is often used in the sense of 'text', i.e., a connected stretch of language, or a chunk of language larger than a sentence (Pennycook, 1994). However, because my focus here is looking at sexual harassment from a discourse analytic perspective, I adopt Fairclough's (1993) dual definition of discourse first as an abstract noun, referring to language use as social practice, and second as a count noun, referring to a "way of signifying experience from a particular perspective" (p. 138). Thus, for example, we might talk about bartenders' discourse (language use), or about various discourses that might influence practices and perceptions in the bar workplace. The concept of discourse as social practice (e.g., Chouliaraki \& Fairclough, 1999; Lazar, 2005; Talbot, 2005) means that discourse is seen as constitutive of and constituted by society, or as Francis and Green (2005) put it, discourse is "something that helps create, rather than merely represent, our social world" (p. 73) ${ }^{2}$. In other words, what bartenders say about their own experiences of sexual harassment is not merely a reflection of what has happened, but rather, their linguistic choices will also impact how they will engage in that context. Therefore, the present study is grounded on the assumption that a social

\footnotetext{
${ }^{2}$ See also section on CDA, next chapter
} 
issue such as sexual harassment cannot be studied thoroughly without reference to discourse. Furthermore, van Dijk (1998) notes that discourse plays "a special role" in the reproduction of ideologies; that is, "various properties of text and talk allow social members to actually express or formulate abstract ideological beliefs, or any other opinion related to such ideologies" (pp. 191-192).

Ideology can be defined as "a set of beliefs, convictions, or ideas which both binds a particular group of people together and determines the actions they take" (Buchanan, 2010, p. 243). I do not conceive of ideology as inherently negative or pejorative, i.e., that only certain beliefs are ideological; rather, I understand ideology to be all beliefs or ideas as defined above. Ideology in this thesis is not conceptualized as something which cannot be contested. According to Fairclough (1992), "ideologies arise in societies characterized by relations of domination on the basis of class, gender, cultural group, and so forth, and in so far as human beings are capable of transcending such societies, they are capable of transcending ideology" (p. 91). That is to say, for the purposes of this thesis, I use ideology in the sense of a group's set of shared beliefs which will be reflected in their actions, but more importantly, reflected in their language use.

\subsection{Statement of the Problem}

\subsubsection{Discourse and Sexual Harassment}

Some work in the field of Discourse Studies has investigated workplace sexual harassment; for instance, Eyre (2000) and Clair (1993) have both written about the discursive aspects of sexual harassment in university settings, and both researchers have emphasized the importance of looking at sexual harassment from this perspective (as discussed more comprehensively in section 2.4). Because bartenders' discourse about sexual harassment shapes and is shaped by their experiences with sexual harassment, it is 
important to study that discourse in order to better understand their experiences.

Furthermore, since sexual harassment is often a natural, taken-for-granted occurrence in the hospitality industry, and since I take it to be the case that discourse can be used to either reinforce or resist this normalisation, investigating the role of discourse in the normalisation of sexual harassment is also crucial.

\subsubsection{Definition of Sexual Harassment}

According to the Ontario Human Rights Commission (OHRC), sexual harassment is "engaging in a course of vexatious comment or conduct that is known or ought to be known to be unwelcome" (Ontario Human Rights Commission, 2014, p. section 2.1); this conduct includes not only such physical behaviours as "unnecessary physical contact" and "leering", but also verbal behaviours such as "questions or discussions about sexual activities" or "rough and vulgar humour or language related to gender" (section 2.1, para. $\left.8^{3}\right)$. In fact, out of the 21 types of behaviours the OHRC lists to exemplify what constitutes sexual harassment, 15 of them explicitly mention language-based behaviours such as "spreading sexual rumours" or "bragging about sexual prowess". Much of the time, then, sexual harassment is accomplished through language. Although the focus here is not verbal sexual harassment per se, this does suggest the centrality of language to sexual harassment in general.

Previous research on sexual harassment in fields other than Discourse Studies has shown that it is more prevalent in the hospitality industry than in most other sectors (Poulston, 2008; Gilbert, Guerrier, \& Guy, 1998). It is challenging to provide a definitive figure; not only is sexual harassment in general underreported (Australian Human Rights

${ }^{3}$ See Appendix E for the full section 2.1, which defines and describes sexual harassment. 
Commission, 2012, p. 40; AWARE, 2008), but it is even rarer for employees to report instances where customers are the perpetrators of sexual harassment (Poulston, 2008, p. 233). According to a report by the Restaurant Opportunities Centers United Forward Together (ROCUFT; 2014), only $33 \%$ of servers complain to their supervisors when customers sexually harassed them, and none file a formal complaint to either the Equal Employment Opportunity Commission ${ }^{4}$ or to relevant state authorities (p. 27). Gilbert, Guerrier, and Guy (1998) found that 19 per cent of companies they studied reported that employees had "resigned due to harassment by customers" and a further " 23 per cent could not say one way or another if this was a reason" (p. 51). Likewise, Good and Cooper (2016) argue that customer sexual harassment is a "significant issue", and “customers are increasingly being recognized as potential perpetrators of sexual harassment in public policy and legislation" (p. 3). But why is it the case that customer sexual harassment is so common in the hospitality industry? The extant research on customer sexual harassment in the service and hospitality industries (in fields other than Discourse Studies) proposes several reasons, such as the high status of the customer in the prevailing culture of the service industry, the gender roles that are performed in hospitality, and the nature of power relations between servers, customers, and managers (these are discussed in more detail in the next chapter). However, although the current literature abounds with explanations for the prevalence of sexual harassment in hospitality, little research has been undertaken to determine the role of discourse in normalising sexual harassment. Furthermore, it is also unclear whether bartenders

\footnotetext{
${ }^{4}$ The United States federal government agency that investigates employment issues and enforces employment laws.
} 
themselves are complicit in this normalisation, resistant to it, or both.

\subsection{Aim of the Research}

The objective of this research is to investigate the perception of bartenders of customer sexual harassment from a discourse analytic perspective, or more specifically, to investigate how customer sexual harassment in bars is constructed in discourse by bartenders. Studying customer sexual harassment from a discourse perspective not only addresses the research gap mentioned above, but also allows for what Eyre (2000) calls a shift of focus "away from individuals and structures to forms of knowledge and relations of power in a specific site" (p. 294). That is, rather than seeing sexual harassment as a behaviour perpetrated by deviant individuals, this type of analysis acknowledges that sexual harassment is systemic and discursively constructed.

In order to meet this research objective, this thesis attempts to answer the following overarching research question: how do bartenders construct their experiences with sexual harassment at work? In doing this, the thesis addresses these sub-questions: Do bartenders use language that resists or reinforces the normalisation of sexual harassment? Do bartenders use the term 'sexual harassment', and if not, why? What other terms might they use to talk about it?

\subsection{Analytical Framework}

To answer these questions, I rely on Critical Discourse Analysis (CDA) as the framework for my research. CDA takes the view that language is inextricably bound up in the social, and vice versa (Fairclough, 1992, 1993; Holmes, 2005; Janks, 1997). From this perspective, not only is language viewed as being implicated in the act of sexual harassment itself, but also in resistance to and perpetuation of it. That is to say, the way 
that bartenders talk about their experiences with customer sexual harassment is an enactment of those experiences; not only does their discourse reflect their perceptions, but also could serve to normalise or resist the normalisation of sexual harassment.

While some studies in fields other than Discourse Studies (as detailed in the next chapter) have looked at the social structures of bars as they relate to sexual harassment, few if any studies have looked at the attendant language use-either by customers or bartenders - and none have made the connection between the discourse related to sexual harassment and bars. I adopt Fairclough's view that the social and the linguistic are inextricably connected (e.g., 1992, 2003). That concept is key to this investigation and to the contribution this project makes, which is to investigate the linguistic and social elements in the context of customer sexual harassment in bars and show their relationship. Furthermore, while CDA focuses on concepts of ideology and power as they relate to language, SFL is not only widely used by CDA researchers, but also recommended by Fairclough $(1992,1993)$ as a useful tool for discourse analysis.

\subsection{Thesis Map}

The organization of this thesis includes five further chapters. The next chapter reviews the literature on sexual harassment in bars, as well as literature on sexual harassment and discourse. This chapter discusses the concept of 'normalisation', the reasons for the prevalence of sexual harassment in bars, and the importance of looking at sexual harassment from a discursive perspective. Because there is a dearth of research on the discursive dimension of sexual harassment in bars, I draw heavily on work from fields such as Organizational Studies and Sociology in situating my research; in the area of Discourse Studies, I rely primarily on CDA scholarship. 
Chapter 3, Research Approach, examines the theoretical framework employed in this project. I trace the epistemological and theoretical influences that guided my research decisions, starting with social constructionism, followed by critical theory and feminism. Following that, I discuss my methodological choices, comprised of critical discourse analysis and systemic functional linguistics.

Chapter 4 outlines data collection and analysis. Each aspect of data collection will be detailed, followed by a discussion of data analysis methods including SFL and CDA analyses and template analysis. Finally, this chapter will explain the theoretical relevance and strengths of these methods.

Chapter 5 presents the analytical findings. The analyses will be presented in the following order: first, the results of the Transitivity analysis will be discussed, followed by the results of the Mood analysis on the reddit data. Following that, the Template analysis will be presented. To conclude this chapter, I use the findings from the interview data to discuss why bartenders do not use the term sexual harassment.

Chapter 6 discusses the findings from chapter 5, comparing them to one another and situating them within Fairclough's (1992; 2003) 3-dimensional framework. Here I will present the findings as they relate to the literature discussed in Chapter 2 as well as their relationship to the theories discussed in Chapter 3. Finally, I will discuss the limitations of this project, as well as its implications for future research. 


\section{Chapter: Literature Review}

\subsection{Introduction}

The previous chapter introduced the claim that sexual harassment is prevalent and normalised in bars, and that discourse should be considered a key element in said normalisation. Because the existing scholarly literature on sexual harassment in bars generally does not incorporate discourse approaches, and because the existing research in discourse studies does not examine sexual harassment in the specific context of bars, this section will be an integration of literature that addresses each of them. In what follows, I review the extant literature on sexual harassment in bars, primarily to report on the main perceived causes of the prevalence of harassment in bars. Following that, I discuss the few studies that investigate sexual harassment in other contexts that do use a discursive approach. Finally, in order to connect the discussion of discourse, sexual harassment in bars, and normalisation, I will define and discuss the concepts of normalization and silencing.

\subsection{Causes of the Prevalence of Sexual Harassment in Bars}

\subsubsection{Gender Norms}

As mentioned previously (see section 1.3.2), there are three primary factors posited for the high incidence of sexual harassment in bars: the gender roles expected of hospitality employees, the pressure to provide good customer service, and the nature of power relations between servers, customers, and managers. Hospitality work is said to be a site where traditional gender roles are played out (Folgerø \& Fjeldstad, 1995; Philaretou \& Young, 2007; Brunner \& Dever, 2014); thus, the first reason for the prevalence of sexual 
harassment in bars is the perpetuation of traditional gender roles. In this industry, according to Brunner and Dever, "A defining part of these jobs is providing men with a performance of female heterosexuality" (p. 465). Philaretou and Young's (2007) study of female servers found that " $[\mathrm{m}]$ ale patrons tended to yield to the traditional view of women as sexual objects" in a sexualized work environment such as a bar (p. 56). Customers have the expectation that female servers will be stereotypically feminine: physically attractive, kind, patient, pleasant, submissive. Furthermore, failing to perform this femininity may result in sanctions from co-workers, supervisors, or customers; for instance, Folgerø and Fjeldstad (1995) explain that refusal to be leered at or touched can be seen as "non-conformance to traditional norms" (p. 304). Thus, the upholding of traditional gender roles in this industry increases the incidence of sexual harassment by encouraging men to view women as sexual objects.

These studies are in agreement that the hospitality industry is a place where women are expected to perform a stereotypical femininity; indeed, this is considered a feature of much retail customer service work (Hughes \& Tadic, 1998; Good \& Cooper, 2016). However, there is a striking inattention to discourse in this scholarship; it is left to the reader to deduce that these performances of traditional femininity, resistant or "nontraditional" performances, and sanctions may all be played out linguistically. In the context of other workplaces, Holmes's (2005) study found that gendered "relations are constructed and reinforced in everyday, unremarkable, workplace interactions" (p. 32), that is, in conversation. Holmes argues that the pattern of discourse in the workplace is one that supports the power of men and the supportive role of women. This type of study and others like it (see, for example, Holmes's review, 2014) illustrate the role of language 
in constructing and maintaining gender roles. Thus, whereas the predominant pattern of sexual harassment in hospitality is male customers harassing female servers, and given the gender roles performed, it would benefit research in this area to consider the attendant discursive aspects of these roles.

\subsubsection{The Cult of the Customer}

Another, related, reason for the prevalence of sexual harassment in the service and hospitality industries is what Hughes and Tadic (1998) refer to as "the cult of the customer"5, that is, the emphasis in service work on the satisfaction of the customer, where the relationship between employee and client is "targeted as a key site of profitability" (Hughes \& Tadic, 1998, p. 209). Brunner and Dever (2014), in their study of employees' perceptions of sexual harassment, note the same phenomenon: "new management approaches...encourage employees to invest in the quality of a customer's service experience" (p. 466). In plain terms, if a customer chooses to sexually harass an employee, then the employee may feel they have no choice but to tolerate it, in the interest of keeping the customer (and hence the management) happy. Hughes and Tadic (1998) point out that women in the service industry are perpetually aware of and held in check by the customer's power to complain about the service. This may be exacerbated in the hospitality industry because of servers' reliance on tips to supplement their income. Poulston (2008) explains that servers are expected to be "compliant and deferential" to customers, and may even take on a subservient role (p. 234).

The importance of tipping as a factor here should not be underestimated. In North

${ }^{5}$ Hughes and Tadic credit DuGay and Salaman (1992) for this phrase. 
America, there are many states and several provinces where servers are paid a lower minimum wage than other minimum wage workers, because their earnings are supplemented by tips. According to ROCUFT, this (U.S.) federally mandated "tipped sub-minimum wage" ${ }^{\circ 6}$ results in servers earning [a wage of] as little as $\$ 2.13$ per hour in certain states (2014, p. 1). Relying on customers for any amount of tips puts a server somewhat at the mercy of the customer's whims; relying on customers for the bulk of one's income exacerbates this. ROCUFT argues that "Living off tips makes an industry already rife with sexual harassment even more dangerous" (p. 2). Moreover, in her review of employment standards legislation in British Columbia, Matulewicz (2015) contends that tipping is a form of "quid pro quo" whereby servers are expected to "engage in sexual labour" in exchange for the tip (p.410). This expectation that servers will both dance attendance on and act out traditional gender roles for the benefit of the customer speaks to the power that customers have over bartenders.

\subsubsection{Power}

A third reason for the high incidence of sexual harassment in hospitality is the power dynamic at play in the industry. For the purposes of this thesis, I adopt Fairclough's (1995) description of power as "asymmetries between participants in discourse events" (p. 1). The connections between discourse and power will be further elaborated in Chapter 3. Regarding power and the hospitality industry, Poulston's (2008) mixed methods study of employees and managers in New Zealand mentions this explicitly argues that bartenders are "particularly vulnerable" to abuse (p. 234), because both

\footnotetext{
${ }^{6}$ Although the U.S. federal government sets this rate, individual states can (and some do) set a higher minimum wage.
} 
customers and managers hold power over them. On the one hand, customers, as mentioned above, have the power to withhold tips from servers, thereby reducing their income; Good and Cooper (2016) argue that hospitality customers have "relatively high status and control” (p. 6). Folgerø and Fjeldstad (1995) also refer to the power of the customer: "The relative power of the provider and the recipient of the services is strongly asymmetrical" (p. 303). On the other hand, managers and owners have the power to not only dismiss employees, but also to alter their work schedules. Certain shifts are more lucrative than others; thus, the employer has the power to directly affect servers' income by either changing or reducing the shifts a bartender works. Matulewicz (2015) explains that the uncertain nature of shift work in restaurants (and bars) makes serving precarious work, which is also linked to increased incidence of sexual harassment (Good \& Cooper, 2016; Uggen \& Blackstone, 2004).

Previous research on sexual harassment links sexual harassment to power; Brunner and Dever (2014), for example, say that "sexual harassment is understood as one mechanism through which power is enacted between individuals to create and maintain control of sexuality, and specifically to mandate women's performance of appropriately feminine heterosexuality" (p. 461). Likewise, according to Dougherty (2006), it is generally agreed that power is "a central component to sexual harassment" (p. 495). That being said, I recognize that the conception of power as operating solely one-way - or topdown - is inaccurate and problematic. While this study primarily deals with the maleperpetrated sexual harassment of female bartenders, I acknowledge that it is also the case 
that males are sometimes harassed and that women sometimes harass ${ }^{7}$. While precarious work such as serving and bartending is often performed by women (Poulston, 2008), men can and do work in the industry, and can be and are sexually harassed. Furthermore, Uggen and Blackstone (2004) present sexual harassment as an expression of heteronormative masculinity over all others rather than as simply the expression of power of men over women in general; that is, "sexual harassment derives from power and masculinity — for males and adolescents as well as for adult women" (p. 88).

Additionally, I do not see the power relationships discussed herein as only or inevitably top-down; targets of sexual harassment can and do resist in certain ways, as will be discussed further in Chapter 5.

Here again, though, we can see a decided gap when it comes to identifying the role of discourse in relationships of power. If sexual harassment is an expression of power, then it follows that both the harassment as power and the resistance to the harassment may be constituted in discourse. 'Power' as it is used in this thesis is conceptualized as linked to language; as Wodak (2001) expresses it: "language indexes power, expresses power, is involved where there is contention over and a challenge to power" (p. 11). Likewise, Fairclough (1992) argues that discourse is "shaped by relations of power and ideologies" (p. 12), and moreover, that language is key to producing, maintaining and changing power relations (1989, p. 1). Bartenders construct their experiences in particular ways and these discursive constructions may resist or uphold the power of the customer; and investigating those linguistic choices may help us better

\footnotetext{
${ }^{7}$ See, for example, Scarduzio \& Geist-Martin's (2010) study on male targets of sexual harassment.
} 
understand the role they play in normalising and/or resisting the normalisation of sexual harassment. Thus, as in the case of stereotypical gender roles, an investigation of power without consideration of language seems inadequate. In the case of research in fields other than Discourse Studies, Brunner and Dever (2014) do acknowledge the importance of discourse in the justification for their choice of a focus group method of data collection by citing Brewis and Linstead (2000): "the discourse of harassment is what generates the understood phenomenon of harassment, what establishes its meaning, its identity and coherence, and what, most significantly, delineates it from 'acceptable' forms of sexuality and/or organizational behaviour" (p. 72, as cited in Brunner \& Dever, p. 462, emphasis added). This understanding of discourse and sexual harassment is at the heart of the research herein, but in the case of Brunner and Dever's study, the findings primarily relate to how various participants construct 'work', rather than how they construct "sexual harassment" ${ }^{\prime}$. Overall, then, despite the acknowledgment of power as a key factor in the prevalence of sexual harassment in bars, there is little to no association made in the literature between language and power. Because this thesis is concerned with the relationship between power, discourse, and sexual harassment, this is gap that needs to be addressed.

\subsection{Discourse and Sexual Harassment}

As aforementioned, there has been some research done about sexual harassment from a discourse analytic perspective (although not in the context of customer sexual harassment of bartenders). For instance, Dougherty (2006) conducted focus groups and individual

\footnotetext{
${ }^{8}$ As well, Brunner and Dever (2014) study employees from a variety of industries; there are only two servers in their sample.
} 
interviews with members of a health care organization to investigate her participants' perceptions of power as it relates to sexual harassment. Her findings showed that while women viewed those who perpetrated sexual harassment-regardless of their hierarchical status in the workplace - as powerful by virtue of the act of harassing, men viewed sexual harassment as something that could be perpetrated only by those in power, and thereby conceptualized sexual harassment differently than women. Dougherty argues that in order to understand complex power relations, we need to "explore how organizational members discursively construct sexual harassment-related power" (p. 496). Similarly, Clair (1993) contends that it is important to not only investigate sexual harassment, but also the discourses about sexual harassment (pp. 127-128). Clair's analysis of the sexual harassment policies of nine Midwestern United States universities revealed that the language used in those policies often reinforced oppressive and patriarchal ideas around sexual harassment. For example, the common advice to "say no" to the harasser, says Clair, not only supports the idea that there is "one best way" to handle sexual harassment while neglecting to offer a variety of strategies, but also serves to privatize the issue by ordering targets to cope on their own and relieves the institution of its responsibility for the harassment (p. 140). While not a Critical Discourse analyst, Clair does contend (like CDA scholars) that the discourse of and around sexual harassment "cannot be viewed as a symbol reflecting a reality that exists outside of the symbol" but rather as "embedded with political-economic meaning" (p. 128).

Like Clair and Dougherty, Eyre (2000) argues for a discursive approach to studying sexual harassment. She maintains that "dominant discursive practices will contribute to the maintenance of the very social conditions that normalise sexual 
harassment" (p. 296). Eyre employed CDA to analyse various texts (e.g., university bulletins, provincial and national media stories) dealing with a sexual harassment case involving a Canadian university professor. She found that the discursive framing (i.e., the dominant way in which the issue was presented and discussed in these texts) legitimized sexual harassment and "support[ed] the idea that the university is not a place for women" (p. 302); as well, feminist discourse was appropriated by "dominant groups for their own interests" (p. 304).

Although her research puts slightly more emphasis on the legal rather than the discursive aspect of sexual harassment, Faraday's (1994) exploration of sexual harassment as human rights discourse corroborates the concept of discourse as bound up with sexual harassment. While framing sexual harassment as a human rights (and therefore, legal) issue is beneficial in that it gives sexually harassed women ${ }^{9}$ recourse, Faraday argues that the same discourse frames harassment as an individual rather than a societal problem. Like Eyre (2000), Faraday notes the tendency of the dominant group to appropriate discourse for their own purposes; to wit, she demonstrates through a review of Canadian legal cases that the same human rights discourse that was meant to enable targets of sexual harassment to seek redress is used by perpetrators of sexual harassment to deny their culpability by claiming that they have the right to free speech; in other words, the harassment was claimed to be "just" bad taste or crude humour, and the complaint against the perpetrators violated their right to free speech. This is similar to Eyre's (2000) findings, as she noted that misogynistic speech was couched as free speech

${ }^{9}$ Again, I acknowledge that men can be targets of sexual harassment, too; however, women are "overwhelmingly" more apt to be harassed and men to be the harassers, as Faraday points out (p. 34). 
in defense of the alleged sexual harasser at the university (p. 299). In other words, using the discourse of human rights to frame sexual harassment can, ironically, do more harm than good. Similarly, Stein (2003) traces the effect of the discourse of 'bullying' in American schools on sexual harassment discourse; she notes that behaviours that rightly, legally, should be classed (and tried) as 'sexual harassment' are now often subsumed under the classification of 'bullying'. In effect, the act of naming certain behaviours as bullying rather than sexual harassment hides the harassment and enables it to occur. Again, this allows the act of sexual harassment to be constructed as an individual, deviant act, rather than a systemic social issue; Stein argues that because schools can be held legally accountable for a student's sexual harassment, it benefits them to be able to frame the behaviour as an act of bullying (i.e., the act of an errant child) and can thereby disavow their responsibility (i.e., not only their legal culpability but also the responsibility of an institution or society to account for its systemic inequalities). Although these last two studies are not discourse analytically focused in the way that other literature mentioned in this section is (e.g., Eyre, 2000; Dougherty, 2006; Clair, 1993), I believe these papers support my claim that discourse is imperative to consider when studying a social problem such as sexual harassment. Faraday's (1994) and Stein's (2003) studies provide a view of sexual harassment discourse that encompasses a much broader scope of influence (i.e., the discourse of a country's legal system) than the other contexts mentioned previously.

I have now covered the reasons for the prevalence of sexual harassment in bars, and the explicit and implicit connections between sexual harassment and discourse, but there is still the issue of normalisation to consider. As mentioned in the introduction, 
bartenders often view sexually harassing behaviour from their customers as an unremarkable - or at least expected - aspect of their work, and often do not use the term 'sexual harassment' to describe it. This will be the focus of the next section.

\subsection{Normalisation of Sexual Harassment}

van Dijk (1998) defines normalisation as something that "enables general, abstract beliefs to be shared by many or most members of groups" (p. 78). Sexual harassment is a common happening in the hospitality industry, and is often normalised. Existing research on sexual harassment in bars (and indeed other service-oriented jobs) shows that many bartenders consider harassment 'just part of the job' (Folgerø \& Fjeldstad, 1995; Good \& Cooper, 2016; Matulewicz, 2015). There are various reasons posited for this; for instance, Poulston (2008) notes that there is an historical association between bartending and prostitution that may still linger today (p. 234), while Good and Cooper (2016) argue that employees gain tacit knowledge from their co-workers about the norms of the job (pp. 6,

12). Either of these reasons might at least partially explain how bartenders could come to perceive sexual harassment as an expected part of their work. Additionally, as mentioned before, bartending is precarious work where pleasing the customer and performing "traditional" femininity are most often mandatory, and bartenders may not feel they have the power to complain, thus becoming accustomed or resigned to the harassment.

What is typically left either unexplored or unspoken in these discussions about the normalisation of sexual harassment in bars is the role of language in this normalisation. This seems to me a serious limitation to our understanding of the prevalence and normalisation of sexual harassment in bars. Conceptions of discourse and power such as Fairclough's (1992) and Wodak's (2001; as explicated in section 2.2.3, above) support 
the view that language is a central factor in understanding power and normalisation; sexual harassment in bars, then, should be looked at from a discourse studies perspective. Dougherty's (2006), Eyre's (2000), and Clair's (1993) discourse analytic approaches ${ }^{10}$ to studying sexual harassment demonstrate how language serves to construct sexual harassment in various ways; moreover, Eyre is explicit in arguing that discourse is complicit in normalising sexual harassment, and she advocates for change: "in order to act as moral agents, we must develop a greater awareness in ourselves of how the discursive framing of sexual harassment contributes to dominant power relations and thereby assists in the perpetuation of sexual harassment" (p. 304). Hence, while research in other contexts (e.g., universities, health care) make connections between discourse, sexual harassment, and normalisation, and while much of the literature in the context of hospitality and the service industry mentions normalisation (for the most part implicitly), none of the latter discuss the role of language. Despite the prevalence of sexual harassment in bars, it has yet to be researched as a social practice that is normalised and maintained through discourse in that context.

According to Fairclough, the connection between power and language is generally not at all apparent to those it affects: "such linkages between discourse, ideology and power may well be unclear to those involved, and more generally...our social practice is bound up with causes and effects which may not be at all apparent" (1993, p. 135). That is to say, bartenders might not see sexual harassment as especially problematic-hence it is normalised, according to van Dijk's (1998) definition (above); however, bartenders also often do not perceive themselves as targets of sexual harassment at all. This is also a

${ }^{10}$ As explained in section 2.3 
common theme in literature about sexual harassment in bars: not only is sexual harassment an expected and mainly condoned behaviour, but many bartenders do not use the term 'harassment' to describe their experiences. This speaks to a concept related to normalisation, that of 'silencing'. Thus, the next section of this chapter will briefly explain silencing as well its relation to sexual harassment and its normalization.

\subsection{Silencing of Sexual Harassment}

Huckin (2002) defines textual silence as "the omission of some piece of information that is pertinent to the topic at hand" (p. 348) and goes on to provide a taxonomy of five distinct types of textual silence. However, the types of silence described by Huckin imply a deliberate choice to be silent; for example, what he terms "presuppositional silence" involves the speaker omitting information that the listener can be presumed to know already (p. 349), while "discreet silence" involves a sensitive or taboo subject that the writer might omit in order to avoid offense (p. 351). Even if these choices are not deliberately manipulative in the sense that he grants to "manipulative silence" (e.g., some types of journalism, advertisements), they are still ideological choices made more or less consciously by the speaker. Thiesmeyer (2003), in contrast, talks about "silencing", which she argues is "accompanied by social and political judgements of what is acceptable and unacceptable" (p. 2). In this case, silence is not necessarily a conscious choice of the speaker, but rather a result of what Eckert and McConnell-Ginet (2013) call a constraint on the range of choices available to a speaker (p. 47). As well, like the construction of normalisation, silencing is often an invisible practice: according to Thiesmeyer, "silencing is a process that works best when disguised, that is, when it displaces the silenced material by means of another discourse, or conceals or filters the 
unacceptable material through a discourse that is more acceptable" (p. 2). Like normalisation, silencing is mentioned only implicitly in much of the literature on sexual harassment in bars. An example of this appears in Folgerø and Fjeldstad's (1995) exploratory study of the experiences of Norwegian hospitality employees. Their interviews revealed a disconnect between what the researchers term "objective" and "subjective" sexual harassment in the participants' recounts; to wit, while the participants had been "objectively" sexually harassed (i.e., customers had perpetrated behaviours upon them that legally constituted sexual harassment), the bartenders did not perceive themselves to be sexually harassed. Folgerø and Fjeldstad call into question definitions of sexual harassment (such as the OHRC's, mentioned in section 1.3.2) that use terms like "unwanted", arguing that it is too limited to account for the experiences of those who are so inured to the harassment that they "actively den[y] that the problem exists" (p. 311). They close by noting that, in the hospitality industry, "sexual harassment remains acceptable - and thereby 'non-existent”' (p. 311). Although Folgerø and Fjeldstad do not label this 'silencing', it seems clear that, by not using the term 'sexual harassment', bartenders are being silenced (whether by others or themselves) and this might contribute to the normalisation of their experiences.

Similarly, (although not as thoroughly), other research on sexual harassment in bars mentions this silencing of bartenders in recounting their experiences. Brunner and Dever (2014), for instance, found that it was challenging for participants to distinguish sexualized behaviour from sexual harassment in the hospitality industry. Although Brunner and Dever do not discuss this, it would seem that silencing is at work here: according to them, "The stated requirement for staff to have 'an open personality' has the 
effect of rendering the demand for - and the consequences of - such (hetero)sexualized performances largely invisible" (p. 466). Drawing on Thiesmeyer's definition, it might be said that the new discourse of 'the cult of the customer' is displacing the discourse of sexual harassment. This might also be seen in the case of Stein's (2003) research, where she argues the discourse of 'bullying' is replacing that of 'sexual harassment'. Towns, Adams, and Gavey (2003) studied the discourse of domestic violence in order to be able to understand the silencing that goes on in that context; similar to Faraday's (1994) and Stein's (2003) arguments, they argue that it is not sufficient to see domestic violence as a deviant, individual issue. Rather, they say we must investigate the social structures that enable the violence; additionally, they maintain that "social patterns upholding violence find their chief manifestation in discourse, as well as the role discourse plays in silencing talk about the extreme outcome of these patterns in violence" (p. 45). Thus, it seems to be the case that silencing is just one possible manifestation of the normalisation of sexual harassment in bars; if bartenders use language that constructs sexual harassment as 'just part of the job', or even fail to use the term altogether, that would serve to make problem invisible, or at least less visible.

\subsection{Summary}

In this chapter, I have discussed the commonly argued reasons for the prevalence of customer sexual harassment in bars: the gender roles often assumed by female servers and male customers, the expectation in hospitality that 'the customer is always right', and the power (especially economic) that customers hold over bartenders. Since there is a dearth of Discourse Studies research on sexual harassment in bars, I have integrated discussion of sexual harassment and its relation to discourse in other contexts. In 
addition to these factors, the issue of normalisation was discussed as a possible factor or consequence of the prevalence of sexual harassment in the hospitality industry.

Normalisation has been defined as the promotion of a shared set of beliefs among a group and its relation to sexual harassment revisited. Finally, silencing has been defined as the suppression of certain types of discourse, as well as the replacement of certain discourses by other discourses. Silencing is one way in which normalisation can be enacted; the relevance to sexual harassment has been made by positing that the discourse of 'sexual harassment' has been replaced with normalising discourse such as the framing of troublesome customer behaviour as 'just part of the job'. In the upcoming chapter, I discuss my theoretical and methodological choices, their relation to the literature here and their influence on my own research design. 


\section{Chapter: Research Approach}

\subsection{Introduction}

In the previous chapter I reviewed literature on sexual harassment in bars, as well as literature on discourse and sexual harassment in other contexts. The gap I identified was that research on bars does not address discourse, while research about sexual harassment and discourse is not undertaken in the context of the hospitality industry. I suggested that investigating sexual harassment in bars must involve the study of discourse. In this chapter, I discuss the theories that inform my research. These theories are lenses through which I view my topic and, accordingly, they have influenced my choice of research questions, methodology, and methods. To illustrate these decisions about my research process, I rely primarily on Crotty (1998), who argues for a four-tiered scaffolded approach to situating one's social-science research: Epistemology (“theory of knowledge") $\rightarrow$ Theoretical Perspective(s) ("philosophical stance") $\rightarrow$ Methodology ("strategy...behind the choice... of particular methods") $\rightarrow$ Methods ("procedures used to gather and analyse data") (1998, pp. 3-4). This schema is a useful way to organize this section, as it "constitutes a penetrating analysis of the [research] process and points up the theoretical assumptions that underpin it and determine the status of its findings" (p. 6). Situating my own research choices into Crotty's proposed structure results in the following: 


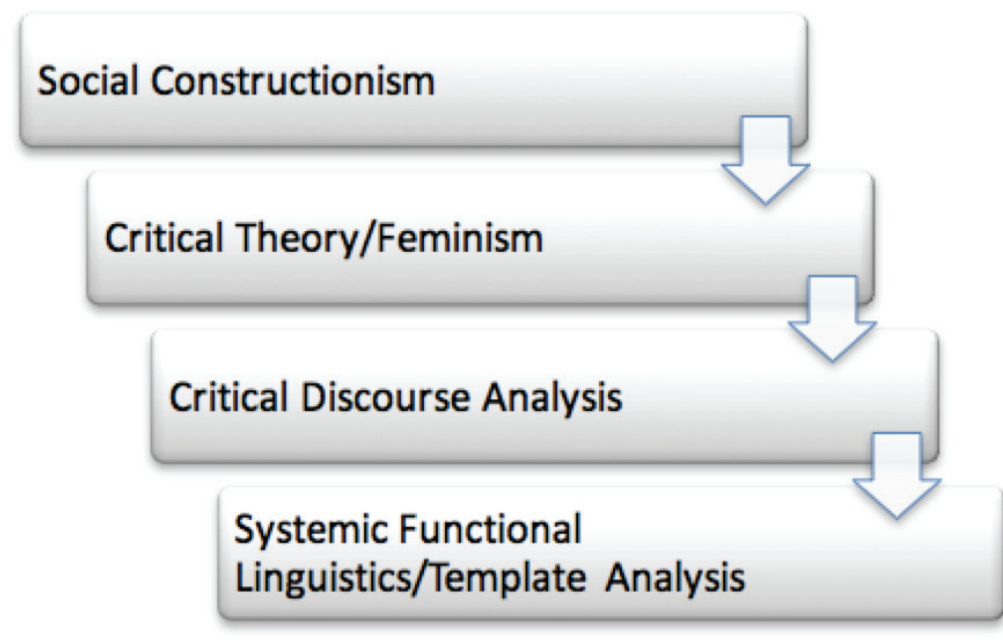

Figure 1: Research Approach

The overarching approach used in this thesis is CDA, which has its roots primarily in both social constructionism and critical theory. Furthermore, since this thesis is concerned with gender roles (i.e., female bartenders and their experiences with male customers; also traditional gender roles, as explained in Chapter 2), feminism has also informed my research. This chapter will discuss these four elements in turn. The sections on Critical Discourse Analysis (CDA) and Systemic Functional Linguistics (SFL) are longer and more in-depth, as they relate directly to language use, which is the focus of this thesis. Although the discussions of epistemology and theoretical perspectives are briefer, it is still worthwhile to examine these first two elements, as they have informed my approach and my assumptions about the relationship between sexual harassment and language at every stage of this research. Thus, I start this chapter by touching on Social Constructionism, Critical Theory, and Feminism, followed by a more detailed explanation of CDA and SFL. 


\subsection{Social Constructionism}

Crotty (1998) defines social constructionism as the view that:

...all knowledge, and therefore all meaningful reality as such, is contingent upon human practices, being constructed in and out of interaction between human beings and their world, and developed and transmitted within an essentially social context. (p. 42)

Social constructionism holds that we live in culture, and culture in turn lives in us (Crotty, 1998, p. 52). In other words, meaning is socially constructed, and cannot exist outside of consciousness. That is not to say that material objects or experiences, or emotions (for example: trees, winning a game, or sadness) are not 'real', but rather that the only meanings we can assign to these phenomena, and the only knowledge we can achieve regarding them, are established socially, though discourse; Bruffee (1986) calls these objects, experiences, and emotions "constructs generated by communities of likeminded peers” (p. 774). According to Burr (1995), “...what we regard as 'truth'...is a product not of objective observation of the world, but of the social processes and interactions in which people are constantly engaged with each other" (p. 3). Language is an integral aspect of this; according to Berger and Luckmann (1966), “An understanding of language is thus essential for any understanding of the reality of everyday life" (p. 52). Sexual harassment is a social construction; it is the process - shaped by our societal values - of labelling certain behaviours as harassment that makes them harassment. That is to say, before 1980 (in Canada), there was not comprehensive term for such behaviours; sexual harassment did not exist legally (Campbell, 1992). As Gloria Steinem said, "it was just called life" (Shriver \& Steinem, 2011). 
Moreover, since language is essential for understanding the meanings we make of sexual harassment, one must look at language, in this case bartenders' discourse about sexual harassment. How do they understand sexual harassment as it applies to them in the context of their job? In order to answer this, I take as my starting point a social constructionist stance, adopting the definition by Crotty (above); this is the point of view which informs the questions I have asked here, and the choices I have made in the research process. However, my research has also been guided by the theoretical perspectives of critical theory and feminism. These are the focus of the next section.

\subsection{Critical Theory and Feminism}

Critical theory and feminism are two separate yet closely related theoretical perspectives. I discuss each in turn, but understand feminism as a branch with its roots in critical theory. As elaborated in the methodology section (below), feminism and critical theory are also closely related to CDA. While I believe that my research is more heavily weighted on the critical side, the feminist influence that I am guided by here cannot and should not be left out.

For a basic definition of critical theory, I turn again to Crotty (1998), who says that "[c]ritical forms of research call current ideology into question, and initiate action, in the cause of social justice" (p. 157) ${ }^{11}$. In this sense, "critical" does not have the commonly held meaning of "disapproving”, but rather “... being reflexive or sceptical about the social world, and... being engaged in a critique of the existing social world"

${ }^{11}$ This is not to say that Crotty presents critical theory as a stable, unvarying research method; moreover, Kincheloe and McLaren (1994) say that the "critical tradition is always changing and evolving" (p. 303). 
(Willis, 2004, p. 105, cited in Beasley, 2005, p. 17). In other words, doing critical research means to challenge and question those worldviews and practices that are considered natural or taken-for-granted. This is what I attempt to accomplish in this thesis: to question the 'natural' viewpoint I once held, namely that sexual harassment is 'just part of the job'. Critical theory is generally credited as having its roots in The Frankfurt School ${ }^{12}$ (who in turn were both influenced by and challenged Marxism), although Crotty argues that the tradition of critical social thought goes back at least to Socrates (p. 113). Critical Discourse Analysis is, as the name implies, a methodology that has critical theory at its roots, and therefore I discuss this critical aspect of my research in more depth in the following section on CDA.

Critical theory has not only been one of the prime theoretical foundations for CDA, but also for feminist research (Hesse-Biber, 2014). Thus, another theoretical perspective that underpins my work is feminism. Hesse-Biber defines feminist research as research that "privilege[s] women's issues, voices, and lived experiences" (p. 3), while Crotty (1998) says that feminism characterises "the world it experiences as a patriarchal world and the culture it inherits as a masulinist culture" (p. 161). However, for the purposes of this research, Creswell's (2007) definition seems to summarize it best: "Feminist research approaches center and make problematic women's diverse situations and the institutions that frame those situations" (p. 25).

Overall, I subscribe to the idea that we live in a (mainly) patriarchal society, and

12 The Frankfurt Institute of Social Research, "a centre for socialist research" (Scott \& Marshall, 2005), often associated with the work of such scholars as Adorno, Horkheimer, and later, Habermas. 
specifically, that female bartenders are sexually harassed because of an imbalance of power between men and women and because of a system that generally privileges the rights of men over those of women, especially women in precarious employment like bartending. Because these assumptions inform my research, it is only appropriate that they be mentioned here.

As mentioned above, feminism and critical theory are closely related. Beasley (2005) argues that feminism "starts from a critique of the mainstream, of 'the norm', of what is taken for granted" (p. 25). He continues: "All of the subfields [of feminism] are characterised, in other words, by an inclination to challenge the notion of a proper, appropriate, natural 'norm' in relation to gender and sexuality" (Beasley, 2005, p. 26) ${ }^{13}$. One of the problems that I am concerned with in my research is the natural, 'commonsense' idea that the sexual harassment of female bartenders by male customers is an inherent and natural aspect of hospitality work; the problem is so unremarkable in the context of bartending as to be almost invisible. This is substantiated both in the literature and in my own findings. Looking at this with a critical lens is vital to understanding why and how this is happening.

To this point, I have explained social constructionism as the overarching theory of knowledge to which I subscribe. Social constructionism maintains that meaning is constructed by and with people; furthermore, language is considered to be of critical importance from this viewpoint. This epistemology is realized in the two theoretical perspectives that influence this research: critical theory and feminism, the former of

${ }^{13}$ For an in-depth explanation of the various "subfields" of feminism, see Tong 2009. 
which has been influential on the latter. According to Hesse-Biber (2014), "critical theory research practice is particularly concerned with exploring issues of power and justice and ways in which matters of class, gender, race, sexuality, ableism, and nation intersect with ideologies and discourse" (p. 54, emphasis added). As such, feminism and critical theory are not only complementary to each other, but also key to my choice of CDA as methodology. Having covered the first two elements of my research approachepistemology and theoretical perspectives - I now move on to discuss my methodology, in which my epistemological and theoretical choices are realized.

\subsection{Critical Discourse Analysis}

In this section, I begin by defining Critical Discourse Analysis, then provide a brief history of the approach focusing on the work of its most influential scholars. I have also included a brief section justifying my choice of CDA for this study. Following that, I discuss Norman Fairclough's approach, specifically his three-dimensional framework, which I use to guide my analysis and findings. Finally, I explain CDA's relationship to Systemic Functional Linguistics.

\subsubsection{What is CDA?}

Huckin (1997) defines CDA as "a highly context-sensitive, democratic approach which takes an ethical stance on social issues with the aim of improving society" (p. 78), while Wodak (1997) says that "[CDA] studies real, and often extended, instances of social interaction which take (partially) linguistic form" (p. 173). CDA thus concerns itself with social and power relations expressed through language. According to Blommaert and Bulcaen (2000), CDA is best considered not a discipline per se but rather a research approach or a "more general process of (partial) convergence in theories and practices of 
research on language" (p. 447). Indeed, van Dijk (1993) maintains that CDA does not "primarily aim to contribute to a specific discipline, paradigm, school or discourse theory" because its first concern is to address social problems and injustices; therefore, the theories and methods used in CDA are the ones that best address the requirements of this goal (p. 252; also see Meyer, 2001, p. 14; Fairclough, Mulderigg, \& Wodak 2011, p. 357). Hence, $\mathrm{CDA}$ is also interdisciplinary in nature. Perhaps the best way to summarize what CDA stands for is to rely on one of its noted scholars, Wodak (1997), who defines the purpose of CDA as follows: "[CDA] studies real, and often extended, instances of social interaction which take (partially) linguistic form. The critical approach is distinctive in its view of (a) the relationship between language and society, and (b) the relationship between analysis and the practices analysed" (p. 173). Blommaert and Bulcaen (2000) add that CDA's "locus of critique" is the connection of language and society (p. 449).

Finally, CDA is also self-reflexive; that is, as Wodak and Meyer (2001) explain, "CDA researchers attempt to make their own positions and interests explicit" (p. 3). Reflexivity is a requirement of much feminist research, as well, making it another element that feminist research and CDA have in common; Hesse-Biber (2014) defines reflexivity as "a process by which [researchers] recognize, examine, and understand how their social background, location, and assumptions can influence the researcher" (p. 3). As a fledgling CDA researcher, I acknowledge how important reflexivity is: because CDA is concerned with ideology in discourse, and value-laden social practice, it follows that all research, including my own, is ideological and value-laden. For this reason, I have attempted, and will continue to attempt, to be clear about my own biases, 
motivations, and assumptions. My aim is to be clear not only about the theoretical assumptions that I am making, but also about where I come from as a social actor and researcher - as explained in Chapter 1 - and about the stance I take on issues such as sexual harassment, patriarchy, and power.

To summarize, CDA is a research approach or perspective that takes as its aim to investigate the relationships between language and society, particularly those relationships involving injustice or power ${ }^{14}$. Furthermore, it is a hallmark of CDA that it conceptualizes language as constituting society as well as being constitutive of society. It is critical in that it questions commonsense assumptions, and reflexive in that researchers acknowledge their own biases. Finally, CDA has a social constructionist stance (Huckin, 1997, p. 79), which is pertinent for my research. In that vein, the next section addresses my rationale for using CDA as the framework for this study.

\subsubsection{Why CDA?}

Considering the primary tenet of CDA - that it is concerned with social and power relations as they are constituted through language - it only makes sense to study sexual harassment from a linguistic perspective. That is, with the understanding that sexual harassment is an issue of power (Uggen \& Blackstone, 2004, p. 88), then it follows that language in some form is often involved; and further, we know that sexual harassment consists of not only physical, but also verbal behaviour. If discourse does ideological work, then it might be the case that language is promoting, normalizing, or otherwise

${ }^{14}$ Although there has recently been a turn to what is called "positive discourse analysis", which investigates texts that the researcher does not react negatively to (for a summary, see Waugh, Catalano, Al Masaeed, Hong Do, and Renigar, 2015, p. 94-96). 
involved in the perpetuation of sexual harassment. Furthermore, given that sexual harassment is a social problem, then CDA is an appropriate research approach with which to address it.

Fairclough (1993) argues that to be related and applicable to the way we actually use language, language studies should also focus on the social, critical, and historical (p. 138). In other words, language should not be studied as if it were a neutral medium through which our ideas about "the real world" pass; Figueiredo (2004) likewise explains that language is not merely a tool that reflects objective reality, but rather "it crystallizes and stabilizes ideas" (p. 219). I hold the inverse to be true, as well; if we are to investigate social problems (such as sexual harassment), it behooves us to look closely at language use. These connections between society and language are what led me to employ CDA as my methodological framework. As well, as mentioned previously, feminist and critical research approaches often inform work in CDA; Lazar (2005), for instance, claims that CDA and feminism share many of the same "social emancipatory goals” (p. 4). Hence, given my stance on gender relations and language, CDA is a fruitful and appropriate approach for me to take.

Having defined CDA, its main principles and characteristics, and having connected these to my own work, I now move on to provide some background on CDA in general, as well as on Norman Fairclough and his three-dimensional approach in particular. 


\subsubsection{A Brief History of CDA}

As mentioned before, CDA has its roots in critical theory, which itself is informed by the Frankfurt School, Marxism, and the work of (for instance) Habermas, Gramsci, and Hall (van Dijk, 1993, p. 251). Furthermore, CDA grew out of critical linguistics (Wodak \& Meyer, 2001, p. 1; van Dijk, 2000, p. 352), whose aim was, in the 1970s and 80s, to investigate the relationship between language and the situations in which it is used (Johnson \& Johnson, 2007). Fowler (2003), one of critical linguistics' founders, says that critical linguistics is "an analysis designed to get at the ideology coded implicitly behind the overt propositions, to examine it particularly in the context of social formations" (p. $3)$.

According to Wodak and Meyer (2001, p. 3), CDA "as a network of scholars" emerged after a meeting between Teun van Dijk, Ruth Wodak, Norman Fairclough, Gunther Kress, and Theo van Leeuwen in the early 1990s (see also Blommaert \& Bulcaen, 2000,p.447). This is not to suggest that there is unity among all CDA researchers; indeed, not only is CDA criticized and contested outside the "network" (Flowerdew, 1999; Widdowson, 1996) but there are varied ideas and methods within its ranks. As Waugh, Catalano, Al Masaeed, Hong Do, and Renigar (2015) explain, "There are many different approaches to CDA and not all adherents of those approaches recognize their affinity with each other" (p.72). Of course, given the interdisciplinary nature of CDA, and the broad spectrum of social issues that it deals with, this is neither surprising nor problematic. Young and Harrison (2004) identify three CDA approaches, according to how closely they follow an SFL program; Waugh et al. (2015), in contrast, identify five approaches to CDA, which include: van Dijk's socio-cognitive approach; 
van Leeuwen's social actors approach; Jäger's and Maier's dispositive analysis; Wodak's discourse-historical approach; and Fairclough's dialectical-relational approach. There are countless examples of specific areas of research undertaken in CDA, and they could not possibly all be listed here. However, a few examples are: Wodak's work on national identity (2009), van Dijk's work on racism (1992), and van Leeuwen's work on social actors (1996). However, Fairclough's work - and more specifically, his research approach -is what informed this study most heavily, and it is this that is the focus of the next section.

\subsubsection{Fairclough and his 3-Dimensional Framework}

\subsubsection{Introduction}

This section explains the three aspects of discourse analysis according to Fairclough's

framework. Each of the three levels are detailed, incorporating examples from hospitality work and my own research in each instance. However, Fairclough's work is often concerned with issues of language and power, as mentioned, and to this point the concepts of power and language have only briefly been discussed. Because these two concepts are so influential in this thesis, I begin this section by elaborating on each of them.

\subsubsection{Power}

As mentioned in Chapter 2, Fairclough (1995) describes power in terms of asymmetries; van Dijk (2000) likens power to control: i.e., a group has “(more or less) power if they are able to (more or less) control the acts and minds of (members of) other groups" (p. 354-355). Recall that in section 2.2.3, the asymmetrical power between 
customers and bartenders was offered as a primary reason why customer sexual harassment of bartenders is so prevalent (Folgerø \& Fjeldstad, 1995; Poulston, 2008). As well, Uggen and Blackstone claim that sexual harassment is an expression of power (p. 67), and this corresponds to van Dijk's definition (above); in the context of a bar, the customer is able to (attempt to) control bartenders via their financial power, i.e., tips. If it is the case that bartenders act in particular ways or modify their behaviour in exchange for tips, then the customer indeed has the balance of power.

There is resistance in varying degrees to the imposition of power; in Fairclough's words: "hegemony ${ }^{15}$ will always be contested to a greater or lesser extent" (2001, p. 124). Likewise, van Dijk (2000) says that power is "seldom absolute", and that

Groups may more or less control other groups, or only control them in specific situations or social domains. Moreover, dominated groups may more or less resist, accept, condone, comply with, or legitimate such power, and even find it 'natural'. (p. 355)

This 'naturalness' speaks to hegemony. That is, a dominated group may consent to power because they find it unremarkable and the way things should be.

In the context of the bar as workplace, it is well documented that bartenders often find nothing unusual or untoward about sexually harassing behaviour - 'it's just part of the job' (see Chapter 1, Chapter 2). Indeed, many bartenders are reluctant to label their harassment as harassment (Matuleicz, 2015; Folgerø \& Fjeldstad, 1995). However, this

${ }^{15}$ Hegemony, according to Scott and Marshall (2005) is "the manufacturing of consent" (p. 266), while Bates (1975) describes the thrust of hegemony as: "man is not ruled by force alone, but also by ideas" (p. 351). 
is not to say that bartenders do not resist sexual harassment. Poulston (2008) notes that many bartenders participate in and even enjoy sexual harassment (p. 239), while Philaretou and Young (2007) claim that servers can "utilize their sexuality to derive tangible/intangible rewards" (p. 57). Folgerø and Fjeldstad (1995) and Hughes and Tadic (1998) both describe various strategies in which targets of sexual harassment might resist, such as ignoring the behaviour or avoiding the customer. These strategies exemplify some types of resistance by bartenders to the expression of power by their customers. One of the major tools of resistance is language, as it is also a powerful tool of domination.

\subsubsection{Language}

According to Fairclough, language is a social practice, from which it follows that first, it is a "mode of action", and that second, it both shapes and is shaped by society (1993, p. 134; see also 1992, p. 39). For Fairclough, this means that discourse analysis must incorporate analysis both of language itself and of its social context (1992, p. 2). Hence, it was not sufficient, for example, for me to conduct this research either from a purely linguistic point of view or a purely social point of view. Taking one point of view at the expense of the other is one of the shortcomings I mentioned in the previous chapter regarding the existing research on sexual harassment. From the standpoint of Fairclough, social issues such as power, resistance, and sexual harassment cannot be viewed as existing separately from language. Indeed, if hegemony is "manufactured consent", or rule by ideas rather than force, then - by definition-language is key to maintaining it. Moreover, if power can be maintained and enforced through language, then resistance to power can be enacted through language as well. 
Thus far in this section, I have attempted to explicate Fairclough's conceptions of both power and language, as well as their relevance to my research. These provide some background to the upcoming section, where I explain Fairclough's three-dimensional framework and its use in this analysis.

\subsubsection{The Framework}

Bearing in mind the connections between language and society, Fairclough conceptualizes discourse analysis as consisting of three parts: analysis of the features of a text itself (be it written, verbal, visual); analysis of the discourse practice ${ }^{16}$; and analysis of the broader social context. This is a reflection of the argument that discourse analysis must be undertaken with a view not only of the linguistic features of a text, but also the social context and relationships that both constitute and are constituted by it. Figure 2 illustrates the framework:

${ }^{16}$ Which Fairclough (1992) defines as the "nature of the processes of text production and interpretation" (p. 4). 


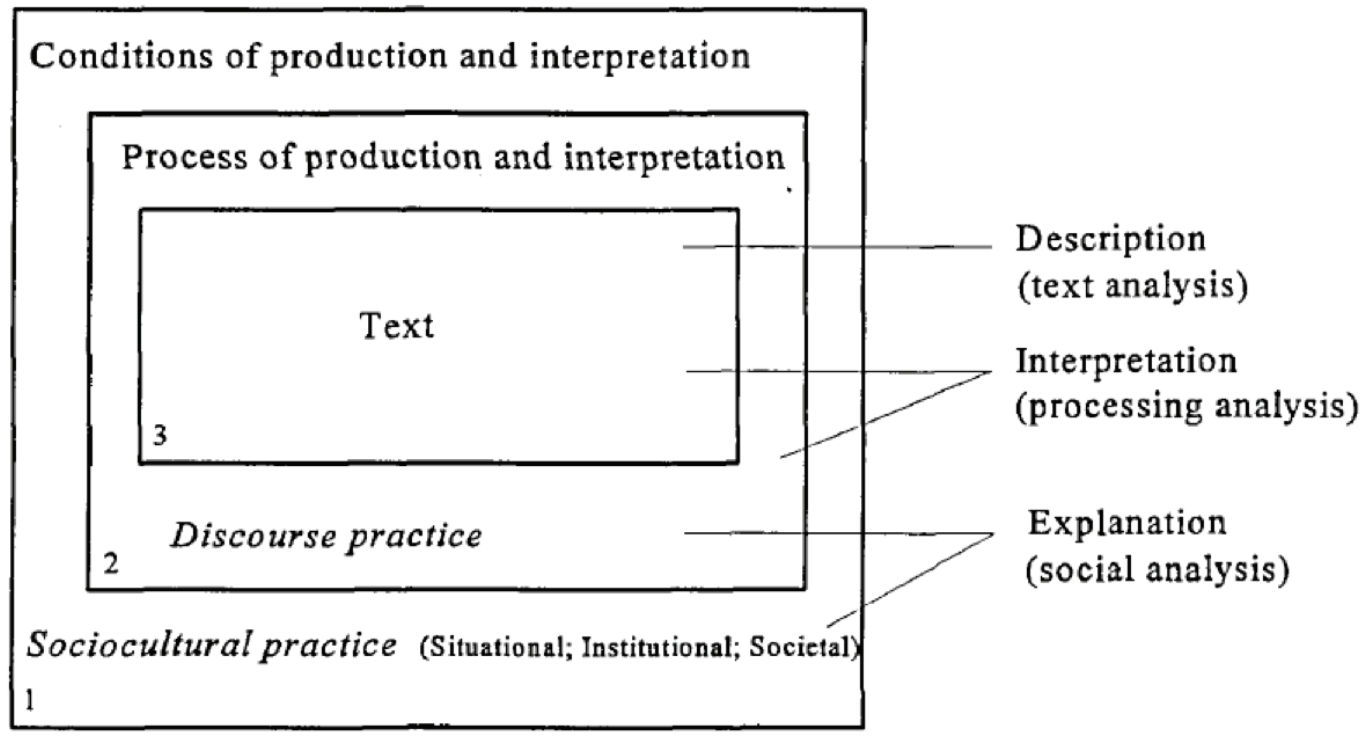

Figure 2: Fairclough's 3-D framework (Janks, 1997, p. 330)

Following is an explanation of each level of analysis (or box) in turn, including a discussion of the general way in which my research will be incorporated into this framework $^{17}$. At the level of Sociocultural Practice (the outermost box), Fairclough says that we need to look at aspects such as "the context of situation, the institutional context, and the wider societal context or "context of culture" (1993, p. 137). Blommaert and Bulcaen (2000) describe this as "the ideological effects and hegemonic processes in which discourse is a feature", and Janks (1997) as "the socio-historical conditions that govern these processes [of text production and reception]" (p. 329). To draw on an example from Fairclough's own work on the way academic discourse is frequently "marketized ${ }^{18 ",}$, situated within this box are factors such as the "particularly strong links between the newer universities and business" (1993, p. 149). In Janks's analysis of a bank advertisement, this outer box situates the ad within the broader social context of

\footnotetext{
17 Although most of these details are to be found in my Findings (see Chapter 5).

${ }^{18}$ That is, some academic discourse now resembles advertising discourse.
} 
"revolutionary change" in South Africa in the (at the time, newly) post-apartheid era (p. 340). Regarding my own research, the level of Sociocultural Practice can include such elements as the nature of the bar as a workplace, the power dynamics between bartenders and both their managers and customers, and the traditions and norms (such as 'traditional gender roles', see my discussion in section 2.2.1) that are characteristic of the relationship between female bartenders and male customers. In other words, this analysis involves the "institutional and organizational circumstances" (Fairclough, 1992, p. 4) of the bar as it relates to bartender/customer relations.

Fairclough explains that the middle box, Discourse Practice, "specifies the nature of the processes of text production and interpretation, for example which types of discourse... are drawn upon and how they are combined" (1992, p. 4). Huckin (1997) explains Fairclough's framework in the following way: "The meaning of a text derives not just from the words-on-the-page but also from how those words are used in a particular social context" (p. 80). From that perspective, Discourse Practice is then "how those words are used". Fairclough (1992) provides examples of the production of texts: a newspaper story, for instance, may have various producers (writer, editor, the 'source' of the story) and this is due to the social context of the production of that text (p. 78). Consumption, too, is not always a straightforward process and is influenced by context; for instance, consumption may be "individual or collective: compare love letters to administrative records" (1992, p. 79). Relating this discussion to bartenders and sexual harassment, I have undertaken a study of language use by bartenders in order to investigate the ways that bartenders discursively construct their experiences of sexual harassment. Thus, at the Discourse Practice level, my analysis necessitates looking at the 
way this language is produced and received by other bartenders. That is to say, from the standpoint that sexual harassment is a discursive construction, my analysis at this level consists of investigating how bartenders' own language use and choices factor into their perception of sexual harassment, and how this might influence other bartenders' perceptions. In the case of this thesis, I have two types of language to compare: interview data and reddit data. The former is comprised of participants who know that they are being recorded (despite their anonymity here) and the latter of anonymous posters with created 'usernames'. The former are produced for me, for this research, while the latter are produced as a social activity whereby one person is volunteering their opinions to aid another. The interview data is likely neither intended nor expected to influence my perceptions - as the interviewer-in any way (although it might be the case that they did), while the reddit data seems to have the express purpose of influencing others (although likely not in a deliberately manipulative sense). Thus, it might be the case that there will be differences in content across the two types of data, given the differences in their production and reception.

The third level of analysis (innermost box) is concerned with analysis of the features of the Text itself. Blommaert and Bulcaen (2000) describe this level as analysis of "the linguistic features and organization of concrete instances of discourse"; i.e., lexical and grammatical features, as well as organizational choices such as cohesion, and structural choices such as turn-taking (p. 448). Fairclough (1992) initially classified text analysis under four broad categories: vocabulary, grammar, cohesion, and text structure; this list was later expanded to become "genre, dialogic organization (turn-taking), cohesion, clause-complex, metafunctions, vocabulary" (1993, p.136). Taken either way, the focus 
at this level of analysis is on the features of the text itself. Janks (1997) provides a list of features than an analyst might investigate (p. 335), some example of which include:

- Nominalization, which is the practice of turning nouns into verbs. For example, rather than saying "I analysed the data and found the following...", one could say "Analysis showed..."

- Active and passive voice. Active voice means that the agent, or "doer" of the action appears in the subject position, as in "Bill threw the ball". Passive voice, in contrast, puts the agent in a later position in the clause, as in "The ball was thrown by Bill". Use of passive voice has the potential to eliminate mention of agency altogether, as in "The ball was thrown".

- Choices of mood, which grammatically refers to the speaker's choice of declarative, interrogative, or imperative clause. Mood is discussed in detail in Section 3.5.2.2.

One example of her text analysis findings is found on p. 335, and involves the naming practices found in the advertisement; in this text, the employer and the employer's child are both referred to by name, while the 'domestic' (servant) is not. Janks argues that this practice "establishes a hierarchy of power" (between the employer and employee in the context of a shifting discourse of apartheid). In my study, the analysis of text is of primary importance, since the language use of bartenders is the key component of my research question. At this level, my concern is with analysis of various textual data that I have collected. The specific tools I use are detailed in the upcoming section on SFL, and in the methods chapter. Heretofore, I have also neither discussed nor defined the various textual analytical tools mentioned in Fairclough's $(1992,1993)$ or Janks's (1997) 
analysis. That omission is deliberate, as I discuss some of these in more detail below.

To summarize, Fairclough's three-dimensional framework incorporates analysis of the three simultaneous instantiations of a discursive event ("any instance of discourse", Fairclough, 1992,p. 4): the text itself, the discourse practices surrounding the text, and the social and cultural context. According to Janks (1997), this means that any text is an example of "socially regulated discourses and that the processes of production and reception are socially constrained" (p. 329). Fairclough illustrates this analysis as three connected boxes; Janks (1997) suggests we imagine them as nesting one inside the other (p. 330). This conceptualization takes into account the view of language as social practice (discussed above). In my research, I situate my linguistic data in the innermost box (Text), the production and reception of the text between bartenders in the middle box (Discourse Practice), which in turn mediates the relationship between the text and the outermost box (Social Practice), in which I situate the institutional context of the bar and its practices as culture/workplace.

Having summarized Fairclough's theoretical and analytical approach, I now move on to a final aspect of CDA, namely the connection between CDA and SFL. Practitioners of CDA use a variety of analytic tools; for instance, Wodak and van Dijk both make use of pragmatics (Waugh et al., 2015, pp. 91-92). Fairclough, though, as mentioned above, often recommends and uses SFL tools in his analyses. Thus, the next section will deal with the links between CDA and SFL, followed by a section devoted entirely to SFL, which has only been briefly mentioned until now. 


\subsubsection{CDA and SFL}

As CDA has developed out of critical linguistics, and critical linguistics was heavily informed by Systemic Functional Linguistics (Fowler, 1996, p. 5), it should be no surprise that there exists a close relationship between CDA and SFL. According to Blommaert and Bulcaen (2000), critical linguistics' work was based on SFL, whose founder Michael Halliday's "linguistic methodology is still hailed as crucial to CDA practices because it offers clear and rigorous linguistic categories for analyzing the relationships between discourse and social meaning" (p.454). Similarly, Young and Harrison (2004) claim that "all researchers in CDA acknowledge that SFL is centrally important to the critical study of situated language events" (p. 3). Janks (1997), for example (as mentioned in the previous section), relied heavily on SFL tools in order to analyse a bank advertisement. Indeed, Fairclough's (1993) inclusion of grammatical features such as "metafunctions" (p. 136) as key to text analysis demonstrates his confidence in SFL. He argues that "a systemic theory of language which sees language as multifunctional, and sees texts as simultaneously representing reality, enacting social relations, and establishing identities" is a good starting point for analysis (1992, p. 9).

SFL deals primarily with language at the level of the clause, i.e., the grammar of language. When working with a topic so socially situated as sexual harassment, one might question the usefulness of a grammatical analysis approach. To answer that question, I draw upon Gee (2011), who says that it is important to study " rules' by which grammatical units like nouns and verbs, phrases and clauses, are used to create patterns which signal or 'index' characteristic social identities and social activities” (p. 158, emphasis added). That is, the grammatical patterns that we use help others define our 
identities. Furthermore, Halliday says that "a discourse analysis that is not based on grammar is not an analysis at all, but simply a running commentary on a text" (1994, xvi, cited in Eggins, 2004, p. 20). Finally, a systemic method of analysis such as SFL provides CDA with a rigorous methodology; Young and Harrison (2004) claim that this protects CDA from the charge of "ideological bias" (p. 4).

There are several other important ties between CDA and SFL. According to Young and Harrison (2004), SFL and CDA share the following ideas: that language is a social construct; that language and society are inextricably linked; and that language influences and is influenced by contexts. As well, Young and Harrison note that both SFL and CDA "emphasize the cultural and historical aspects of meaning" (pp. 1-11).

This section has thus far explored the relationship between SFL and CDA, citing their similarities in the way they conceive of the relationship between language and society. Furthermore, I have noted that SFL tools are often used by CDA scholars (such as Fairclough and Janks), and have argued additionally for the importance of including grammatical analysis in a critical discourse analysis. The next section will explain SFL in more depth.

\subsection{Systemic Functional Linguistics}

Volumes have been written about SFL by other researchers, but the discussion here focuses on the aspects of SFL most relevant to this project. To begin with, SFL is a both a theory of how language is structured for use, and a method for analysing texts ${ }^{19}$ (Eggins, 2004, p. 21). Halliday's thesis is that language does not exist in a vacuum but

${ }^{19}$ Halliday defines a "text" as "any instance of language, in any medium, that makes sense to someone who knows the language" (2014, p. 3). 
rather is always used for some purpose. A main theme in SFL is that, in using language for a purpose, a speaker ${ }^{20}$ makes certain choices, and that entails the rejection of certain other choices. For instance, when saying "the cat died", the speaker has chosen to not say "a cat died", "a dog died", or "a cat danced". Thus, SFL looks at language as a meaning-making system of choices. Thompson (2014) expresses it thusly:

Functional Grammar ${ }^{21}$ sets out to investigate what the range of relevant choices are, both in the kinds of meanings that we might want to express (or functions that we might want to perform) and in the kinds of wordings that we can use to express these meanings; and to match these two sets of choices. (p. 9)

\subsubsection{Metafunctions}

In this research, I have chosen to draw on two types of SFL analysis, both of which relate to the Metafunctional level of meaning. Halliday (e.g., 2014) proposes that there are three levels of meaning (i.e., three metafunctions) realized simultaneously in a clause: ideational, interpersonal, and textual. The ideational metafunction expresses the content, or message, of the clause; Thompson (2014) describes it as conveying "our experience of the world" (p. 28). For example, in the clause "the cat died", the content of the message is that there was a specific cat, and it died. The interpersonal metafunction realizes the level of meaning that expresses our enactment of our relationships with others (Halliday, 2014, p. 30). In the clause "the cat died", for example, the speaker is in a relationship of

${ }^{20}$ Rather than referring constantly to "speakers and/or writers, I use the term "speaker" to refer to either or both of these. In the same manner, I use the term "listener" to refer to both readers and listeners.

${ }^{21}$ While I use the term, following Eggins (2004), as "Systemic Functional Linguistics", Halliday and others name it "Systemic Functional Grammar". 
providing information to the listener. Halliday classifies the various interactions we might have with others into four types: requests, statements, commands, and offers. This level of clausal meaning also encompasses the speaker's attitudes and appraisal, such as agreement or disagreement, or certainty versus doubt. The third and final level of meaning realized in a clause is called the textual metafunction, which refers to the organization of the clause/text. Eggins (2004) defines this as "enabl[ing] the clause to be packaged in ways which make it effective given its purpose and its context" (p. 298). Because of limitations of space and time, I have not addressed the textual metafunction in this research, and will not discuss this level of meaning any further in this thesis.

An analysis of a text according to Halliday's metafunctions can reveal patterns of use that reference socio-cultural preferences and ideologies (see, e.g., Thompson, 2014, p. 265; Eggins, 2004, pp. 349-350; Hasan, 2004, p. 38). These analyses are useful for attempting to answer my research questions by revealing patterns; that is, the patterns of choices that bartenders make in the discussion of their experiences with sexual harassment may reveal their beliefs about and reactions to sexual harassment. In what follows, I provide more detail about the Ideational and Interpersonal metafunctions.

\subsubsection{Ideational Metafunction}

The ideational metafunction is divided into two parts: the experiential and the logical meaning. This thesis deals solely with the experiential (i.e., the speaker's description of experience). Experiential meaning focuses on three main aspects of the clause: the Process (what we normally refer to as the 'verb', or the 'action' of the clause); the Participants (who or what is involved in the Process, usually a noun or noun group); and the Circumstances (the circumstances under which the Process took place, typically 
realized by prepositional phrases and adverbs). Going back to our sample clause "the cat died", the Process here is "died", while the sole Participant is the cat. There are no circumstances, but we could easily add one: "The cat died last night", or "The cat died under my bed". Halliday (2014) recognizes six categories of Process: Material, Mental, Verbal, Relational, Behavioural, and Existential. Material processes are generally realized through verbs of action, or doing; e.g., running, building, blowing. Mental processes are verbs of sensing; e.g., think, know, like. Verbal processes are verbs of speaking, including in a metaphorical way such as "the textbook said to...". Relational processes are verbs that express a relationship between two Participants, and are usually expressed by the verbs to be, to have, or some variation thereof. Behavioural processes are a sort of middle ground between Material and Mental processes: Matthiessen, Teruya, and Lam (2010) describe them as "physiological processes involving a biological organism, ranging from involuntary ones to potentially voluntary ones that can also be social in nature" (p. 65); some examples include: laughing, sneezing, dancing, and watching. Existential processes express states of being, and are prototypically realized in English by the phrase "there is" (p.91); e.g., "there is no more wine left", or "there were books on the table".

Categories of Participants are dependent on the type of Process they are associated with; for example, Material clauses typically feature an Actor (who or what is responsible for the action), and possibly a Goal (who or what is acted upon), and a Beneficiary (who or what "benefits" from the action, as in "I gave Henry the ball", where "I" is the Actor, "the ball" is Goal, and "Henry" is Beneficiary). Mental clauses, in contrast, always demand a Senser (congruent with the Actor in Material clauses), and 
may take Phenomenon (who or what is on the receiving end of the Mental Process; e.g., "Britt likes me", where "Britt" is Senser, and "me" is Phenomenon). Circumstances, as mentioned, are typically realized by adverbial and prepositional phrases; however, as I did not take into consideration the amount or type of Circumstances in my final analysis, I will not discuss them further here.

In order to analyse a text for its Experiential patterns, one performs what is called a Transitivity analysis. This analysis involves labelling each constituent of a clause for its Experiential function, i.e., its Process type, followed by the attendant Participant roles and Circumstances. As in other types of SFL analysis, the initial task is identification and labelling, followed by identification of patterns that might be indicative of beliefs, values and ideologies of the speaker. In a Transitivity analysis, it matters not only what types of Process are the most frequently used, but what types of Participants are attributed to those Processes. This is the essence of the analysis I have performed on my data, and is discussed further in the Methods and the Findings chapters.

\subsubsection{Interpersonal Metafunction.}

The Interpersonal metafunction involves, as mentioned, the relationship(s) between speaker and listener. While analysing this aspect of clausal meaning, one needs to look at Mood and Modality. The Mood of a clause refers to whether it is structured as a command, question, statement, or offer ${ }^{22}$; i.e., whether the clause is imperative, interrogative, or declarative. The Mood is realized by the arrangement of the Subject, Finite and Predicator of a clause; 'Finite' refers to the part of a verb that expresses tense

\footnotetext{
${ }^{22}$ An offer, however, unlike the other three structures, has no congruent realization (Thompson, 2014, p. 48).
} 
or modality, while 'Predicator' refers to the rest of the verb. Thus, typically a declarative clause is realized by the arrangement Subject+Finite; Interrogative by Finite+Subject (or WH-subjects such as "who" or "where"+Subject); and Imperative by Subject (often unexpressed)+Predicator ${ }^{23}$. Examples of these are illustrated in Figure 3.

\begin{tabular}{|l|l|l|}
\hline Declarative & "She did ask for help." & Subject (she) + Finite (did) \\
\hline Interrogative & "Did she ask for help?" & Finite (did) + Subject (she) \\
\hline Imperative & "Give me some help!" & Subject (you-understood) + Predicator (give) \\
\hline
\end{tabular}

Figure 3: Examples of Mood type

Modality, another aspect of the Interpersonal metafunction, involves words that express judgments such as probability, obligation, and polarity. Examples of these include:

- I may have supper later (probability)

- You must finish your homework (obligation)

- Yes, she is smart (polarity)

Mood analysis, like Transitivity analysis, involves first labelling clause constituents for their Mood components and looking for patterns. Mood choices are meaningful in that they can reveal relationships between interactants; for example, whether the speaker chooses to represent themselves as having more or less power (adopting the role of asking versus commanding). As well, a Mood analysis, though an investigation of Modal choices, can illustrate the speaker's judgments and opinions. This

${ }^{23}$ There are a few other ways that these (interrogatives and imperatives) might be structured for Mood, but those illustrated here are the most common ones. 
explanation is necessarily brief; there are far more complexities and details involved in discussing and analysing Mood and Modality choices. However, many of the finer details of these are discussed in the Findings chapter.

\subsubsection{Summary}

In conclusion, I have only been able to skim the surface of SFL as a theory and Metafunctions as a basis for analysis here. I have explained the idea that SFL is primarily concerned with: that language is a system of meaningful choices. Furthermore, I have defined what Halliday has termed 'metafunctions', which are the three simultaneous meanings realized in every clause. As well, the Experiential and Interpersonal metafunctions, which are the two types of SFL analyses used in this research, have been defined with examples. One important aspect of SFL is that it is a link between grammar and meaning that is often missed in more traditional grammar theories; as well, it provides an array of detailed analytical tools for linguistic research. As mentioned, many CDA scholars (e.g., Teo, Fairclough, Janks) utilize SFL analyses to perform their research, and it has proven to be a fruitful avenue to pursue for this project. With the theoretical ideas detailed, the next chapter concerns itself with the more practical aspects of this project. 


\section{Chapter: Methods}

\subsection{Introduction}

This chapter details the methods of data collection and analyses employed in this research. The primary motivation for these choices were: (1) my research question(s), and (2) ethical considerations. My research questions are:

- How do bartenders construct their experiences with sexual harassment at work?

- Do bartenders use language that resists or reinforces the normalisation of sexual harassment?

- Do bartenders use the term "sexual harassment", and if not, why?

- What other terms might they use to talk about it?

Ethical considerations dictated that certain types of data would be available to me and others not. For instance, recording conversations between patrons and bartenders would only be possible with consent, which patrons would not be likely to give; hence, audio recording was not a viable or ethical option. The structure of this chapter is as follows: first is a section related to data collection, participants, and ethics; next, I discuss methods of analysis followed by a brief section about the theoretical relevance of these methods and a short discussion of their strengths.

\subsection{Data collection}

\subsubsection{Online data}

The data used in this study include three online 'threads' (a series of questions and answers, or comments) from the social media website reddit.com (hereafter 'reddit'). 
Within reddit are various sections or pages ('sub-reddits') pertaining to different topics (e.g., "r/news”, “r/funny”, "r/books”) where users ('redditors') may, for instance, post questions, make comments on other redditors' posts, or share pictures or other content. The three threads that comprise the data used here are from a sub-reddit called "r/bartenders", which has over 13,000 subscribers ${ }^{24}$. Figure 4 shows a screenshot of the r/bartender page, while Figure 5 shows a screenshot of a comment thread on that subreddit.

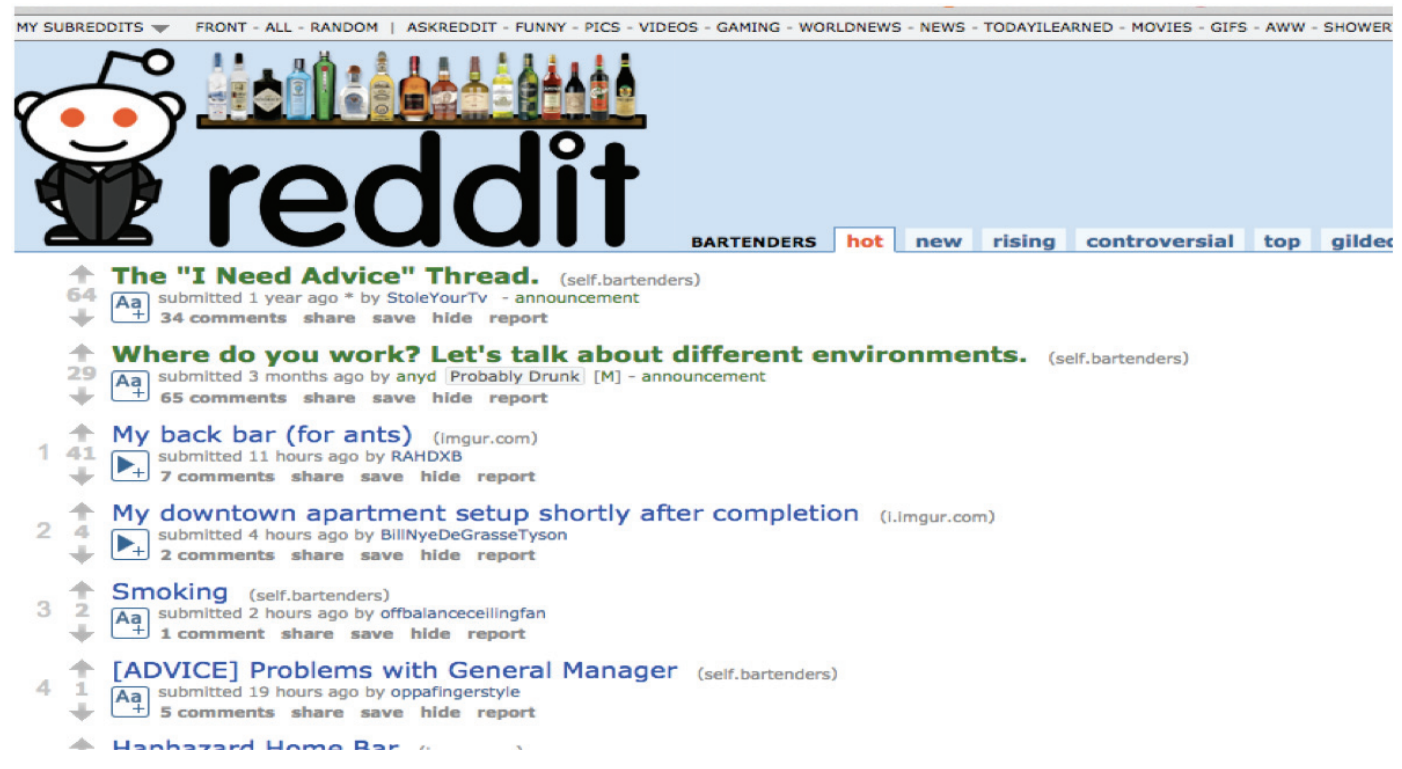

Figure 4: reddit.com/r/bartenders

${ }^{24}$ Reddit had over 8 million people posting content in 2015 (http://www.redditblog.com/). One does not need to subscribe in order to read or comment in every sub-reddit. 


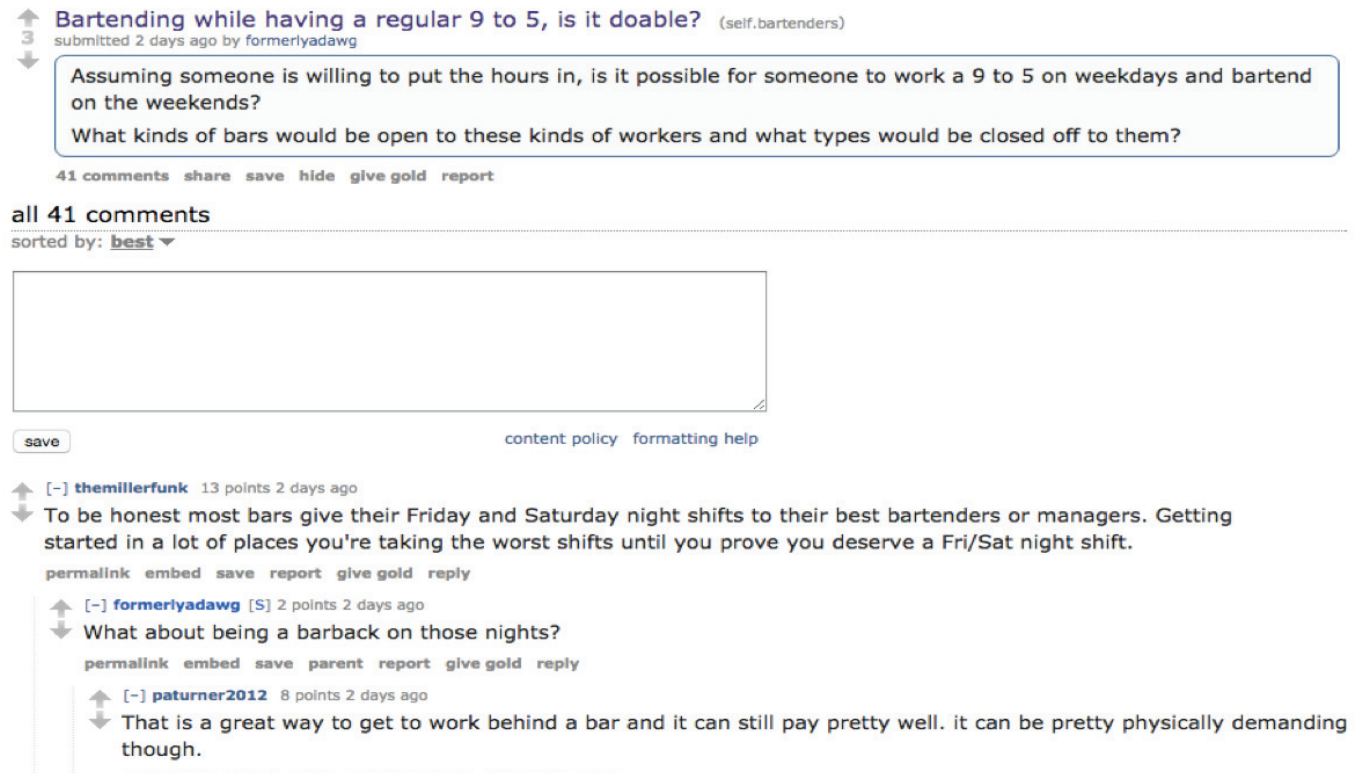

Figure 5: Bartending sub-reddit (comment thread)

Each thread in the data begins with a question from an inexperienced female bartender posed to the rest of the community regarding how to deal with customers "hitting on" them. The responding comments (ranging from 13 to 30 in number) are generally from more experienced bartenders who attempt to answer the question ${ }^{25}$.

When starting this project, I performed a search on reddit.com/r/bartenders using search terms such as 'sexual harassment' (only 1 result), 'hit on' and 'hitting on', and selected threads that dealt specifically with customer sexual harassment. I took the 'sexual harassment' comment thread plus the first 8 of the other results ("sorted by relevance" on Reddit) and then randomly selected 3 of the 9 posts.

${ }^{25}$ See Appendix B for excerpts of transcripts of reddit texts. 


\subsection{2 'In Real Life' (IRL) $\operatorname{data}^{26}$}

The second source of data used here is transcripts of three semi-structured interviews conducted with three female bartenders employed in Canadian bars or restaurant/bars. During a pilot project for this research last year, several bartenders involved in the pilot expressed interest in my research. As a result, these four female bartenders were asked to participate. All four responded positively, although one participant dropped out a day before her interview. Interviews included seven questions (Appendix A). The primary question in the interviews was the same question common to the reddit posts: how do you deal with it when customers hit on you? This, I felt, would allow me to compare the answer to that question across IRL and online responses. Additionally, one of the motivations for conducting interviews was that redditors failed to use the term 'sexual harassment' in their discussions ${ }^{27}$; therefore, I wanted to ask bartenders if they considered customers 'hitting on' them to be sexual harassment, and why or why not. The interviews averaged about 15 minutes each, and each participant was asked the same seven questions, although, as they were semi-structured interviews, additional or clarifying questions at various points were asked of participants if necessary. For instance, when Shaniqua mentioned that she felt differently about interactions with customers since her separation from her husband, I followed up by asking her to elaborate on that difference (Interview $\mathrm{S}^{28}$ ). As well, when Delta talked about her experience serving food versus serving behind the bar, I asked her if she felt there was a

26 'IRL' stands for "in real life", generally used to distinguish interactions and relationships that take place off-line as opposed to those that take place on the internet.

${ }^{27}$ Recall that three reddit texts were randomly selected, and the one that mentioned the term 'sexual harassment' explicitly was eliminated.

${ }^{28}$ Excerpts from each interview appear in Appendix A. 
difference between the two jobs. Following the interviews (completed within one week), I transcribed and redacted the interviews.

\subsubsection{Online versus IRL Data}

Using online data had significant advantages for this research: it was relatively easy to collect, there was a substantial amount of it available, and (since the website is public and the redditors anonymous) it did not require ethics approval. Furthermore, using the internet as a data resource is also a widely accepted practice now: Koteyko (2010) argues that the internet is a valid and useful resource for the collection of not only linguistic, but also socio-cultural data (pp. 655-656), while according to Stewart and Williams (2005), collecting data online is "now part of the mainstream canon of methodological choices" (p. 395). That is not to say that using internet data is problem-free; one the one hand, it could be argued that anonymous online commenters have the freedom to lie about their identities, experiences, and feelings. On the other hand, however, it might be the case that anonymity provides security; that is, whereas bartenders might feel constrained in talking about these issues around customers or bosses, the anonymity of reddit might enable them to be more honest than in other cases. Collecting data from IRL participants conceivably poses a similar problem; for instance, Dörnyei (2007) points out that, no matter how neutral and well-thought out the interview questions, it is likely the participants will be "influenced by...the "social desirability bias"” (p. 141). That is to say, it may be that IRL participants are prone to give what they believe are preferred answers. Additionally, whereas IRL participants might feel pressure to give a certain type of answer, online participants might feel free, under their cloak of anonymity, to be free and honest in their comments. In the case of my data, the answers and statements 
provided by redditors and IRL participants were very similar, so the results seem reliable.

\subsubsection{Ethics}

All data were collected and handled in accordance with the Carleton University Research Ethics Board A (CUREB-A) (see Appendix D). As mentioned, ethical considerations were influential in shaping the design of this research. Due to the considerable sensitivity and restraints necessitated by conducting ethical research, my research design was modified as necessary.

All interview participants were recruited via email, and signed consent forms prior to being interviewed. All participants were promised anonymity, so I recorded the interviews on my audio recording device and immediately transferred the audio files to an encrypted, password-protected USB drive, which was with me at all times while I was visiting the city where the participants lived. When transcribing, any identifying words or phrases were eliminated from the transcript including, for example, names of bars, cities, husbands, friends. As well, all participants are referred to by pseudonyms. After transcription, each participant was emailed a copy of her interview transcript and allotted one month in which to redact, eliminate, or otherwise edit parts of her interview that she might be uncomfortable sharing; this month was also a chance for any participant to withdraw their data from the study if they so wished. No participants requested any further edits and were satisfied with the handling of their privacy. At the end of the allotted month, each audio file was deleted. 


\subsection{Data Analysis}

In order to triangulate my findings, I chose to employ two main types of analysis. For the reddit data, I performed SFL (Transitivity analysis and Mood) analyses; then Template analysis was used across both reddit and interview data. This section will detail first, each type of analysis, and second, the procedures I followed during analysis.

\subsubsection{SFL analysis}

In order to determine the most productive SFL and CDA analytical tools for a given text, Janks (2005) advocates a thorough linguistic analysis of each of many text features including, for example: voice; definite and indefinite articles; nominalization; and euphemism. However, the text that Janks uses to demonstrate this strategy is a relatively short advertisement, whereas my data run to hundreds of clauses. For this reason, I was obliged to narrow my choice of tools early on, based on what other researchers have done and my previous knowledge of the application of SFL to discourse analysis.

\subsubsection{Metafunction Analysis}

Halliday (2014) defines the Ideational metafunction as "the clause as representation" (p. 83); and, as previously noted, the concern in Experiential meaning is who is doing what and to whom, in what circumstances (p. 212). Transitivity analysis ${ }^{29}$ may reveal ideologies of the speaker; Eggins (2004) explains that by selecting certain processes, speakers "are actively choosing to represent experience in a certain way" (p. 253). Teo (2000), in turn, describes Transitivity analysis as a means to understand how agents are

${ }^{29}$ Recall that Transitivity analysis is how one identifies Experiential patterns, and Mood analysis is how one identifies Interpersonal patterns. 
constructed (p. 25). Because the redditors were talking about their experiences with customers, it was important to me to understand how they were constructing both the customers and themselves. The Interpersonal metafunction is the level of meaning described by Halliday (2014) as "clause as exchange", or a "transaction between speaker and listener" (p. 83). The reddit texts, as mentioned, are primarily comprised of a collection of answers to the original poster's question. I was curious to know what a Mood analysis would reveal about the relationships between the questioner and the respondents. Unlike a relationship between an experienced bartender and a new bartender in, for example, a situation where the former is responsible for training the latter in the workplace, the redditors are presumably strangers to one another "in real life”. Mood analysis, according to Eggins (2004), can reveal power relationships, as well as the speaker's attitudes and judgments (p. 184). In summary, my choice of Transitivity and Mood analyses was motivated by my interest in the participants' representation or construction of themselves, their customers, and their experiences, as well as the relationship dynamics between bartenders.

Because the unit of analysis in SFL is the clause, the first step for an analyst is to divide the text into clauses. After re-typing the Reddit texts (copied and pasted from the internet) so as to have them in an editable (Word document) format, I next divided each comment into sentences, and then clauses. Once clause division was complete, each word in each clause was labelled according to their Mood and/or Transitivity functions ${ }^{30}$.

${ }^{30}$ Because I chose not to perform a Textual metafunction analysis on these texts, I left words out of the analysis that would only be meaningful in that type of analysis. For example, the word "and" is a conjunctive adjunct (in Mood analysis), but as I did not consider elements of cohesion, I simply ignored them. 
This results in a 4-level array, an example of which can be seen in Figure 6, below ${ }^{31}$. As can be seen in this example, words are only labelled for their function in the relevant metafunctional row; that is, words like "not" and "exactly" are not part of the Experiential meaning of the clause, but are part of the Interpersonal meaning. Thus, although each word in a clause is labelled at some level of analysis, not all words are labelled at each level.

19 Declarative/active
\begin{tabular}{|l|l|l|l|l|}
\hline I & 'm & not & exactly & a flirty person \\
\hline Subject & Finite & Adj: polarity & Adj: mood & Comp/Attribute \\
\hline MOOD & Pr: Rel/Attributive & & & RESIDUE \\
\hline Carrier & & & Attribute \\
\hline
\end{tabular}

Figure 6: Example of clause analysis

After the analyses were complete, they were checked for errors; at the same time, any un-analysed clauses were addressed. At least two attempts were made to analyse difficult clauses. Altogether, fewer than $3 \%$ of the total clauses were labelled "unknown". Another category of clauses that I chose not to analyse (comprising approximately $2 \%$ of total clauses) were what I termed 'meta' comments. These are clauses that were clearly made about another redditor's comment, and thus did not address the general topic of the conversation. An example of this is Reddit text \#8, comment 3 , clause $1(8 / 3 / 1)^{32}$ : "That is the best comment here". If such a meta-comment appeared by itself (i.e., if a commenter made only a meta-comment), I left it out of the analysis altogether. However, if the meta-comment appeared in a comment with other,

\footnotetext{
${ }^{31}$ Colour was used to differentiate Process types, for ease of counting.

32 This is the system of notation employed for identification of reddit texts: (text\#/comment\#/clause\#).
} 
topical clauses, I labelled them as "meta" and chose not to analyse them. I believe that these comments may add to the Interpersonal meaning of the texts. However, analysing them along with all the other clauses would have skewed the Transitivity results, as the meta-comments related only to other comments, not the topic at hand.

Following the completion of the SFL analysis, process types and mood choices were counted and charted (see excerpts in Appendix C), in accordance with Janks (2005), who argues that the "analysis of any feature requires one to examine each instance of its use in order to establish the patterns of meaning" (p. 104). Thus, counting process and mood types and charting them allowed for an examination of the instances of each choice, while noting the most frequently occurring choices.

\subsubsection{Template analysis}

Template analysis is a qualitative method of coding whereby the analyst starts with a list of a priori codes with which to examine the data; this is an iterative process, with the analyst adding and subtracting codes through various passes of the data in order to develop a template of codes or themes that are present in the text. Brooks, McCluskey, Turley, and King (2015) argue that template analysis provides "a relatively high degree of structure" while still allowing flexibility for the researcher to adapt it to their needs (p. 204). Because of the many commonalities between comments in the reddit data, I used King's (2004) framework to develop an a priori list of codes based on Lonsway, Cortina, and Magley's (2008) list of sexual harassment myths (p. 608). This article, which came to my attention during the reddit analysis, outlines the various myths surrounding sexual harassment. While reading their article, I noted that many of the sexual harassment myths were similar to statements in my reddit data (for instance, "It was just verbal not 
physical misconduct", p. 604). As a result, I chose the sexual harassment myths as my a priori codes. The interviews, then, while not utilized for my SFL analysis, proved useful as both (1) additional data for my template analysis, and (2) a small sample of answers to the question "do bartenders use the term 'sexual harassment' when describing their experiences, and if not, why not"? These will be further discussed in the findings chapter.

In order to conduct this analysis, I started with the list of a priori codes, based on the above-mentioned list of sexual harassment myths. I coded both the reddit data and the interview transcripts, noting all instances where participants appeared to make statements that corresponded to any of the myths. While coding for the myths, I also highlighted statements that seemed to recur across participants; for example, many participants mentioned the existence of 'a line', whereby they will tolerate certain behaviours from customers but not others. These types of recurring statements were added to the original template, while any of the sexual harassment myths that were not invoked were excised. This process was repeated several times, until the template consisted of a final list of eleven codes (see Figure 9). Following this, a secondary coder checked approximately one-half of the data to verify the template. This is an important aspect of template analysis, as it confirms the reliability of the analysis; Dörnyei (2007) recommends the use of a second coder (p. 57), as does Creswell (e.g., 2007, pp. 210211). Finally, the template was then compared to the SFL findings; the results of these are discussed in the Findings chapter. 


\subsubsection{The 3-dimensional framework}

Although the metafunctional analysis of the linguistic features of the reddit texts took the most time to perform, the other aspects of analysis according to Fairclough's three dimensional framework were not neglected. I suspect it is possible to forget the other two dimensions, as one must look so closely at the categorization of each and every word in a metafunctional analysis; however, performing the template analysis allowed me to step back, as it were, and look at the texts as a whole to situate them in the other two boxes of Fairclough's framework. Since the template analysis was performed across all reddit data as well as the interview texts, coding these allowed me to examine them for patterns and lexical choices that the Transitivity and Mood analyses alone did not reveal. As Janks (1997) points out, the three dimensional framework is designed so that the analyst may go back and forth between the three "boxes" and fill in aspects of analysis as they go (p. 330). On a practical level, this entailed keeping detailed and copious notes regarding my impressions and discoveries as I went, going back and forth between metafunctional analysis, the various data, my notes, and the literature on SFL and CDA. Through this iterative process, I was able to situate my findings within the three dimensional framework.

\subsection{Theoretical Relevance}

Aside from answering my research questions and addressing ethical considerations, I also made an effort to keep this research design consistent with the theoretical framework within which I would conduct this project. Keeping in mind particularly the tenets of critical theory, feminism, and CDA, I made the following choices regarding this research:

1. As mentioned in Chapter 3, Hesse-Biber (2006) and Creswell (2007) both argue 
that feminist research must privilege women's experiences. For this reason, I chose to interview female bartenders about their experiences. Semi-structured interviews, according to Dörnyei (2007), allow a flexibility in that questions may be broad enough to not "limit the depth and breadth of the respondent's story" (p. 136).

2. Using two separate yet complementary methods (metafunction analysis and template analysis) afforded me not only a broader and richer understanding of my data, but also may strengthen my findings. Furthermore, it might also address the possible challenge that CDA researchers sometimes face: that critical discourse analysts are biased and their findings questionable because of this ${ }^{33}$.

3. Critical theory, and CDA as well, holds that power relationships and ideologies must be challenged, as explained in Chapter 3. This principle is at the heart of not only my research questions, but also my choice of analytical tools. That is, through use of both Metafunctional and Template analyses, I have looked for patterns in the ways that bartenders are talking about their experiences with customers, patterns that might reflect or resist 'common sense' notions of how bartenders are meant to deal with sexual harassment.

\subsection{Strengths of the Design}

One great strength of this research design is that it has achieved triangulation; that is, by using both grammatical analysis through SFL and qualitative coding using Template analysis, through the lens of Fairclough's 3-dimensional framework, my findings are

33 This is addressed in more detail below. 
stronger. The methods of analysis are diverse and sound. SFL provides a systematic and rigorous method of analysis. Template analysis, while not as mathematically precise, has the benefit of undergoing several separate rounds of coding by this researcher, as well as being coded again by an independent coder to gauge the effectiveness of the proposed template. Thus, there were a combination of analytical methods used which not only serve to answer the research question, but also attempt to ensure the maximum reliability of findings. According to Dörnyei (2007), “methodological triangulation ${ }^{34}$ can help to reduce the inherent weaknesses of individual methods by offsetting them by the strength of another" (p.43). While CDA has at times been criticized for being biased (Flowerdew, 1999, p. 1093; Widdowson, 1996, p. 62), CDA scholars acknowledge that their work is motivated by the need for social change; that is certainly the case in this project - my research is motivated by my experiences in bartending and my belief that sexual harassment in bars is a problem that needs be addressed. However, balancing that personal bias is the triangulation of my chosen analytical methods; each focusses on different aspects of language use, which helps to ensure my findings are not skewed by my own assumptions.

\subsection{Summary}

In conclusion, this chapter has explained the data collection I performed both through online searches on the social media website reddit.com, and semi-structured interviews with bartenders. Following that, I described the ethics procedures I followed, and defined the difference between online and 'IRL' data. The procedures used to perform both

\footnotetext{
${ }^{34}$ Dörnyei (2007) points out that "triangulation" was originally a term for mixing qualitative methods, not qualitative/quantitative mixing, as is commonly understood today (p. 43). However, I am using it here in its original sense.
} 
Metafunctional analyses and Template analysis were explained, as well as their suitability to this study in relation both to my research question and to my theoretical framework.

Finally, the strengths of these methods were explained. In the next chapter, the results of each of these types of analysis will be explained, starting with Transitivity, followed by Mood, and ending with Template analysis. As well, I present the answer to the question I asked the IRL participants regarding their use or non-use of the term 'sexual harassment'. 


\section{Chapter: Findings}

\subsection{Introduction}

This chapter presents the results of the analyses described in the preceding chapter. Keeping in mind Fairclough's 3-dimensional framework, I structure this chapter as follows: first, a brief review of my research questions followed by a short summary of the data. Next, I present findings from each type of analysis, starting with Transitivity analysis, followed by Mood analysis, then Template analysis. Each section will discuss the findings from two perspectives: the Description level of analysis (see Figure 7, below) and the Interpretation level of analysis. The Description level entails a summary of the textual features of the data, that is, the linguistic and grammatical features of the data; the aim of Interpretation, as Fairclough (2013) describes it, is to "specify what conventions are being drawn upon, and how" (p. 11). The final level of analysis, Explanation, will be discussed in Chapter 6, Discussion and Conclusion. Following the discussion of these findings, I address the issue of naming sexual harassment that was dealt with in the interviews.

Findings from Transitivity analysis show that bartenders construct sexual harassment primarily from the representation of bartenders as possessing certain attributes and performing preferred actions. Mood analysis findings demonstrate the medium of reddit as a forum whereby redditors are constructed as experts who can advise other bartenders in the ways in which a bartender can deal with harassment. Template analysis, which was performed across both reddit and interview data, shows that bartenders regularly express their experiences with harassment in terms of either 'coping' with the harassment or 'contesting' it. Interview participants (whom I call 'IRL' 
participants) consistently rejected the use of the term 'sexual harassment' to describe their experiences, citing various reasons for the rejection, including the distinction between verbal and physical behaviours as the 'line' that divides harassment from nonharassment. Before continuing with the findings, I revisit here my list of research questions, as well as Fairclough's 3-dimensional framework (see Figure 7) as a reference. My research questions are: How do bartenders construct their experiences with sexual harassment at work? Do bartenders use language that resists or reinforces the normalisation of sexual harassment? Do bartenders use the term 'sexual harassment', and if not, why? What other terms might they use to talk about it?

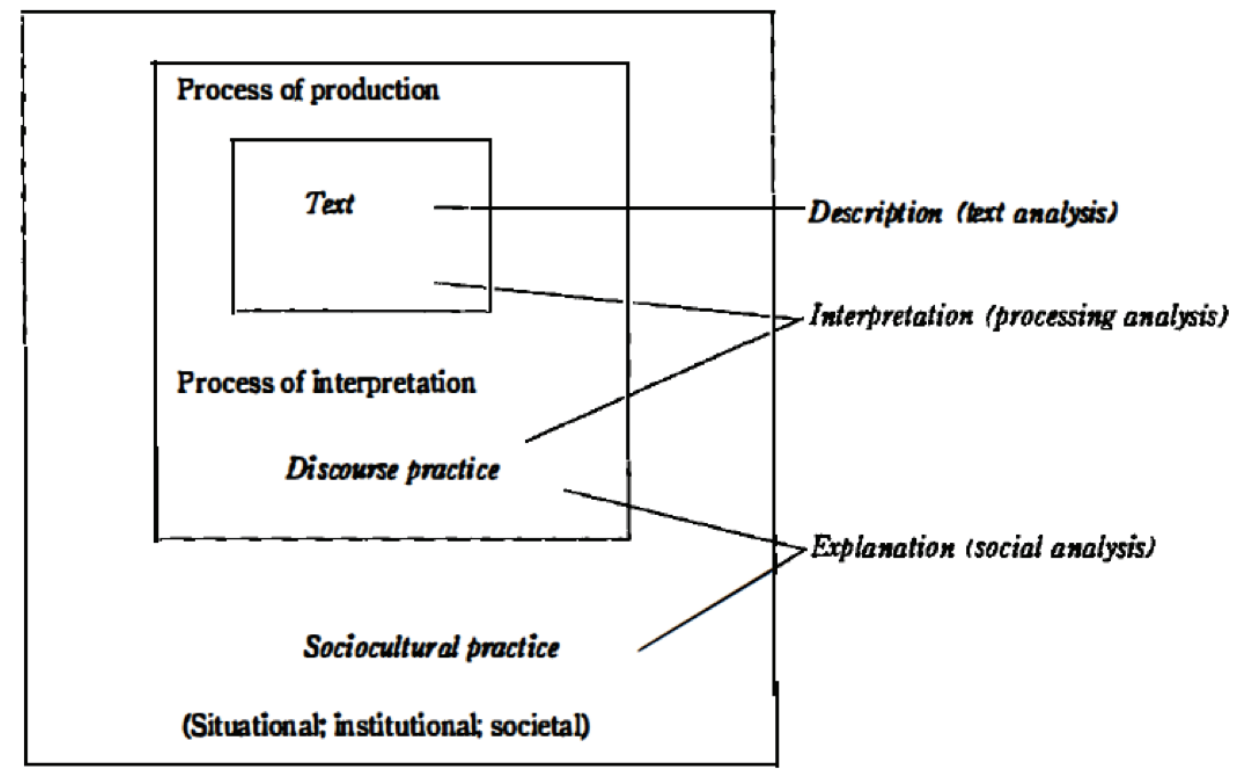

Figure 7: Fairclough's 3-D framework (Fairclough, 1995, p. 98)

\subsubsection{Description of the data and analysis}

For the SFL analyses, as mentioned previously, I used only the reddit data. The Template analysis was conducted across both reddit and interview data. Excerpts from the 
interview transcripts can be found in Appendix A; each interview consisted of five scripted questions and ran to approximately five pages each transcribed. As explained in Chapter 4, the data collected from reddit consists of three threads in the sub-reddit 'r/bartenders'. Each thread consists of an initial question from a female bartender about customers hitting on them, and corresponding responses from other redditors, ranging in number from 12-27. Table 1 shows the basic details of each comment thread. Excerpts of reddit data are presented in Appendix B.

\begin{tabular}{|c|c|c|c|}
\hline $\begin{array}{c}\text { Text } \\
\text { number }\end{array}$ & Title of post & $\begin{array}{c}\text { Number of } \\
\text { comments }\end{array}$ & $\begin{array}{c}\text { Number of } \\
\text { clauses }\end{array}$ \\
\hline $\begin{array}{c}\text { Reddit text } \\
\# 7\end{array}$ & $\begin{array}{c}\text { "How do you respond to drunk } \\
\text { patrons hitting on you?" }\end{array}$ & 27 & 284 \\
\hline $\begin{array}{c}\text { Reddit text } \\
\# 8\end{array}$ & "Help? Bartending and Male \\
Attention" & 19 & 167 \\
\hline $\begin{array}{c}\text { Reddit text } \\
\# 9\end{array}$ & "Tips for a new female bartender" & 12 & \\
\hline
\end{tabular}

Table 1: Summary of reddit texts

For the purposes of this thesis, the demographic information is not necessarily relevant, as the objective here is to investigate how bartenders in general construct their experiences with sexual harassment. Factors such as age, gender, and class have not been taken into consideration for this study. Furthermore, providing the demographic of these texts is not possible here. This is because, for one reason, the redditors rarely mentioned their age or geographic location, and it is uncertain how many commenters were female as opposed to male; some commenters mentioned their husbands or boyfriends, but that is not a definitive indicator of gender. The redditors in reddit text \#7 indicated their gender 
were more frequently than in the other two texts; one redditor began his response with "I am a male bartender" (7/21/1), while another said “I'm not gay, so I don't go after the guys" (7/28/4-5). The prevalence of gender references in this text is likely a reaction to the original question, as that redditor made the following comment:

I originally thought I'd ask about female bartenders getting hit on by drunk males, but I suppose this question applies to all bartenders/servers.

It was interesting, too, that some redditors felt the need to express both their biological sex and their sexual orientation (e.g., "I'm a man and I'm straight"). However, that is not a matter for the present study, although it might be a fruitful avenue for future research. As mentioned in Section 2.3, Dougherty found that male and female employees talked about power and sexual harassment in different ways; thus, it might be the case that male bartenders experience and talk about sexual harassment in different ways than do female bartenders. Because I do not have access to that information, I limit myself to addressing the research questions as they pertain to all bartenders, regardless of gender, age, or class.

\subsection{Transitivity and the Construction of the Ideal Bartender}

Transitivity analysis investigates a speaker's representation of who is doing what to whom. Section 3.5.1.1 detailed the various Process types identified in Transitivity analysis, and I provide a brief summary in Table 2 (below). 


\begin{tabular}{|c|c|c|}
\hline Process & General type of verb & Example \\
\hline Material & Actions, physical & Run, lose, grow \\
\hline Mental & Thinking, feeling & Love, think, want \\
\hline Relational & Relationship between entities & Is, have \\
\hline Verbal & Speaking & Say, write, speak \\
\hline Behavioural & $\begin{array}{c}\text { Blend of Material \& Mental } \\
\text { processes }\end{array}$ & Sneeze, stare, laugh \\
\hline Existential & $\begin{array}{c}\text { State of being } \\
\text { "there is..." }\end{array}$ \\
\hline
\end{tabular}

Table 2: Summary of Process types

Table 3 summarizes the various process types found in the reddit data.

\begin{tabular}{|c|c|c|}
\hline Process Type & Total number/reddit texts & Percent of total clauses \\
\hline Material & 263 & 36.59 \\
\hline Relational & 250 & 34.77 \\
\hline Mental & 95 & 13.21 \\
\hline Verbal & 88 & 12.24 \\
\hline Behavioural & 12 & 1.67 \\
\hline Existential & 11 & 1.53 \\
\hline
\end{tabular}

Table 3: Totals of Processes by type 
As shown in Table 3, Material and Relational processes comprise the majority of total clauses across all reddit texts (over 71\%). Some examples of these clauses are:

- I recently started bartending at a gay bar (Material, 9/13/2)

- Treat 'em like daycare kids (Material, 8/4/19)

- Numbers are left on the bar (Material, 7/18/14)

- Dirty old men are the worst (Relational, 9/7/1)

- I have a long term boyfriend (Relational, 8/10/3)

- I'm male (Relational, 7/18/19)

[processes in italics]

According to Eggins (2004), "in selecting what process type to use, and what configuration of participants to express, participants are actively choosing to represent experience in a particular way" (p. 253). Recall that in Chapter 3, it was said that SFL analyses can reveal patterns of use that reference socio-cultural preferences and ideologies. Thus, in this context, the redditors, by using certain process types and their attendant participants, are choosing to represent their experiences with customers in a specific way. In this case, Material and Relational clauses were used with near identical frequency, and were by far the most prevalent choice of processes by redditors. Hence, I begin by discussing the Relational processes and participants, and then move on to a brief discussion of Material processes and the attendant actors. 


\subsubsection{Relational Processes}

Relational processes, as previously mentioned, express a relationship between two concepts or entities, and further, are comprised of several sub-types, as seen in Figure 8.

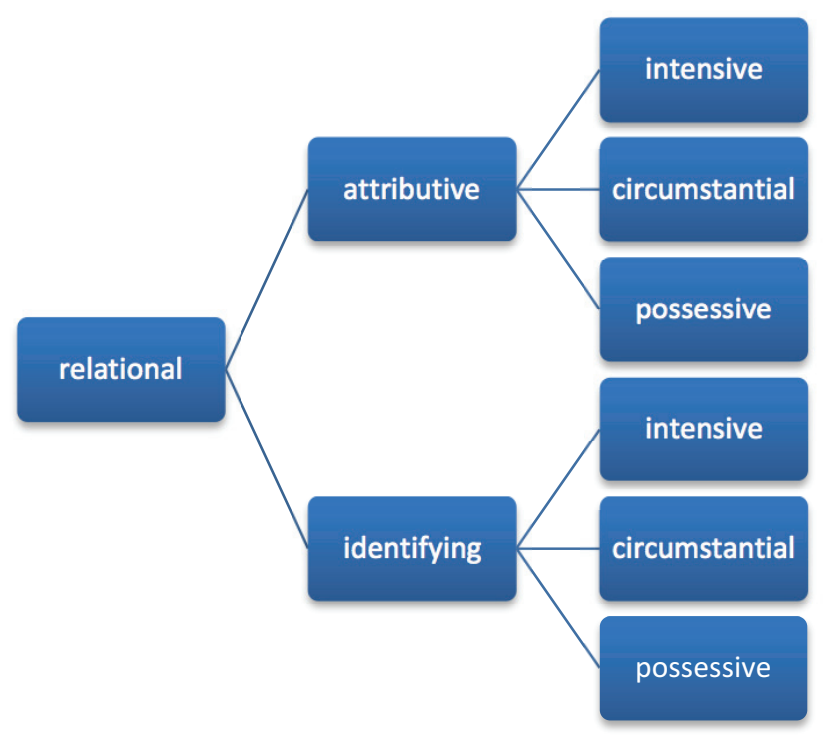

Figure 8: Relational sub-types (adapted from Eggins, 2004, p. 239)

For the sake of simplification, I have chosen to distinguish only between the Relational categories of attributive, identifying, circumstantial, or possessive. Attributive Relational processes describe the characteristic(s) or attribute(s) of an entity; for example, Brittany is smart. Identifying Relational processes describe one entity in terms of another (Thompson, 2014, p. 102); for example, Brittany is my sister. Put another way, Eggins (2004) explains Attributive processes as the relationship ' $x$ carries the attribute $y$ ', while Identifying processes are ' $x$ serves to define the identity of $y$ ' (pp. 240-241).

Circumstantial Relationals are realized with one of the participants as a circumstance (e.g., a place, a location, a period of time); for example, I was down the street. Finally, Possessive Relational processes express a relationship of possession, as in Darrell has short hair. In the reddit data, the breakdown of Relational sub-types is as follows: 


\begin{tabular}{|c|c|c|}
\hline Relational sub-type & Number of each sub-type & Percentage of total clauses \\
\hline Attributive & 165 & 22.95 \\
\hline Identifying & 44 & 6.12 \\
\hline Circumstantial & 13 & 1.81 \\
\hline Possessive & 28 & 3.9 \\
\hline
\end{tabular}

Table 4: Sub-types of Relational processes

As seen in Table 4, Attributive Relational processes make up the greatest share of total Relationals, comprising almost $23 \%$ of the total clauses in the data. Relational processes demand two participants, one called 'Carrier', the one to whom the characteristic is assigned, while the other obligatory participant is called 'Attribute'. An examination of Carriers and Attributes reveals that 'bartenders' are the most common Carriers in these texts; in other words, in the majority of these Relational clauses, it is bartenders (either specific bartenders or bartenders in general) or bartending as an occupation which are being assigned particular attributes. Of the 165 Attributive processes, 74 of them describe attributes of bartenders or bartending. Some examples include:

- ...you are equal parts an actor when working (9/3/1)

- $\quad$ Be witty, be assertive $(8 / 9 / 2,3)$

- I try to be polite $(7 / 21 / 3)$

- ...I need to work on being more straightforward (7/7/4)

Briefly, to this point I have summarized the findings of the Transitivity analysis, which showed that Relational processes (which express a relationship between two 
concepts) comprise just over a third of the total clauses in the reddit data. As well, I have listed and described the sub-types of Relational processes; of these sub-types, the majority that appear in these texts are Attributive, which describe a particular Carrier's characteristics ( $x$ carries the attribute $y$ ). How redditors describe bartenders and bartending is important because, as seen in the examples above, bartenders are discussing attributes that they claim (1) bartenders/bartending have, or (2) bartenders should have. Why is this relevant? The primary research question in this research is how do bartenders construct their experiences with sexual harassment at work? Each of the three original posters request advice about coping with being 'hit on' at work, and the comments (generally) attempt to answer that question in one way or another; in fact, it seems that one of the ways that bartenders attempt to advise other bartenders in this matter is through a construction of what bartenders are or should be, or what bartending is or should be, in the context of customer sexual harassment. In other words, one of the ways bartenders construct their experiences with sexual harassment at work is by creating an ideal bartender. The recurrent use of Attributive Relational processes by redditors seems to express the view that the best way for bartenders to deal with customer sexual harassment is to possess certain qualities. A strong example of this appears in reddit text \#8, comment 2, where redditor sorchaxin says:

Never ever forget you are in charge... being a bartender is like being on a stage. In real life, I am fairly introverted, but when bartending I am a badass bitch.

[Relational processes bold; Carriers and Attributes underlined]

This excerpt illustrates the point made above; i.e., this redditor is advising the original poster on what qualities she needs in order to best deal with the harassment from her 
customers. This commenter claims that:

- bartenders (generic) are in charge

- bartending is like acting

- this bartender (specific) is introverted, BUT

- when at work, this bartender (specific) is a bitch

Because CDA and SFL hold that language is purposeful (Janks, 2005, p. 97), these statements cannot be considered isolated commentary about the profession of bartending, or even just about the characteristics of this particular bartender; rather, these statements are meant as advice to a young female bartender who "feels powerless" $(8 / \mathrm{O} / 23)$ when "dealing with men that hit on" her $(8 / \mathrm{O} / 8)$. These constructions of the ideal characteristics with which to handle sexual harassment are not only expressed through Attributive Relational processes, although Attributive Relationals are the most common realization, as for example in reddit text \#7, where WeekendHedonist commented: the females I work with just kind of allow harmless flirting (7/2/9). Similarly, theaftercath stated: I usually just let dudes flirt with me (7/6/1). Although these are not Attributive clauses, they perform the same function: the construction of the ideal bartender and the ideal manner of handling customer sexual harassment. The ideal bartender is constructed by times as 'a tough bitch', 'sassy', 'witty', 'not offended', and 'not flustered'. The exact description varies from commenter to commenter, but the overall pattern is of bartenders constructing this ideal. According to Janks (2005), "Only once one has an overall grasp of the design of the text is one really able to offer an interpretation of how the text means, that is, of how the patterned choices produce meaning effects" (p. 108). A similar pattern 
of choices was found in the configuration of Material processes, which is the focus of the following sub-section.

\subsubsection{Material Processes}

As mentioned, Material processes were also prevalent in the reddit data (see Table 3 above), accounting for over $36 \%$ of the total clauses. Material processes can be defined as what Thompson calls "doing words", i.e., Material processes are most often physical actions (p.95). Again, however, it is not the processes alone that allow us to interpret the grammatical patterns in a text; the participants who are assigned roles around the process will provide a stronger base for analysis. In the case of the reddit data, of the 263 Material processes, the Actor was some variation of 'bartender' 140 times ( 53\%), while 'customer' was Actor 59 times ( 22\%), and the remainder of Material processes were assigned a variety of other Actors such as 'boss', 'bouncer', and various inanimate or abstract entities such as 'some playful flirting' (9/13/21), 'a quick harmless jab' (8/12/4), or 'the restaurant' $(8 / \mathrm{O} / 3)$.

Material processes where customers were Actor tended to be similar; examples of what customers were 'doing' include:

- $\quad$ They keep pushing $(9 / 13 / 32)$

- People are overtly flirting $(9 / 3 / 17)$

- $\quad$ They come in small groups $(9 / 9 / 2)$

- People come to you to drink (8/11/10)

- $\quad$ They will [touch you] (8/23/9)

- He would actually give me his number (7/8/8)

- One really gross old guy wouldn't leave me alone (7/15/10) 
In most of the instances where customers were Actor in Material processes, then, the customer was hitting on the bartender in some form or another. In contrast, in many Material clauses where bartenders were Actor, the process was some sort of action meant to address, avoid, or curtail harassment:

- I just flirt with them casually (7/12/2)

- I don't give my number to drunk people (7/33/5)

- I pretty much avoid them $(7 / 35 / 34)$

- You could move them to a table (9/3/25)

- You are not going to go home with them (8/9/19)

- You should immediately remove yourself (8/11/12)

Other common types of actions represented by Material clauses where bartender was Actor included 'working" (e.g., I have been waitressing [8/O/2], I work at a high volume bar [7/2/6], I don't tend busy bars [7/18/37]), and 'wearing a ring' (e.g., get a nice and big...ring [7/15/1], I only wear mine [7/24/6], and I have again resorted to wearing a wedding band [9/11/15]). 'Working' appears to be used to help reinforce the identity of these redditors as bartenders, and, given their role as advisor in these texts, to perhaps reinforce that as well. In other words, it seems as if redditors, in their construction of themselves as 'working', are situating themselves within the industry as knowledgeable. It might be the case that bartenders do this to have some control over their stories, to compensate for the fact that, in most cases, the customer is the one with the power to act.

Recall that my overarching research objective was to understand how bartenders are constructing their experiences with sexual harassment. By looking at Transitivity choices, patterns emerge that answer that objective. In the case of Material processes, 
what I have found is that customers are typically represented as doing something that could be considered inappropriate (flirting, touching, keep pushing). Bartenders, however, are most often depicted as 'reacting' rather than acting. When a customer is said to overtly flirt, the response by the bartender is trying to pull back (9/3/17); when a customer is said to try and get the bartender to leave my boyfriend, the bartender responds by have to leave the bar (7/35/17). In these constructions, the customer is represented in the discourse as having all the power to act, to make the first move, while the bartender is mainly represented as re-acting to the customers. These findings are in line with the findings from the Template analysis, described in the upcoming section 5.4, whereby bartenders typically describe coping strategies in response to harassment rather than contesting strategies. Before addressing Template analysis, however, the other type of Metafunction analysis I undertook will be discussed.

\subsection{Mood and Interpersonal Metaphor}

Mood, as explained in section 3.5.1.2, refers to whether a clause is structured as a statement, question, command, or offer. In the case of the reddit data, I anticipated finding many imperatives (commands); because the original posts sought advice of other redditors, it would stand to reason that commenters would respond with an order. For example, if the original post said "how should I deal with men hitting on me?", then the expected response would be "do this", or "don't do that". However, imperatives were not as prevalent as I expected. Imperatives only accounted for 70 of the total clauses $(\sim 9.7 \%)$, and interrogatives an additional $12(\sim 1.7 \%)$. In fact, there were 637 declarative clauses, for a total of over $88 \%$ of the total clauses. The text with the largest percentage of imperatives was reddit text \#8, with just over $19 \%$ of total clauses imperative. 
However, it still seemed to me that redditors were giving commands (in the form of advice). Consider the following declaratives:

1. ...I'd always get management involved before getting more direct (9/2/9)

2. I do not think it's wrong to just bluntly tell them you are not interested (9/14/1-3)

3. If you look like a tough bitch who's seen it all, these disgusting old men will be completely intimidated by you (8/3/5-6)

4. I let them flirt as long as they're not being rude (7/36/1-2)

5. ...especially for women, one of the best things to do is buy some kind of nice looking ring to wear on your left finger (7/24/1-2)

Because SFL views language as a system of choices, these clauses can be re-phrased grammatically as imperatives to contrast the meanings:

1. Get management involved before getting more direct

2. Bluntly tell them you are not interested

3. Act like a tough bitch who's seen it all

4. Let them flirt as long as they're not being rude

5. Buy a ring to wear on your left finger

The choice to phrase these commands as declaratives might suggest the speakers' intention was to be polite. On the one hand, because these redditors are (presumably) strangers to one another, they might not feel comfortable giving explicit orders. On the other hand, it might be that bartenders want to mitigate their opinions; if, as Folger $\varnothing$ and Fjeldstad (1995) suggest, bartenders are sanctioned for deviating from the expectations of 
their workplace, then even in an anonymous context, they could mitigate or downplay the topic of harassment by using softer phrasing. Another possibility is that, being in a position of less power than the customer (recall the asymmetrical power between customer and bartender in section 2.2.3), the bartenders have become accustomed to downplaying their own opinions.

Halliday and Matthiessen (2014) discuss the phenomenon of incongruent mood choice - in this case the choice of a declarative form to express an order - which they term “interpersonal metaphor" (pp.698-707). They say, “One prominent type [of metaphor of mood] involves a shift in the realizational domain of commands from 'imperative' to 'indicative' [declarative or interrogative] clauses" (p. 705); in other words, it is common for speakers to phrase a command as a statement or question. Furthermore, Thompson (2014) explains:

The meaning is then a fusion of the function of command and the declarativeness of the structure...In this case the fusion results in an utterance that would be described in everyday terms as advice (i.e., a command that puts less pressure on the addressee to obey). (p. 233, emphasis added)

Thus, the examples above are examples of advice, grammatically as well as semantically speaking. There were some redditors who did respond with commands, as in the case of commenter DenOfThieves, who employs imperatives in 6 of their 22 clauses:

Don't flirt. Be witty, be assertive, and maybe even be a little mean...just remember, there's no reason you should ever need to feel uncomfortable at your job... (8/9/1-4,12-14) 
However, most advice was grammatically structured as declarative.

According to Eggins and Slade (1997), "the social role that participants are occupying in an interaction will constrain the speech functions they have access to when interacting with specific others" (p. 182). In this case, the role that the original posters occupied was that of one seeking advice; that in turn assigns the respondents the role of advisor. Furthermore, by seeking advice, the original posters place the respondents in a social role of authority; that is to say, the respondents are assumed to be more experienced and knowledgeable bartenders.

There is one more aspect of interpersonal metaphor relevant to this research, and that is the moral undertone of the role of advisor; Halliday and Matthiessen (2014) state that "The 'indicative' realization of proposals has the effect of blurring the line between proposals directed to the addressee and propositions about how the world ought to be" (p. 706). To wit, advice carries not only the explicit message of what the listener should do, but also the implicit message of what is the right thing to do. This concept relates these mood findings to the previously mentioned Transitivity findings: in the Experiential analysis, it appears that speakers are making judgements of what the 'best' qualities are in a bartender who wants to mitigate sexual harassment. It seems that the interpersonal strategy of giving advice is serving the same function. Thus, in both Experiential and Interpersonal ways, bartenders are proposing an 'ideal'.

In this section, I have described the mood choices of the reddit data, explained the incongruent manner in which redditors choose to express commands, and provided examples of these choices. Furthermore, I have attempted to explain why these incongruent mood choices might be made: the interpersonal roles of the participants 
govern speakers' choices. In this case, the original posters are granting authority to responding redditors by asking their advice. Again, recall that the research questions posed in Chapter 1 included the question: do bartenders use language that resists or reinforces the normalisation of sexual harassment? In and of themselves, these mood findings do not answer this question - for a more definitive answer, the content of their discourse must be investigated. However, the interpersonal aspect of bartenders' discourse does play an important role in both resisting and reinforcing the normalisation of sexual harassment, which will be discussed further in Chapter 6. In the next section, the content of bartenders' discourse is examined through the reporting of the Template analysis findings.

\subsection{Template analysis: Coping versus Contesting}

Bartenders across reddit data and interview data described their experiences with customer sexual harassment in various ways, but with many commonalities. Bartenders generally discussed their experiences either through narratives about how they deal with sexual harassment (across interview and reddit texts) or in the form of advice for other bartenders (reddit texts); furthermore, bartenders tended to provide description of either resistance to sexual harassment or coping strategies. Following Good and Cooper (2016), I have labelled these 'coping' or 'contesting'; their pilot project on bartenders' experiences with customer sexual harassment found that "employees respond to sexual harassment from customers using coping strategies and engaging in contestations, which can be individual or collective" (p. 3). The final template is shown in Figure 9. The first type of coping strategy that emerged from the data is what I call 'justification', and is the focus of the next section. 


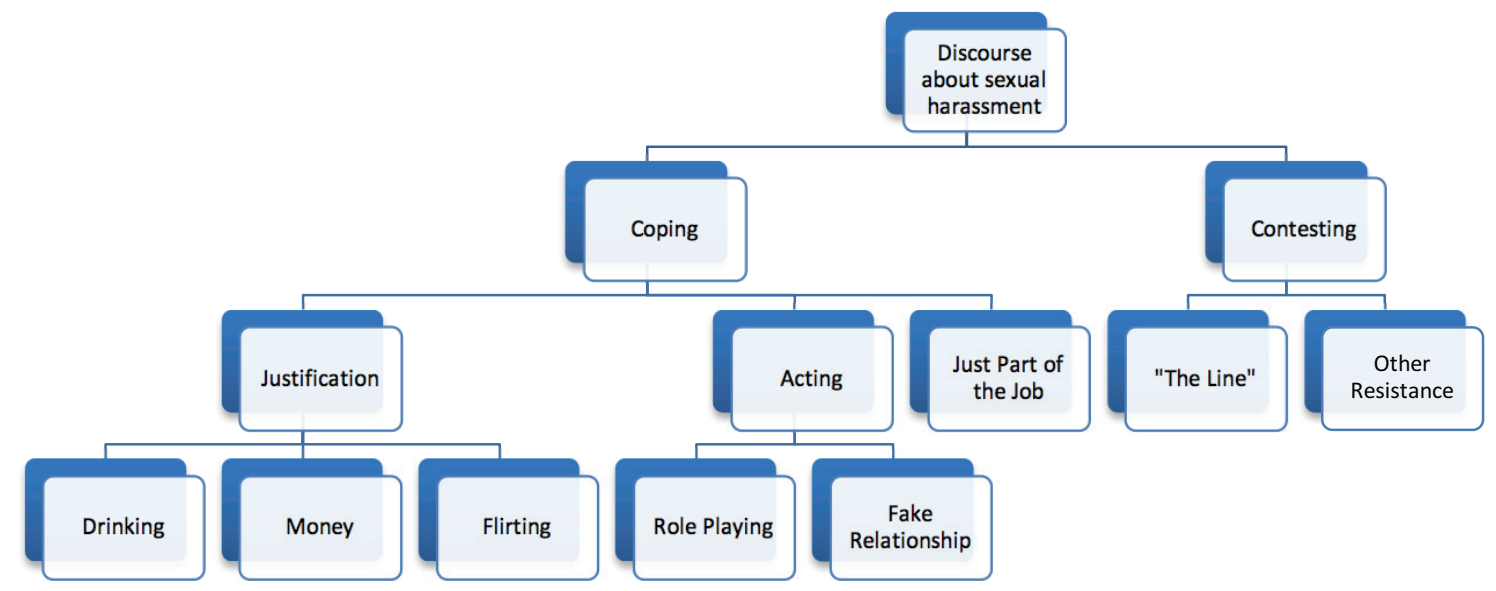

Figure 9: Template analysis identified themes

\subsubsection{Justification for sexual harassment}

There were three themes that emerged in the category I have termed 'Justification'; that is, many bartenders made statements concerning why sexually harassing behaviours ('hitting on') were excusable or not problematic. These three themes are Drinking, Money, and Flirting, and each are here discussed in turn.

\subsubsection{Drinking}

Drinking was sometimes used to excuse or at least to explain customers' behaviour, as in the following excerpts:

- It's important to give a little slack-after all people come to you to drink (8/11/910)

- When you're literally serving alcohol, people are going to get drunk and flirty $(7 / 14 / 2-3)$ 
- When you're dealing with people and alcohol, it's bound to happen (Interview D, $\left.Q 7^{35}\right)$

This type of comment justifies the behaviour in that it constructs customers as unable to help themselves; customers are drinking, thus not accountable for their harassing behaviours. Notice that these are assumptions - no further evidence is provided by the bartenders; the assumption is that the customers are powerless to stop their behaviour because they are under the influence of alcohol, and that the bartender should then just accept it. The statement that a customer who is drinking is naturally going to harass bartenders and that bartenders should then tolerate and excuse that behaviour - a clear example of normalising discourse-seems ludicrous when put into other contexts; for instance, it seems unlikely that women in other professions such as law or banking, would find it unremarkable or unproblematic for an intoxicated customer or client to sexually harass them. Even in the context of other workplaces where liquor is served, such as a family restaurant or an airplane, one might question whether such harassing behaviour would be considered acceptable.

\subsubsection{Money}

A second type of justification that bartenders make for tolerating sexually harassing behaviours concerns the money they earn from tips. As noted in Chapter 2, tipping creates a type of quid pro quo relationship between customer and server whereby the servers may trade on their sexuality in order to earn more money. Commenter BarredBird says: It's always a delicate balance when someone crosses the line, because

\footnotetext{
${ }^{35}$ Interview excerpts are notated by Interview D, S, or F according to the participant's pseudonym, and by question number where the quote is found.
} 
you don't like the comment/person, but you want the money (9/2//1-3). Some other examples include:

- You do what you want. But if you go with it, you'll go home with an extra tip $(8 / 17 / 1-3)$

- [Flirting]...usually gets me a little bit more in tips, so why not right? (9/13/7-8)

- I'll just lead the ladies along hoping to get more money (7/10/2-3)

- They also always leave a very large tip, so I try not to be rude... (7/35/21-22)

This was one code that occurred only in the reddit data; the IRL participants did not mention money. However, that might be a reflection of the way the various questions were phrased; whereas the IRL participants were asked how they dealt with customer harassment, the redditors were asked how to deal with it. It might be the case that the distinction between being asked to recount experiences results in slightly different answers than being asked for advice. However, although the IRL participants did not discuss it, the idea that money is a motivation for tolerating harassment in the service industry has been established in other research, such as ROCUFT's (2014) report, as well as by Matulewicz (2015), both referred to in Chapter 2 .

\subsubsection{Flirting}

As previously mentioned, the words 'sexual harassment' do not appear in any of the reddit data, although by legal definition, many customer behaviours mentioned do constitute sexual harassment. For instance, Shaniqua (Interview S, Q7) talks about customers requesting hugs from her, which is a sexually harassing behaviour as listed by the OHRC (see Appendix D); similarly, although slumbercat09 calls her customers' 
behaviour "grotesque sexual attention" $(9 / \mathrm{O} / 7,9)$, she still fails to call it sexual harassment. One word that does appear with great frequency, however, is 'flirting'. On the one hand, the term is used sometimes to distinguish between flirting and other, more disturbing behaviours; but on the other hand, the term seems to be used primarily as a euphemism for sexual harassment. The following excerpts help illustrate both these instances of use:

- I usually just let dudes flirt with me if that's all they are doing (7/6/1-2)

- I enjoy interacting with people and even some light, innocent flirting is no sweat $(9 / \mathrm{O} / 6-7)$

These are examples that I believe could reflect the first instance of use, that of flirting as flirting. Merriam-Webster (2015) defines flirting as "to behave in a way that shows a sexual attraction for someone but is not meant to be taken seriously", and that seems to be the usage of the commenters above. However, it might also be considered a euphemism for more harassing behaviours. For this type of usage, consider the following example:

- If people are overtly flirting and it's getting uncomfortable... (9/3/17-18)

In this excerpt, TwiceKnightley had already said that he gets "treated like a piece of meat" at work, but then used the term 'flirting' when he described a situation that could make someone uncomfortable; this suggests to me that 'flirting' used in this context is a euphemism for more severe behaviours, much in the same way that 'hitting on' could be said to be a euphemism for sexual harassment. This might be a coping mechanism (i.e., calling the behaviour flirting allows the bartender to avoid feeling like a sexual object), or 
it could reflect the difficulty in distinguishing between sexualized behaviour and sexual harassment mentioned by Brunner and Dever (2014; see Chapter 2).

In summary, there are three instances of what I term 'justification', in that these recurring ideas in the data seem to show that bartenders justify their customers' harassing behaviour. First, they excuse the customer behaviour as a natural consequence of alcohol consumption; second, they cite their tip income as fair compensation for tolerating harassment; and third, they minimize the severity of harassment by calling it 'flirting'. The next section deals with the strategies bartenders employ in dealing with customers' harassment directly; that is, how bartenders describe their actions at work in order to deal with problem customers.

\subsubsection{Acting in the Workplace}

This section concerns the coping strategy that I call 'Acting'. There appear to be two types of acting that bartenders use in order to cope with customers' harassment; the first involves the bartender as a role that employees' play and concerns a type of persona that the bartender assumes, while the other involves the bartender pretending a non-existent relationship that seems to 'protect' them from the customer.

\subsubsection{Playing a Role}

Bartenders often describe themselves as acting, or playing a role, when it comes to their work. This was often mentioned in reddit data as a way to deal with customers hitting on them, as a sort of minimization; in other words, going along with the customers was seen as part of the job and redditors especially tended to describe themselves as actors. 
- It's work, but it's the character act that I put on when tending...it's all fake $(7 / 18 / 23-24,44)$

- Sometimes I'll play along (7/36/3)

- A lot of new bartenders and servers are unaware that you are equal parts an actor when working $(9 / 3 / 1)$

- Being a bartender is like being on a stage (8/2/5) - notably, this redditor also goes on to distinguish between her persona at work and "real life"

- Bartending is an acting job (8/3/2)

Acting in this manner refers to the bartender 'playing along', or humouring the customer; i.e., in order not to offend the customer or lose tips, bartenders act like the customer's behaviour is acceptable or even enjoyable to them. This sort of acting might be beneficial not just in terms of ensuring the bartender's continued employment and income; that is to say, the acting might not be for the customer's benefit only. In fact, it could be the case that bartenders shield themselves from the harassment through this persona; i.e., 'it's not happening to me, it's happening to my character'. This idea cannot be expanded on in this thesis, but could be a topic for future research. In any case, it seems clear that bartenders commonly use this strategy for coping with harassment from customers.

There is another type of acting mentioned by bartenders, although this one is less explicit; in this case, the bartender acts like she is busy in order to avoid the customer, or in some cases, acts like the customer's behaviour does not bother her, as opposed to the type of acting mentioned above, where bartenders assume a certain 'bartending persona'. 
Some instances of this second type of acting in the texts include:

- When somebody's so blatant, is right in your face and...I didn't know what to say or do or-I just laughed and tee-hee'd about it and ran away (Interview S, Q6)

- I play up the charm but act like I'm super busy (7/18/1-2)

- One thing I've done in the situation...was to ignore the comment when it's made (9/2/4-5)

\subsubsection{Faking a Relationship}

The final type of acting discussed by redditors and IRL participants was to pretend they have a romantic partner. This was often suggested as a strategy to end harassing behaviours. Some of the bartenders who actually are involved in a relationship advised that mentioning that relationship was a sure way to avoid the harassment:

- Straight up I'm married, the ring was on the finger and it-people understood that (Interview S, Q6)

- If telling them I have a boyfriend doesn't get them to stop, which it usually does $(7 / 35 / 8-9)$

More often, however, the bartenders expressed this as a need to pretend that they were romantically involved:

- I usually say I have a boyfriend (7/33/1-2)

- Honestly even if I didn't have a boyfriend I'd probably say I did because some people are very pushy (Interview F, Q6) 
- I used to work with a girl who wore a ring to discourage over-amorous patrons $(7 / 25 / 1-2)$

- Get a nice and big... and really noticeable engagement ring for your left hand. It will deter more than you'd think (8/15/1-2)

- I'm not married but I wear a ring on that finger (Interview D, Q5)

This type of acting is somewhat troubling as it suggests that one of the more common ways that female bartenders cope with sexual harassment is by invoking the protection of a male - real or imaginary - and moreover, they seem to feel that it is the most effective way of stopping the behaviour as opposed to, for example, asking the customer to stop. Redditor givegold, for instance, advises to "be gracious but straightforward" by telling the customer "listen, I'm flattered but I have a boyfriend" (8/10/10,14-15). However, it is not clear from these data whether this type of acting is the most effective, in that customers cease the behaviour as soon as they hear mention of another man, or whether the bartenders simply believe that this is the most effective way of stopping the behaviour. Another, related element that appeared only a few times in the data was invoking the actual protection of a real male; in some cases, bartenders advised seeking help or support from (male) employers and bouncers. Of course, a bouncer (bar security) is paid to do just that sort of work, and employers are obliged to help their employees handle difficult situations; I do not mean to suggest that bartenders should not rely on their support. However, it lends credence to the fact that many female bartenders cite their reliance on males (real or fictional) to prevent customer harassment.

Thus far, I have described two broad categories of what I believe constitute 
coping mechanisms, namely, that bartenders justify customers' inappropriate behaviours in various ways such as minimizing the customers' culpability, invoking the financial reward involved, and by calling it 'flirting' rather than harassment. Furthermore, they describe strategies they employ to manage the interactions, which involve some type of role-playing. There is one further type of coping strategy which I discuss here, followed by a brief discussion of resistance, or contestation.

\subsubsection{Just Part of the Job}

As mentioned in Chapter 2, it is often the case that bartenders view sexually harassing behaviours as a normal, expected part of their jobs. That was a fairly common finding of this analysis as well. Some participants were explicit about this, as in the following examples:

- $\quad$ On one hand, it's part of the job (7/14/1)

- It's the current nightlife power dynamic that this is deemed acceptable (7/18/6)

- It's just part of-almost part of the job description (Interview D, Q7)

- I think it just comes with the territory (Interview S, Q7)

- One truth about this industry is that it's sexually charged... I do think you have to understand that mixing drinks and serving food isn't the only part of the job $(9 / 5 / 7,12-14)$

However, even participants who did not explicitly use these words still hinted at the fact that harassment is an expected behaviour; for instance, the commenters (above) who mentioned the inevitability of drunk customers hitting on bartenders seem to suggest that 
these behaviours are a normal and unexceptional part of bartending.

It might seem to this point that the data demonstrate that bartenders consistently use only coping strategies in the workplace, but that is not the case. In fact, there were several bartenders in this study who described their experiences with resisting sexual harassment, and these are the focus of the next section.

\subsubsection{Resistance}

Although resistance, or contestation, was not as prevalent in the data as the coping strategies mentioned heretofore, there was discussion of resistance. One main theme emerged out of the data, which I will discuss first, followed by a short presentation of the various other forms of resistant discourse.

\subsubsection{The Line}

A recurring idea across all data was 'the line', or 'balance'. What the bartenders consistently mentioned was there is a 'line' that customers cross whereby on one side of the line, everything is fine and no action need be taken. Another way it is phrased is it's a delicate balance $(9 / 2 / 1)$. If action is taken by the bartender, it is often nonconfrontational action such as avoiding the customer or 'laughing it off'. If the customer crosses over the line, however, stricter action must be taken. Some suggested responses when the line is crossed include: telling a manager, notifying security, asking the customer to leave, or calling the police. The problem is that there is no definitive division between one side of 'the line' and the other; that is to say, one bartender's line might be different from another bartender's. For some bartenders, the line is between physical and verbal behaviours; for example, in Shaniqua's interview, she said: there's a 
line... I've been cracked on the ass before... um... and I put the customer in his place (Interview S, Q7). Additionally, according to one redditor, It's not a problem for me unless they are physically hitting on me... then I call the cops (7/32/1-3). For most other participants, however, the line is less clear; sometimes it is defined as:

- I let them flirt as long as they're not being rude (7/36/1-2)

- Any guy that gets too pushy usually has to talk to one of the male bartenders or bouncers $(7 / 2 / 10)$

- If they're being persistent but not pushy, I'll joke with them about how I don't know that they're not a serial killer (7/6/4-9)

- Anyone crosses your line, gets a warning first and then action (8/23/27)

There are two ways of thinking about this. On the one hand, this concept could be taken as another example of bartenders coping with sexual harassment versus contesting it, perhaps. However, the common denominator here is that, while each individual's 'line' might be different, most of the bartenders in this study recommend some sort of corrective action when that line is crossed. That the suggested course of action may not be the most effective one is not the point; rather, it is the fact that bartenders do not just accept all harassing behaviours passively that is important. Bartenders can and do resist sexual harassment from customers, even if 'the line' is perhaps flexible and far more lenient than in some other workplaces.

On the other hand, it might be that 'the line' might be another euphemism for 'sexual harassment', in which case the bartenders might be resistant to the behaviours while still keeping silent about the underlying issue. In other words, they might be 
resistant to individual customers but still be contributing to the normalisation of sexual harassment by not calling it that. Whichever the case, the data show that there is resistance to the behaviour, if not to the normalising discourse, and hence this theme is situated on the 'contesting' side of the template. The next section will discuss further examples of resistance by bartenders.

\subsubsection{Other Forms of Contestation}

On the opposite end of the spectrum from 'it's just part of the job' are those bartenders who aver that harassment is not an acceptable workplace practice. Several redditors expressed this view, and some of these are listed here:

- I as a female bartender do not flirt or encourage it.. Also, if you do flirt you are encouraging that type of clientele $(8 / 16 / 2,9-10)$

- Flirting is not required...you're in control and have the power as the bartender $(8 / 1 / 21,23-24)$

- I do not think it's wrong to just bluntly tell them you are not interested (9/14/1-3)

As well, several bartenders described their experiences dealing with harassment in terms not of placating the customer, but of turning the tables on them or making fun of them. For instance,

- If they're getting aggressive I just say straight out “you're sweet to ask, but I'm not interested. Go back to drinking your beer like a good boy and please stop asking” (7/6/10-15) 
- My friend responded with "what's your name, little man". I was on the floor laughing $(7 / 19 / 1-2)$

- Friend of mine used to hint at the fact that she might have a penis $(9 / 12 / 1-2)$

Thus, there were two basic types of reactions bartenders recounted from their experiences with customer sexual harassment. On the one hand, most of the data suggests that bartenders employ - and recommend - a variety of coping strategies, such as excusing the behaviour, minimizing it by calling it 'hitting on' or 'flirting', or various types of acting such as going along with it or pretending to be in a relationship. On the other hand, bartenders sometimes resist sexual harassment; not all bartenders tolerate harassment from customers, although the types of resistance are varied.

These categories are fluid and subject to my interpretation as analyst. Discourse analysis, according to Fairclough (1995), is "obviously an interpretative exercise which depends upon...the analyst's interpretative and strategic biases" (p. 212). It might be the case that some themes I have labelled 'coping' might be seen by another analyst as 'contesting', and vice versa. However, based on my experiences as a bartender, my familiarity with this type of discourse, and my knowledge of Discourse Analysis, I believe my interpretation to be accurate.

\subsection{Is it Sexual Harassment?}

One finding remains to be discussed, although it was not the focus of either SFL or Template analysis. One of the research questions posed in Chapter 1 was whether bartenders used the term 'sexual harassment' to describe the sexually harassing behaviours they endure at the hands of their customers, and if they do not use that term, 
why not? As mentioned previously, other research has noted the tendency of bartenders not to identify as 'sexually harassed', and that was true in reddit and interview data as well. Because I could not ask the redditors about this, I asked my IRL participants if they believed their experiences constituted sexual harassment (none of them had used the term up to that point). To begin with, I asked each IRL participant how they dealt with customers 'hitting on' them; following that, I asked "do you call it sexual harassment when that happens?" In each case the answer was an unequivocal "no". Why did they say no? Here are their answers:

- Shaniqua: I think it just comes with the territory-there's a line...I've been cracked on the ass before...um... and I put the customer in his place. He knows not to do it again. I don't consider anything that's...verbally coming out of somebody's mouth to be any kind of harassment. If it's bugging me I'll tell ya to shut up about it um but don't-you don't need to put your hands on me. As far as you know, some customers will request a hug or something like that-sometimes that's a little uncomfortable um but certainly I think a crack in the ass is out of line, I don't care how good of a customer you are...

- Delta: I think it's part of the job...when you're dealing with people and alcohol it's bound to happen. If you try to put an end to it and they persist then I think that carries over then it's-then I would consider it harassment but you know if they're just you know start-you know-ah, no...

- Foxy: I can never ever say I got sexually harassed at work. If anybody asked I would say no... 
Unlike the redditors, these participants were asked explicitly if they consider themselves sexually harassed, and they rejected that label with the explanations above. There did appear to be instances whereby Shaniqua and Delta might consider themselves harassed-physical touching in the former instance and 'persistence' in the latter; these are instances of 'the line' that was discussed previously. I believe this is an important finding, as it suggests that bartenders may contribute to the normalisation of sexual harassment. That is to say, if bartenders do not-or cannot-perceive themselves as sexually harassed, it is likely that this will be reflected in their conversations with others, especially co-workers or other bartenders, who might be taking their cue from them.

\subsection{Summary}

In conclusion, this chapter has presented the findings of my Experiential, Mood, and Template analyses. The findings from the Experiential analysis showed that bartenders construct an 'ideal' bartender when advising others how to deal with sexual harassment; this ideal varies, but is often expressed in terms such as 'witty', 'assertive', and 'confident'. Furthermore, when customers are Actors in Material processes, they tend to be acting upon the bartender, while when bartenders are Actors, they tend to be reacting to the customers' behaviour. Mood analysis suggests that redditors are designated by other bartenders as authoritative regarding their experience with sexual harassment and might be influential in establishing occupational mores. Finally, Template analysis revealed that some bartenders discuss their experiences with sexual harassment in terms of resistance, although most relate various coping strategies. In the next and final chapter, I situate these findings in a CDA frame of reference and discuss them in 
connection with the theories about sexual harassment, normalisation, and language previously discussed. 


\section{Chapter: Discussion and Conclusion}

\subsection{Introduction}

This project is concerned with the ways that bartenders construct their experiences with sexual harassment. Previous research has noted the prevalence of sexual harassment in the larger hospitality industry, as well as the tendency in the industry to construct sexual harassment as an inherent and natural feature of the workplace. Some researchers have connected sexual harassment to issues of power and others to discourse, but none have connected all these concepts in the context of bars. This research has attempted to address that gap by investigating the discourse of bartenders, specifically, in order to determine how they construct their experiences with customer sexual harassment, and furthermore, if they contribute to or resist the normalisation of sexual harassment.

This chapter will be structured as follows: first, I briefly review my findings, which to this point have been examined only in relation to the Description and Interpretation levels of Fairclough's 3-Dimensional framework. Next, I situate the findings in terms of their socio-cultural context - the outermost and final of Fairclough's analyses (Explanation) - and discuss their relation to power, resistance, and normalisation. Following that section, I explain some of the limitations of this research and suggest some areas for future study. Finally, I revisit my research questions and address the answers to them.

\subsection{Review of Findings}

SFL metafunctional analyses (Transitivity and Mood) were conducted on reddit data, and found the following patterns: 
- Bartenders tend to talk about coping with sexual harassment from customers in terms of the types of attributes a bartender should have. Traits such as wit and assertiveness were commonly expressed as the best way 'to be' in order to handle problem customers.

- Although bartenders were more frequently the Actor in Material clauses, customers were the ones who were constructed as doing things to the bartenders, while bartenders as Actors were most often constructed as reacting to the customer behaviour.

- Bartenders used Interpersonal metaphor to express their commands as advice rather than orders. Whether redditors were complicit in or resistant to the normalisation of sexual harassment, they have been assigned the role of expert advisor by the original posters in each of the three reddit texts, and their views must therefore be considered potentially influential on other bartenders.

Template analysis was conducted on all data - reddit and interview — and found there were two main categories that bartenders' discourse about their experiences with harassment fell into: coping and contesting. Coping was the larger category, and consisted of the following concepts:

- Justification for sexual harassment: this code comprised ideas that were sorts of reasons or excuses why bartenders should tolerate harassing behaviour, and included Customer was drunk/drinking, Bartender makes good tips, and Mitigation of the harassment by calling it 'flirting'.

- Acting: types of acting described by bartenders included Playing a role (by having a 'sassy' or 'tough' persona, as well as pretending not to be bothered 
by the harassment), and Faking a relationship so that the customer would leave them alone.

- 'Just part of the job': this was the most explicit expression of the normalisation of sexual harassment. Many bartenders expressed the view that being harassed (i.e., being 'hit on') was an expected part of their work.

Contesting consisted of one major category, which was most often expressed as 'the line', whereby customers' behaviour was not problematic until it crossed a line (often this line was between verbal and physical behaviours, or the level of persistence a customer displayed). Other forms of resistance to sexual behaviour were evident in the bartenders' discourse; bartenders at times described situations where they used more direct strategies to handle customers, including calling the police or security, or telling the customer to stop. A few redditors even described instances where they made fun of customers for the harassment.

Finally, the IRL participants were asked during their interviews why they did not use the term 'sexual harassment' to describe their experiences with customers. Their answers related to the findings mentioned above about 'the line'; that is, they felt that their experiences were generally not serious enough (because of lack of physical contact

or lack of persistence) to constitute sexual harassment. Having provided this summary of my findings, I now move on to the final phase of analysis, that of social practice.

\subsection{Socio-cultural Explanation of the Findings}

\subsubsection{Normalisation}

The institutional norms of a bar, or its social context, have been covered in some detail already in the first two chapters of this thesis. It has already been established that sexual 
harassment happens with alarming frequency in the hospitality industry, and that customers are often the perpetrators of that harassment. Furthermore, various reasons have been suggested by researchers such as Poulston (2008), Folgerø and Fjeldstad (1995), and Matulewicz (2015) for the prevalence of sexual harassment in the hospitality industry. One key reason, in the context of this research, with its focus on bars, is that sexual harassment is normalised in bars; that is, it is often unremarked or considered 'just part of the job'. According to Figueiredo (2004), "systems of categorizing and classifying phenomena frequently seem so natural that they become 'common sense', thereby corresponding to an objective 'reality' instead of a 'world-view', 'theory', 'hypothesis', or 'ideology'” (p. 220). CDA maintains that ideas like this that appear 'natural' (at least to those in the bar industry) are just the sort of ideas that we need to be most critical of. The idea that sexual harassment is par for the course in bars and restaurants is so common that the term 'sexual harassment' is not even used by bartenders; that has been the finding of this research as well. This finding also corresponds with my personal work experience. Normalisation occurs when something is so common to a group of people that it is perceived as 'natural', and while I cannot say with certainty how this normalisation occurred, it seems that to some extent, bartenders themselves - through their discourse - perpetuate it. Furthermore, as none of the participants in this research used the term 'sexual harassment' but instead used euphemisms such as 'hit on' or 'flirting', then it would appear that silencing, as per Theismeyer's (2003) definition, is occurring as part of that normalisation. 


\subsubsection{Power}

Based on the results of my analysis, it seems there are two types of power which bartenders employ (or at least, represent themselves as employing) in these texts: first, they have the power to advise other bartenders about the best way(s) to deal with sexual harassment. Because this thesis is concerned with normalisation, which can be realized in discourse, this is an important aspect to consider. That is, if bartenders influence other bartenders, and their discourse is complicit in the normalisation of sexual harassment, then they have the power to pass that idea on. Bartenders work with other bartenders as well as train new bartenders; if it is generally accepted by bartenders that being harassed is 'just part of the job', and they then perpetuate that idea with new or other bartenders, it could consequently be a difficult belief to challenge or change. The second type of power that bartenders talk about is the behaviours that they use to challenge sexual harassment. Some of these were detailed in the previous chapter, and include confronting the customer or calling the police. However, as the Transitivity analysis showed, while bartenders often construct themselves as the Actor of Material processes (i.e., they are the ones who are most often represented as 'doing' things), the processes related to them are often ones that react to customer behaviour. Representing themselves as reacting rather than acting serves to represent them as less powerful.

This is not surprising in light of the existing research on sexual harassment in bars; several researchers point out the asymmetrical power relations between bartenders and customers (e.g., Poulston, 2008; Folgerø \& Fjeldstad, 1995) as well as the typical powerlessness that service workers in general have (Hughes \& Tadic, 1998). As well, sexual harassment is considered a display of power; Brunner and Dever (2014) argue that 
it is "one mechanism through which power is enacted between individuals to create and maintain control of sexuality" (p. 461). The relevance of this is that, in this case, we can see that power is maintained through discourse, and discourse reflects power. As I explained in Chapter 3, one of the hallmarks of CDA is that it posits language as constituting, and constitutive of, society. In light of the findings in this thesis, I conceptualize that as follows:

- Discourse enables and maintains power: sexual harassment, as noted, is often a verbal behaviour. When the bartenders in this study talk about being 'hit on', they are referring to verbal behaviours. Since sexual harassment is an expression of power by customers over bartenders, this entails that their power is realized in discourse. Furthermore, the way that bartenders themselves talk about the harassment normalises the behaviour, i.e., it perpetuates and maintains the power that the customer already has over them.

- Discourse is shaped by power: perhaps the best way to express my meaning here is to use a hypothetical example; if tomorrow, suddenly all bartenders believed that their customers' behaviours constituted sexual harassment (as defined by the law) and that, accordingly, those behaviours were unacceptable, we would expect to see a change in their discourse. Rather than saying 'it's just part of the job', bartenders might instead say things like 'that is unacceptable behaviour, it's sexual harassment and has no place in our industry'. This is not conjecture; consider, for instance, the idea of sexual harassment as a social construction (as discussed in Chapter 2). Less than 40 years ago, there was no term for sexual harassment; until then, a woman had to tolerate such behaviours with no recourse. 
There was not even a word for it. Today, we have a term for sexual harassment, and attendant laws to address it. It is often the case in other workplaces that sexual harassment policies are in place and upheld regularly. Thus, it is not unreasonable to conclude that bartenders' discourse, which normalises sexual harassment, is shaped by the power over them. Correspondingly, if the power is lessened, then the discourse should change. What is now acceptable would become unacceptable.

It is often the case that oppressed people do not realize that they are oppressed, or put another way, they feel that the power over them is natural. van Dijk (2000) expresses it this way:

power is not always exercised in obviously abusive acts of dominant group members, but may be enacted in the myriad of taken-for-granted actions of everyday life, as is typically the case in the many forms of everyday sexism or racism. (p. 355)

Hence it seems that bartenders are not only subscribing to the 'taken-for-granted' idea that sexual harassment is normal, but are also perpetuating that idea. Explicitly, they urge each other to accept the harassing behaviours, and implicitly, sexual harassment is constructed as something not to be challenged, or even not to be named.

It might seem to this point that this account fails to consider resistance. This is not the case; whereas most of the participants in this study either recounted or recommended coping rather than contesting strategies to their colleagues, there were several instances in the data of bartenders describing or advising resistant strategies such as ordering the customer to stop, reporting the behaviour to a manager, or belittling the 
customer. As mentioned earlier in this thesis, I do not conceive of power as only an uncontestable top-down imposition; there is room for resistance. Indeed, there would be little point to this project if I believed that change was not possible with growing awareness and resulting resistance. In the context of this research, however, it seems that the bartenders in this study are generally complicit in the normalisation of sexual harassment, although probably not consciously complicit.

\subsection{Limitations and Future Research Directions}

While I believe that this thesis was designed and conducted to the best of my knowledge and ability, there are necessarily areas which could not be addressed here. For instance, as mentioned in Chapter 3, this research did not take into account factors that could have an influence on bartenders' perceptions and their discourse, such as class, age, or even gender. While I generally refer here to female bartenders being harassed by male customers, I do know that male bartenders are harassed by female customers. However, my concern has been with how bartenders in general construct their experiences with harassment, and in any case, the reddit data, as stated, did not allow me any demographic information. For future research, it would be beneficial to take these factors into account, or perhaps to analyse the discourse of male versus female bartenders, or hetero- versus homosexual bartenders, in order to see if there are differences in how they experience and construct sexual harassment. In the same vein, I have not distinguished here between servers in bars and servers in restaurants. Intuitively, I believe there is a difference between the two workplaces; my IRL participant, 'Delta', discussed this in her interview (see Appendix A). Several times already since undertaking this research, I have been asked why I am not considering sexual harassment in these various other contexts. My 
answer to this is that I would be interested in pursuing that research, given world enough and time. In the same manner, it would be beneficial to study language use by managers and customers; however, that was too much for the scope of this thesis. Another possibility for future research is further exploration of the idea that bartenders are actors. Goffman (1959), for instance, talks about "the presentation of self", and it could apply to bartending in that bartenders in their job assume a persona-possibly to protect themselves from having to perceive themselves as targets of harassment.

\subsection{Conclusion}

In Chapter 1, I posed the following research questions:

- How do bartenders construct their experiences with sexual harassment at work?

- Do bartenders use the term "sexual harassment", and if not, why?

- What other terms might they use to talk about it?

- Do bartenders use language that resists or reinforces the normalisation of sexual harassment?

To conclude this study, I would like to discuss the answers to each of these in turn. With regard to the first question, bartenders grammatically — through transitivity and mood choices - and lexically construct their experiences with sexual harassment at work in terms of ideals - ideal attributes that a bartender should have in order to deal with customers (for example, badass, witty, confident), and ideal strategies with which to cope (for example, acting, pretending to have a partner). Furthermore, bartenders construct themselves in their discourse as reacting to customer harassment. On the one hand, it could be argued that it only makes sense to find this type of construction; after all, the original questions in the reddit data ask the question 'how do you deal with harassment 
by customers?'. Hence, it might be expected that responses are structured as 'customer behaves in x manner, and bartender responds in y manner'. However, language choices are choices, and the pattern of presenting the discourse in just this manner has meaning. I have suggested that the choice reflects the bartenders' general feeling of powerlessness in dealing with customer harassment. Both in narrative and advising contexts, bartenders tend to construct their experiences in terms of coping rather than contesting.

With respect to the second and third questions, the bartenders in this study did not use the term 'sexual harassment', and even those bartenders who were asked explicitly if they perceived themselves to be sexually harassed answered no. This is in line with the findings of Folgerø and Fjeldstad (1995), whose participants were sexually harassed according to the legal definition of the term, but who failed to label their experiences 'harassment'. Instead, bartenders in this study used terms like 'crossing the line', 'hitting on', and even 'flirting'. Why do they use these terms? On the surface, according to my IRL participants, it seems that they are unclear about the definition of sexual harassment. On a deeper level, however, I believe that the culture of the bar is such that the very concept of sexual harassment is silenced; bartenders even with the knowledge of the legal definition might refuse to perceive themselves as harassed.

Regarding the fourth question, the findings of this study show that bartenders generally use language that could be considered as reinforcing the normalisation of sexual harassment; through the silencing of the term 'sexual harassment' and the replacement of that term with other discourse (e.g., 'flirting'), bartenders not only fail to take into account the problematic nature of their workplace in this regard, but also contribute to the silencing (and therefore, the normalisation) themselves. Furthermore, 
by recommending strategies with which to deal with individual, troublesome customers, bartenders neglect to consider the harassment as symptomatic of a serious social issue. This is similar to the problem of 'bullying' discourse that Stein (2003) discussed: replacing sexual harassment discourse with bullying discourse creates the impression that the crime is one of an aberrant individual rather than the systemic problem it really is. Because bartenders are advising other bartenders about best practices, these ideas are reinforced and perpetuated, although it seems likely that the bartenders are unaware of their participation in normalising sexual harassment.

By studying this issue from a discourse analytic perspective, I was able to not only investigate what bartenders are saying about sexual harassment, but also how they are saying it. According to the tenets of Critical Discourse Analysis, in order to understand the causes of the prevalence of customer sexual harassment in the hospitality industry, we need to investigate discourse. Fairclough's 3-dimensional framework proved to be a valuable tool not only as a guide to analysis, but also for situating the results in the social context. Furthermore, Systemic Functional Linguistics provided rigorous analytical tools with which to investigate the finest grammatical details of language use. This suggests that both CDA and SFL are productive approaches from which to study social problems like sexual harassment and that these methods should be utilized with more frequency in research.

In closing, I would like to address the matter of social change; CDA, after all, is an emancipatory approach to social research. The question could be asked - and indeed has been asked - what is it that I hope to accomplish by this research? Certainly the ramifications of addressing sexual harassment in the hospitality industry are daunting. 
And specific to my research, the problem by all accounts seems to have a long history in bars. As well, as a real problem that is often unacknowledged as a problem by those it most affects, sexual harassment could appear to be insurmountable. However, according to Poulston (2008), as values change, expectations change (p. 239). Thus, a better understanding of the prevalence of sexual harassment and the reasons behind it might lead to increased awareness by bartenders, which in turn could lead to changed values and expectations. With more awareness, we might hope that bartenders become more attuned to, and more resistant to, sexual harassment. 


\section{Appendices}

\section{Appendix A Interview Data}

\section{A.1 Interview Script}

1. How long have you been a bartender?

2. What types of bars have you worked in?

3. How do you deal with difficult customers?

4. Can you describe a challenging situation you had to deal with in the past and how you handled it?

5. How do you deal with customers hitting on you?

6. Can you think of a specific situation where a customer hit on you and how you dealt with it?

7. Do you call it sexual harassment when someone hits on you at work?

\section{A.2 Interview Transcripts (excerpts)}

Transcription Conventions:

- [ ] overlap between the speakers

- ( ) transcriber uncertainty

- = latching

- - indicates speaker cutting off a word or interrupting themselves

- ... short pause

- (0.0) timed pause

- \{\} non-speech sounds

- [0:00] time stamp

- ? rising intonation

- “" speaker changing voice/quoting someone else

\section{Shaniqua}

S: so-but that-that was like the one that stands out the most and how I handled it probably wasn't the best but...it's-when you don't have any bouncers and you're the one that's in control of keeping uh no-the chaos out of your bar then you do what you gotta do and you know something that other people don't know? You know as far as mental state or how 
much they've had to drink or anything like that-that's [how I handled that

$\mathrm{R}$ :

[right Yeah wow. Um how do you

deal with customers hitting on you?

S: it's like in one ear and out the other [00:04:23]. After 14 years of doing it you hear a lot of it and I-I... it's certainly a confidence booster but I don't let it go any further than that= $\mathrm{R}:=\mathrm{mmmhmm}$

S: like it's kind of in one ear and out the other and-and you hear enough of the same compliment, you believe it=

R: =right

S: you-you're forced to believe it=

$\mathrm{R}:=\mathrm{mmmhmm}$

S: um [00:04:46] so I-I don't entertain it...I don't er-I smile and wave or you know "ok" or "you've had too much to drink" or something like that but I don't know it's kind of-in the beginning it was a confidence booster and it-it still is if you hear enough of it like I said-I don't know it's rolls off the back now \{laughs\}

$\mathrm{R}$ : that maybe is a little different though do you think? Uh between somebody complimenting you and somebody hitting on you?

$\mathrm{S}:(3 \mathrm{~s})$ maybe $=$

R: do you think there's a difference? I mean

S: okay if it's a-you're right compliments are different and compliments I acknowledge and say thank you and-but I kind of just let them roll too. Um hitting on you...for instance about a month ago...very pushy with the-you know with the compliments and get the-get the number I was uneasy about it I was half-embarrassed about it I didn't know how to 
handle it \{laughs\} I just started walking away from the customer \{laughs\}[00:05:52]. Um yeah

\section{Delta}

R: can you uh think of a specific situation like where somebody hit on you and like uh how you dealt with it?

D: um...not really. It's been a long time actually...

$\mathrm{R}$ : since someone hit on you=

$\mathrm{D}:=\{$ laughs $\}$ since someone hit on me in the bar, um...used to be awkward uptown when girls were hitting on me. I found it way more awkward and that happened a lot more uptown than anywhere else, um but-but no like I-I can't even think of specifics right now ...(but it was) always just like you know um with somebody or just kind of cut it right off but

R: do you uh-do you think that you're-not think, sorry, do you call it sexual harassment when someone hits on you at work?

$\mathrm{D}: \mathrm{no}=$

$\mathrm{R}:=\mathrm{no} ?=$

D: =no I think it's part of the job...when you're dealing with people and alcohol, it's bound to happen [00:15:03]. If you try to put an end to it and they persist then I think it carries over then it's-then I would consider it harassment but you know if they're just you know start-you know-ah, no I think (indecipherable) I think it's part of the job but if you ask them to stop or you tell them you're not interested and they persist then I think I would consider it harassment at that point but...just the initial instigation or starting (it) I don't 
think so

Foxy

F: I don't know I just think there's a difference between a 25-year old and a 50-year old hitting on you...am I-do you think the same thing?

R: well um I don't really know...yeah I think that just intuitively you know there is a difference $=$

$\mathrm{F}:=\mathrm{yeah}$

R: but I was just wondering if you like-what would be the difference like what would be that...thing-what would be that characteristic that would make it [ok (or not ok)

F:

[creepy like staring at

you saying gross things...where you know I wanna take you home and fuck you or there's a guy that comes in and says "you're beautiful and I'd like to take you to a movie". That's a creep to me. So yeah you get them fucking creeps.

R: (ok) Um do you call it sexual harassment when that happens?

F: no. I don't

R: no? um why not?

F: I don't know I just don't [00:10:19] I can never ever say I got sexually harassed at work $=$

$\mathrm{R}:=\mathrm{mmmhmm}$

F: if anybody asked I would say no

$\mathrm{R}: \mathrm{mmmhmm}$

F: um I don't know 'cause you know I've always had my boyfriend there at my job so- 
except for the past year and nobody's ever really sexually harassed me (though...do you find it easy)

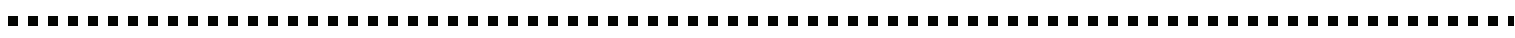




\section{Appendix B Reddit Data (excerpts)}

\section{B.1 reddit Text \#7}

Original Post: grapefruitloop

How do you respond to drunk patrons hitting on you?

1. I originally thought

2. I'd ask

3. about female bartenders getting hit on by drunk males,

4. but I suppose

5. this question applies to all bartenders/servers.

6. I was at work last week (a small business bar/restaurant)

7. where servers are in charge of making drinks for our own table sections.

8. Sometimes I get sectioned the bar instead of tables.

9. Usually a "hahaha, well my boyfriend and I have plans after my shift" will suffice,

10. but this particular patron was a semi-regular

11. and knows I don't have a boyfriend.

12. Side note: I look young.

13. Most patrons guess I'm around 17-19 years

14. (must be some sort of fun game for them,

15. I guess.

16. It makes sense for them to ask, though,

17. because in our restaurant you can't serve alcohol until you're 19,

18. and can't prepare any liquor drinks until you're 21.) 
19. My thoughts on this though are

20. if you have to ask how old someone is before you start hitting on them,

21. maybe you shouldn't be hitting on them in the first place.

\section{$14 \operatorname{kem} 74$}

1. On one hand, it's part of the job.

2. When you're literally serving alcohol,

3. people are going to get drunk and flirty.

4. However, there is a line.

5. If someone is getting too pushy or aggressive,

6. just because you're their bartender does not give them the right to make you uncomfortable.

7. I personally take it as a compliment,

8. but I've never had anyone get too creepy

9. (I'm sure it helps I am a dude).

\section{B.2 reddit Text \#8}

Original Post: glittermtl

$\underline{\text { Help? Bartending and Male Attention }}$

1. I'm only 19 (Canada)

2. and I've been waitressing since I was 17 .

3. The restaurant where I first started working didn't serve alcohol

4. and had a much different clientele. 
5. I now work at a resto-bar

6. where I'm occasionally required to do some light bartending, making basic drinks and whatnot, but mainly waiting tables.

7. There are instances, however, when people are just there to drink.

8. My problem is dealing with men that hit on me.

9. When I was 17 , I looked it

10. but between my shorter hair, learning proper make-up and my supposedly mature demeanor, I get mistaken for 23-24 quite often

11. and have to deal with (much) older men hitting on me.

12. When you waitress, it's not that big of a deal;

13. you can brush it off with a joke or being modest/shy

14. but behind the bar, it's different.

15. It seems expected that the bartender flirts with the clients

16. and it's not as though I can leave and attend to other tables/people.

17. I'm not exactly a flirty person,

18. it's never been my way.

19. I have difficulty dealing with these men,

20. usually drunk pigs who frankly, disgust me more than a little.

21. It makes me pretty uncomfortable.

22. It makes me extra uncomfortable

23. since I feel powerless as I'm serving them.

24. What do I do?

25. Do I suck it up? 
26. Is flirting required for female bartenders, bartenders in general?

27. How do I deal with this?

10 give gold

1. I don't know why this has been downvoted.

2. I totally agree.

3. I have a long time boyfriend,

4. I'm not interested in anyone at my bar

5. (even if I was single that's not where I like to meet people),

6. but I'll be sassy

7. and make sure you're having fun.

8. So you go home with a good experience

9. and I go home with my tip jar full.

10. The best for me has been to be gracious but straightforward

11. if you think

12. it's going past just noncommittal flirting

13. and it's bothering you:

14. "listen, I'm flattered

15. but I have a boyfriend/

16. but I'm not interested/

17. I'm not going to monopolize you from all these other lovely ladies in here" etc. 


\section{B.3 reddit Text \#9}

Original Post: slumbercat09

Tips for a new female bartender

1. To start, I love my new job.

2. I work at a fairly upscale restaurant and bar,

3. and it's as if I'm getting paid to network/make new friends.

4. The customers are on the more mature/older spectrum,

5. and so are normally well behaved.

6. I enjoy interacting with people

7. and even some light, innocent flirting is no sweat,

8. but I'm stumped

9. when I receive very blatant and grotesque sexual attention.

10. The feminist side of me wants to punch them in the face,

11. and the tip-garnering side wants to figure out a witty way to appease them while making them back down.

12. Any suggestions?

13. Should I just forgo tips for the sake of pride

14. and ignore them?

15. Where is the fine line?

\section{4 mbillion}

1. I do not think

2. it's wrong to just bluntly tell them 
3. you are not interested.

4. And if it goes any further than that

5. just tell a manager. 


\section{Appendix C SFL Analyses}

\section{C.1 Transitivity and Mood analyses (excerpts)}

reddit Text \#7:

\section{Comment 32 [wikipuff]}

1 Declarative/active

\begin{tabular}{|l|l|l|l|l|}
\hline It & 's & not & a problem & for me \\
\hline Subject & Finite & Adj: mood & Complement & Adj: circumstance \\
\hline MOOD & \multicolumn{4}{l|}{ RESIDUE } \\
\hline Token & Pr: Rel/Identifying & & Value & Circ: manner \\
\hline
\end{tabular}

2 Declarative/active

\begin{tabular}{|l|l|l|l|l|l|}
\hline unless & they & are & physically & hitting on & me... \\
\hline & Subject & Finite & Adj: circ. & Predicator & Complement \\
\hline \hline & MOOD & & RESIDUE & \\
\hline & Actor & & Circ: manner & Pr: Material & Goal \\
\hline
\end{tabular}

3 Declarative/active

\begin{tabular}{|l|l|l|l|l|}
\hline then & I & \multicolumn{2}{|c|}{ call } & the cops \\
\hline & Subject & Finite & Predicator & Complement \\
\hline & MOOD & RESIDUE \\
\hline \hline & Sayer & Pr: Verbal & Receiver \\
\hline
\end{tabular}

\section{Comment 33 [yesimaunicorn]}

1 Declarative/active

\begin{tabular}{|l|l|l|l|l|l|l|l|}
\hline I & usually & \multicolumn{2}{|c|}{ say } & & I & have & a boyfriend \\
\hline Subject & Adj: mood & Finite & Predicator & & Subject & Finite & Complement \\
\hline MOOD & & RESIDUE & & MOOD & RESIDUE \\
\hline Sayer & & Pr: Verbal & & Carrier/Possessor & Pr: Rel/Possess. & Possessed \\
\hline
\end{tabular}


reddit Text \#8:

5 Declarative/active

\begin{tabular}{|l|l|l|l|l|l|}
\hline Sometimes & $\begin{array}{l}\text { a little playful } \\
\text { sarcasm... }\end{array}$ & can & deflect & the situation & while... \\
\hline Adj: mood & Subject & Finite & Predicator & Complement & Adj: circ. \\
\hline MOOD & & RESIDUE & \\
\hline & Actor & & Pr: Material & Goal & Circ: manner \\
\hline
\end{tabular}

5(a) Declarative/active

\begin{tabular}{|l|l|l|l|}
\hline while & (you) & playing up to & the guys who [[want the attention]] \\
\hline & (Subject ellipsed) & Predicator & Complement \\
\hline & (MOOD ellipsed) & RESIDUE & Goal \\
\hline & (Actor ellipsed) & Pr: Material &
\end{tabular}

\$6 Declarative/active

\begin{tabular}{|l|l|l|l|}
\hline You & do & n't & have to flirt \\
\hline Subject & Finite & Adj: polarity & Predicator: modulated \\
\hline MOOD & & & RESIDUE \\
\hline Actor & \multicolumn{2}{|l|}{} & Pr: Material \\
\hline
\end{tabular}

7 Imperative/active

\begin{tabular}{|l|l|l|l|}
\hline but & you & do & have to interact \\
\hline & Subject & Finite & Predicator: modulated \\
\hline & MOOD & & RESIDUE \\
\hline & Actor & & Pr: Material \\
\hline
\end{tabular}

8 Declarative/active

\begin{tabular}{|l|l|l|}
\hline that & 's & part of the job \\
\hline Subject & Finite & Complement \\
\hline \hline MOOD & Pr: Relational/Identifying & RESIDUE \\
\hline Token & Value \\
\hline
\end{tabular}


reddit Text \#9:

8 Declarative/active

\begin{tabular}{|l|l|l|}
\hline Most of my customers & seem & to get \\
\hline Subject & Finite & Predicator \\
\hline \hline MOOD & RESIDUE \\
\hline Senser & & Pr: Mental \\
\hline
\end{tabular}

9 Declarative/active

\begin{tabular}{|l|l|l|l|}
\hline that & the whole "flirting..." thing & isn't & an invitation to anything more \\
\hline & Subject & Finite: neg & Complement \\
\hline & MOOD & RESIDUE \\
\hline \hline & Carrier & Pr: Relational/Attributive & Attribute \\
\hline
\end{tabular}

10 Declarative/active

\begin{tabular}{|l|l|l|l|}
\hline it & 's & just & $\begin{array}{l}\text { part of the bar experience and [[having a good } \\
\text { time }\end{array}$ \\
\hline Subject & Finite & Adj: mood & Complement \\
\hline MOOD & RESIDUE \\
\hline Carrier & Pr: Rel/Attributive & & Attribute \\
\hline
\end{tabular}

11 Declarative/active

\begin{tabular}{|l|l|l|l|l|}
\hline If & they & \multicolumn{2}{|c|}{ ask } & for my number \\
\hline & Subject & Finite & Predicator & Complement (oblique) \\
\hline \hline & MOOD & RESIDUE \\
\hline \hline & Sayer & Pr: Verbal & Verbiage (oblique) \\
\hline
\end{tabular}




\section{Appendix D Ethics}

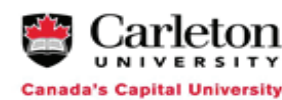

Ethics Clearance Form - New Clearance
Carleton University Research Ethics Office Research Ethics Board 511 Tory, 1125 Colonel By Drive Ottawa, ON K1S 5B6 Canad

Tel: 613-520-2517, ethics@carleton.ca

This is to certify that the Carleton University Research Ethics Board has examined the application for conditional ethical clearance. The REB found the research project to meet appropriate ethical standards as outlined in the Tri-Council Policy Statement: Ethical Conduct for Research Involving Human, 2nd edition, and the Carleton University Policies and Procedures for the Ethical Conduct of Research.

Date of Clearance: October 14, 2015

Researcher: Jaffer Sheyholislami (Primary Investigator)

Graham Smart (Research Supervisor)

Lisa Armstrong (Student Research: Master's Student)

Department: Faculty of Arts and Social Sciences/Linguistics and Applied Language Studies (School of)

University: Carleton University

Research Supervisor (if applicable): Prof. Jaffer Sheyholislami

Project Number: 103386

Project Title: "Just Part of the Job": Deconstructing the Normalization of Sexual Harassment in Bars

(Phase 1)

Funder (if applicable):N/A

Clearance Expires: May 31, 2016

All researchers are governed by the following conditions:

Annual Status Report: You are required to submit an Annual Status Report to either renew clearance or close the file. Failure to submit the Annual Status Report will result in the immediate suspension of the project. Funded projects will have accounts suspended until the report is submitted and approved.

Changes to the project: Any changes to the project must be submitted to the Carleton University Research Ethics Board for approval. All changes must be approved prior to the continuance of the research.

Adverse events: Should a participant suffer adversely from their participation in the project you are required to report the matter to the Carleton University Research Ethics Board. You must submit a written record of the event and indicate what steps you have taken to resolve the situation.

Suspension or termination of clearance: Failure to conduct the research in accordance with the principles of the Tri-Council Policy Statement: Ethical Conduct for Research Involving Humans, 2nd edition and the Carleton University Policies and Procedures for the Ethical Conduct of Research may result in the suspension or termination of the research project.

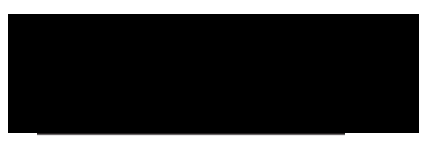

Louise Heslop

Chair, Carleton University Research Ethics Board

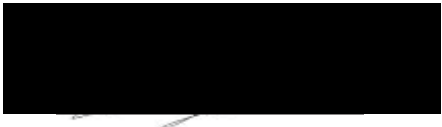

Andy Adler

Vice-Chair, Carleton University Research Ethics Board 


\section{Appendix E Ontario Human Rights Code excerpt-Section 2.1}

\section{Identifying sexual harassment}

\subsection{Defining sexual harassment}

Section 10 of the Code defines harassment as "engaging in a course of vexatious comment or conduct that is known or ought to be known to be unwelcome." Using this definition, more than one event must take place for there to be a violation of the Code. However, depending on the circumstances, one incident could be significant or substantial enough to be sexual harassment.

Example: A tribunal found that an incident where a male employee "flicked the nipple" of a female employee was enough to prove that sexual harassment had taken place. The reference to comment or conduct "that is known or ought reasonably to be known to be unwelcome" establishes a subjective and objective test for harassment. The subjective part is the harasser's own knowledge of how his or her behaviour is being received. The objective component considers, from the point of view of a "reasonable" third party, how such behaviour would generally be received. Determining the point of view of a "reasonable" third party must take into account the perspective of the person who is harassed. In other words, the Human Rights Tribunal of Ontario (the HRTO) can conclude on the basis of the evidence before it that an individual knew, or should have known, that his or her actions were unwelcome.

It should be understood that some types of comments or behaviour are unwelcome based on the response of the person subjected to the behaviour, even when the person does not explicitly object. An example could be a person withdrawing, or walking away in disgust after a co-worker has asked sexual questions. 
Human rights case law has interpreted and expanded on the definition in section 10 of the Code. In one of the earliest sexual harassment cases in Canada, a tribunal found that in employment, discriminatory conduct may exist on a continuum from overt sexual behaviour, such as unsolicited and unwanted physical contact and persistent propositions, to subtler conduct, such as gender-based insults and taunting, which may reasonably be perceived to create a negative psychological and emotional work environment. In another decision, the Supreme Court of Canada stated:

Sexual harassment may take a variety of forms. Sexual harassment is not limited to demands for sexual favours made under threats of adverse job consequences should the employee refuse to comply with the demands. Victims of harassment need not demonstrate that they were not hired, were denied a promotion or were dismissed from their employment as a result of their refusal to participate in sexual activity. This form of harassment, in which the victim suffers concrete economic loss for failing to submit to sexual demands, is simply one manifestation of sexual harassment, albeit a particularly blatant and ugly one...

Over time, the definition of sexual harassment has continued to evolve to reflect a better understanding of the way sexual power operates in society. For example, it is wellestablished that harassment and discrimination based on sex may not always be of a sexual nature. Behaviour that is not explicitly sexual may still amount to harassment because of sex. The situation must be viewed in the overall context.

Example: A tribunal found that while the most common understanding of sexual harassment is conduct such as making passes, soliciting sexual favours, sexual touching, etc., the definition of sexual harassment also includes conduct that denigrates a 
woman's sexuality or vexatious conduct that is directed at a woman because of her sex. Human rights law clearly recognizes that sexual harassment is often not about sexual desire or interest at all. In fact, it often involves hostility, rejection, and/or bullying of a sexual nature. For more information, see the section entitled "Gender-based harassment." The following list is not exhaustive, but it should help to identify what may be sexual and gender-based harassment:

- demanding hugs

- invading personal space

- unnecessary physical contact, including unwanted touching, etc.

- derogatory language and/or comments toward women (or men, depending on the circumstances), sex-specific derogatory names

- leering or inappropriate staring

- gender-related comment about a person's physical characteristics or mannerisms

- comments or conduct relating to a person's perceived non-conformity with a sexrole stereotype

- displaying or circulating pornography, sexual pictures or cartoons, sexually explicit graffiti, or other sexual images (including online)

- sexual jokes, including circulating written sexual jokes (e.g. by e-mail)

- rough and vulgar humour or language related to gender

- sexual or gender-related comment or conduct used to bully a person

- spreading sexual rumours (including online)

- suggestive or offensive remarks or innuendo about members of a specific gender

- propositions of physical intimacy 
- gender-related verbal abuse, threats, or taunting

- $\quad$ bragging about sexual prowess

- demanding dates or sexual favours

- questions or discussions about sexual activities

- requiring an employee to dress in a sexualized or gender-specific way

- paternalistic behaviour based on gender which a person feels undermines their status or position of responsibility

- threats to penalize or otherwise punish a person who refuses to comply with sexual advances (known as reprisal). 


\section{References}

Australian Human Rights Commission. (2012). Working without fear: Results of the sexual harassment national telephone survey 2012. Retrieved from:

https://www.humanrights.gov.au/working-without-fear-results-sexual-harassmentnational-telephone-survey-2012

AWARE. (2008). Research study on workplace sexual harassment 2008. Retrieved from: http://www.aware.org.sg/wpcontent/uploads/AWARE_Research_Study_on_Workplace_Sexual_Harassment.pdf

Bates, T. R. (1975). Gramsci and the theory of hegemony. Journal of the History of Ideas, 36(2), 351-366.

Beasley, C. (2005). Gender \& sexuality: Critical theories, critical thinkers. Thousand Oaks, Calif: Sage.

Berger, P. L., \& Luckmann, T. (1966). The social construction of reality: A treatise in the sociology of knowledge (1st ed.). Garden City, N.Y: Doubleday.

Blommaert, J., \& Bulcaen, C. (2000). Critical discourse analysis. Annual Review of Anthropology, 29(1), 447-466. doi:10.1146/annurev.anthro.29.1.447

Brooks, J., McCluskey, S., Turley, E., \& King, N. (2015). The utility of template analysis in qualitative psychology research. Qualitative Research in Psychology, 12(2), 202222.

Bruffee, K. A. (1986). Social construction, language, and the authority of knowledge: A bibliographical essay. College English, 48(8), 773-790. doi:10.2307/37672

Brunner, L. K., \& Dever, M. (2014). Work, bodies and boundaries: Talking sexual harassment in the new economy. Gender, Work \& Organization, 21(5), 459-471. 
Buchanan, I. (2010). A dictionary of critical theory. Oxford, UK: Oxford University Press.

Burr, V. (1995). An introduction to social constructionism. London: Routledge. doi:10.4324/9780203299968

Cameron, D. (2005). Language, gender, and sexuality: Current issues and new directions. Applied Linguistics, 26(4), 482-502. doi:10.1093/applin/ami027

Campbell, D. A., \& Queen's University (Kingston, Ont.). Industrial Relations Centre. (1992). The evolution of sexual harassment case law in canada. Kingston, Ont: Industrial Relations Centre, Queen's University.

Chouliaraki, L., \& Fairclough, N. (1999). Discourse in late modernity: Rethinking critical discourse analysis. Edinburgh: Edinburgh University Press.

Clair, R. P. (1993). The Bureaucratization, commodification, and privatization of sexual harassment through institutional discourse: A study of the Big Ten universities. Management Communication Quarterly, 7(2), 123-157.

Creswell, J. W. (2013). Qualitative inquiry and research design: Choosing among five approaches (3rd ed.). Los Angeles: Sage Publications.

Crotty, M. (1998). The foundations of social research: Meaning and perspective in the research process. London: Sage.

Dörnyei, Z. (2007). Research methods in applied linguistics: Quantitative, qualitative, and mixed methodologies. Oxford: Oxford University Press.

Dougherty, D. S. (2006). Gendered constructions of power during discourse about sexual harassment: Negotiating competing meanings. Sex roles, 54(7-8), 495-507. 
Eckert, P., \& McConnell-Ginet, S. (2013). Language and gender (2nd ed.). Cambridge: Cambridge University Press.

Eggins, S. (2004). An introduction to systemic functional linguistics (2nd ed.). New York: Continuum.

Eggins, S., \& Slade, D. (1997). Analysing casual conversation. London: Continuum.

Elliott, R. (1996). Discourse analysis: Exploring action, function and conflict in social texts. Marketing Intelligence \& Planning, 14(6), 65-68. doi:10.1108/02634509610131171

Eyre, L. (2000). The discursive framing of sexual harassment in a university community. Gender and Education, 12(3), 293-307. doi:10.1080/713668301

Fairclough, N. (1992). Discourse and social change. Cambridge, MA: Polity Press.

Fairclough, N. (1993). Critical discourse analysis and the marketization of public discourse: The universities. Discourse \& Society, 4(2), 133-168. doi: $10.1177 / 0957926593004002002$

Fairclough, N. (1995). Critical discourse analysis: The critical study of language. New York: Longman.

Fairclough, N. (2001). Language and power (Second ed.). London: Longman.

Fairclough, N. (2003). Analysing discourse: Textual analysis for social research (1st ed.). London: Routledge.

Fairclough, N. (2013). Critical language awareness. New York: Routledge.

Fairclough, N., Mulderrig, J., \& Wodak, R. (2011). Critical discourse analysis. In T. A. Dijk (Ed.), Discourse studies: A multidisciplinary introduction (pp. 357-378). Thousand Oaks, CA: Sage Publications. doi:10.4135/9781446289068 
Faraday, F. (1994). Dealing with sexual harassment in the workplace: The promise and limitations of human rights discourse. Osgoode Hall Law Journal, 32(1), 33-63.

Figueiredo, D. d. C. (2004). Representations of rape in the discourse of legal decisions. In L. Young \& C. Harrison (Eds.), Systemic functional linguistics and critical discourse analysis: Studies in social change. (pp. 217-230). New York: Continuum.

Flirting. (2015). In Merriam-Webster.com. Retrieved July 8, 2016, from http://www.merriam-webster.com/dictionary/flirting

Flowerdew, J. (1999). Description and interpretation in critical discourse analysis. Journal of Pragmatics, 31(8), 1089-1099.

Folgerø, I. S., \& Fjeldstad, I. H. (1995). On duty - off guard: Cultural norms and sexual harassment in service organizations. Organization Studies, 16(2), 299-313. doi:10.1177/017084069501600205

Fowler, R. (1996). On critical linguistics. In M. Coulthard \& C. R. Caldas-Coulthard (Eds.), Readings in critical discourse analysis (1st ed.). New York: Routledge. doi:10.4324/9780203431382

Francis, H., \& D'Annunzio-Green, N. (2005). HRM and the pursuit of a service culture: Managerial encounters with competing discourses. Employee Relations, 27(1), 7185. doi:10.1108/01425450510569319

Gilbert, D., Guerrier, Y., \& Guy, J. (1998). Sexual harassment issues in the hospitality industry. International Journal of Contemporary Hospitality Management, 10(2), 48-53.

Goffman, E. (1959). The presentation of self in everyday life. Garden City, NY: Doubleday. 
Good, L., \& Cooper, R. (2016). 'But it's your job to be friendly': Employees coping with and contesting sexual harassment from customers in the service sector: Sexual harassment in the service sector. Gender, Work \& Organization, 23(5), 447-469. doi:10.1111/gwao.12117

Halliday, M., \& Matthiessen, C.M. (2014). An introduction to functional grammar. New York: Routledge.

Hasan, R. (2004). Analysing Discursive Variation. In L. Young \& C. Harrison (Eds.), Systemic functional linguistics and critical discourse analysis: Studies in social change (pp. 15-52). London: Continuum.

Hesse-Biber, S. N. (2013). Feminist research practice: A primer (Second ed.). Thousand Oaks, CA: Sage Publications, Inc.

Hesse-Biber, S. N. (2006). The practice of qualitative research: Engaging students in the research process (3rd ed.). Thousand Oaks, California: Sage Publications, Inc.

Holmes, J. (2005). Power and discourse at work: Is gender relevant? In M. M. Lazar (Ed.), Feminist critical discourse analysis: Gender, power, and ideology in discourse (pp. 31-60). Houndmills: Palgrave Macmillan. doi:10.1057/9780230599901doi:10.1057/9780230599901

Huckin, T. (1997). Critical Discourse Analysis. In Miller, T. (1997). Functional approaches to written text: Classroom applications (pp. 78-92). Washington, DC: United States Information Agency.

Huckin, T. (2002). Textual silence and the discourse of homelessness. Discourse \& Society, 13(3), 347-372. 
Hughes, K. D., \& Tadic, V. (1998). 'Something to deal with': Customer sexual harassment and women's retail service work in Canada. Gender, Work and Organization, 5(4), 207-219. doi:10.1111/1468-0432.00058

Janks, H. (1997). Critical discourse analysis as a research tool. Discourse: Studies in the Cultural Politics of Education,18(3), 329-342. doi:10.1080/0159630970180302

Janks, H. (2005). Deconstruction and reconstruction: Diversity as a productive resource. Discourse: Studies in the cultural politics of education, 26(1), 31-43.

Johnson, K., \& Johnson, H. (Eds.). (2007). Encyclopedic dictionary of applied linguistics. Blackwell.

Kincheloe, J. L., \& McLaren, P. L. (1994). Rethinking critical theory and qualitative research. In N. Denzin \& Y. Lincoln (Eds.), Handbook of qualitative research (pp. 138-157). Thousand Oaks: Sage Publications Inc.

King, N. (2004). Using templates in the thematic analysis of texts. In C. Cassell \& G. Symon (Eds.), Essential guide to qualitative methods in organizational research (pp. 256-270). Thousand Oaks: Sage Publications Inc.

Koteyko, N. (2010). Mining the internet for linguistic and social data: An analysis of 'carbon compounds' in web feeds. Discourse \& Society, 21(6), 655-674. doi:10.1177/0957926510381220

Lazar, M. M. (2005). Feminist critical discourse analysis: Gender, power and ideology in discourse. New York: Palgrave Macmillan. doi:10.1057/9780230599901doi:10.1057/9780230599901

Lonsway, K. A., Cortina, L. M., \& Magley, V. J. (2008). Sexual harassment mythology: Definition, conceptualization, and measurement. Sex Roles, 58(9/10), 599. 
Matthiessen, C. M., Teruya, K., \& Lam, M. (2010). Key terms in systemic functional linguistics. London: Continuum.

Matulewicz, K. (2015). Law and the construction of institutionalized sexual harassment in restaurants. Canadian Journal of Law and Society, 30(3), 401. doi: $10.1017 /$ cls. 2015.12

Meyer, M. (2001). Between theory, method, and politics: Positioning of the approaches to CDA. In R. Wodak \& M. Meyer (Eds.), Methods of critical discourse analysis, (pp. 14-31). London: Sage. doi:10.4135/9780857028020

Ontario Human Rights Commission. (2014). Policy on preventing sexual and gender based harassment. Retrieved from: http://www.ohrc.on.ca/en/policy-preventingsexual-and-gender-based-harassment-0

Pennycook, A. (1994). Incommensurable discourses. Applied Linguistics, 15(2), 115-138. doi:10.1093/applin/15.2.115

Philaretou, A. G., \& Young, C. L. (2007). The social construction of female sexuality in a sexualized work environment (SWE): The case of a comedy club. Sexual Addiction \& Compulsivity, 14(1), 41-62.

Poulston, J. (2008). Metamorphosis in hospitality: A tradition of sexual harassment. International Journal of Hospitality Management, 27(2), 232-240. doi:10.1016/j.ijhm.2007.07.013

Scott, J., \& Marshall, G. (2005). A dictionary of sociology. Oxford: Oxford University Press. 
Shriver, M. (Interviewer) \& Steinem, G. (Interviewee). (2011). Interview Magazine [Interview transcript]. Retrieved June 10, 2016, from http://www.interviewmagazine.com/culture/gloria-steinem/print/

Stein, N. (2003). Bullying or sexual harassment? The missing discourse of rights in an era of zero tolerance. Arizona Law Review, 45(3), 783.

Stewart, K., \& Williams, M. (2005). Researching online populations: The use of online focus groups for social research. Qualitative Research, 5(4), 395-416.

Talbot, M. (2005). Choosing to refuse to be a victim: 'Power feminism' and the intertextuality of victimhood and choice. In Lazar, M. (Ed.), Feminist critical discourse analysis: Gender, power and ideology in discourse. (pp. 167-180). New York: Palgrave Macmillan. doi:10.1057/9780230599901doi:10.1057/9780230599901

Talbot, M. M. (2010). Language and gender (2nd ed.). Cambridge: Polity.

Teo, P. (2000). Racism in the news: A critical discourse analysis of news reporting in two Australian newspapers. Discourse \& Society, 11(1), 7-49.

The Restaurant Opportunities Centers United Forward Together. (2014). The glass floor: Sexual harassment in the restaurant industry. Retrieved from http://rocunited.org/wp-content/uploads/2014/10/REPORT_TheGlassFloor_SexualHarassment-in-the-Restaurant-Industry.pdf

Thiesmeyer, L. (Ed.). (2003). Discourse and silencing: Representation and the language of displacement. Amsterdam: John Benjamins. doi:10.1075/dapsac.5

Thompson, G. (2014). Introducing functional grammar. New York: Routledge. doi:10.4324/9780203431474 
Towns, A., Adams, P., \& Gavey, N. (2003). Silencing talk of men's violence towards women. In L. Thiesmeyer (Ed.), Discourse and silencing: Representation and the language of displacement (pp. 43-78). Amsterdam: J. Benjamins. doi:10.1075/dapsac.5

Uggen, C., \& Blackstone, A. (2004). Sexual harassment as a gendered expression of power. American Sociological Review, 69(1), 64-92.

van Dijk, T. A. (1992). Discourse and the denial of racism. Discourse \& Society, 3(1), 87-118.

van Dijk, T. A. (1993). Principles of critical discourse analysis. Discourse \& Society, 4(2), 249-283. doi:10.1177/0957926593004002006

van Dijk, T. A. (1998). Ideology: A multidisciplinary approach. London: Sage. van Leeuwen, T. (1996). The representation of social actors. In M. Coulthard \& C. R. Caldas-Coulthard (Eds.), Readings in critical discourse analysis (1st ed.). New York: Routledge. doi:10.4324/9780203431382

Waugh, L. R., Catalano, T., Al Masaeed, K., Do, T. H., \& Renigar, P. G. (2016). Critical discourse analysis: Definition, approaches, relation to pragmatics, critique, and trends. In A. Capone \& J. L. Mey (Eds.), Interdisciplinary Studies in Pragmatics, Culture and Society (pp. 71-135). Switzerland: Springer International Publishing. http://doi.org/10.1007/978-3-319-12616-6_4

Widdowson, H. G. (1996). Reply to Fairclough: Discourse and interpretation: conjectures and refutations. Language and Literature, 5(1), 57-69. 
Wodak, R. (1997). Critical discourse analysis and the study of doctor-patient interaction. In B. Gunnarsson, P. Linell, \& B. Nordberg (Eds.), The construction of professional discourse, (pp. 173-200). London: Longman.

Wodak, R. (2001). What CDA is about: A summary of its history, important concepts and its developments. In R. Wodak \& M. Meyer (Eds.), Methods of critical discourse analysis (pp. 1-13). London: Sage.

Wodak, R., Cillia, R. D., Reisigl, M., \& Liebhart, K. (2009). The discursive construction of national identity. Edinburgh: Edinburgh University Press Ltd.

Wodak, R., \& Meyer, M. (2001). Methods of critical discourse analysis. London: Sage. doi:10.4135/9780857028020

Young, L., \& Harrison, C. (2004). Systemic functional linguistics and critical discourse analysis: Studies in social change. New York: Continuum. 